\title{
Infrastructure Practices Of Select World-Class \\ Research Organizations - A Benchmark Of Campus Design, Development, And Implementation Strategies
}

Kevin M. Kostelnik, Ph.D.

Ann Marie Phillips

July 2005

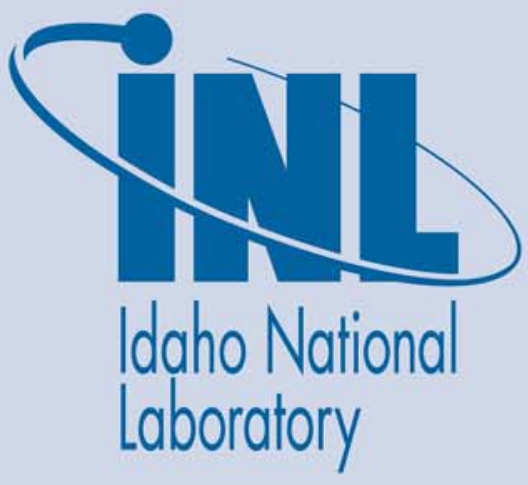

The INL is a U.S. Department of Energy National Laboratory operated by Battelle Energy Alliance 


\title{
Infrastructure Practices of Select World-Class Research Organizations - A Benchmark of Campus Design, Development, and Implementation Strategies
}

\author{
Kevin M. Kostelnik, PhD \\ Ann Marie Phillips
}

July 2005

Idaho National Laboratory

Infrastructure, Optimization, Integration, and Planning Idaho Falls, Idaho 83415 
This page intentionally left blank. 


\section{Acknowledgements}

The completion of this infrastructure benchmarking assessment project would not have been possible without the support and contributions of the administration and research staff of the selected world-class research institutions and the Idaho National Laboratory (INL).

The authors would like to acknowledge and thank these organizations and individuals for providing their time, and insights as well as access to their fine institutions. In particular, we would like to thank Dr. Robin Williams, Mr. Ray Diaz, Ms. Sarah Mosso, Ms. Christina Oliveira, Mr. Anais Nguyen, Mr. Steve Wheat, Mr. John Beacher, Mr. Robert Scott, and Mr. Mark Carlson of IBM Almaden; Dr. Michael Lawrence, Mr. Marty Conger, Mr. Bill Kuhn, Mr. Monty Rosbach, Ms. Linda Connell, and Ms. Julia White of PNNL; Dr. James Luyten, Mr. William McKeon, and Ms. Shelley Waicki of WHOI; Ms. Deborah Poodry, Dr. Peter Cooper, Ms. Talitha Fabricius, Mr. Walter Henry, Mr. Justin Adams, and Ms. Arne Abramson of MIT; Mr. Carlo Melbihess, Mr. Lanny Bates, Ms. Karla Gaither, Mr. Tony Medley, Mr. Cecil Peters, Mr. Dirk Van Hoesen, and Mr. Jack Stellern of ORNL; and Ms. Margaret Dyer-Chamberlain, Mr. Herb Fong, Mr. David Lenox, Ms. Adalaide Dawes, Mr. Mike Mithen, and Mr. Charles Carter of Stanford.

The authors would also like to thank the INL Fellows, Dr. Paul Meakin, Dr. James Delmore, Dr. William Apel, Dr. David Petti, and Dr. Herschel Smartt. Their support and advice in formulating this project and their active participation with site visits provided extreme value in achieving the studies results. In addition, we thank Mr. Lyle Stephenson for coordinating the Stanford site visit. And finally, we thank Mr. Douglas Hamelin whose excellent technical editing and graphics support improved the quality of this final product. 
This page intentionally left blank. 


\section{Executive Summary}

This report presents information about the best practices of select world-class research organizations in the area of infrastructure planning and implementation. Research organizations were selected from the DOE National Laboratory complex, commercial organizations, universities, private non-profit institutes, and international laboratories. The facilities selected were based on recommendations from the INL Fellows and Infrastructure Optimization, Integration, and Planning management. The final selection was based on the institutions' willingness to participate, schedules, and a desire to have a mix of types of research organizations. The selected institutions were as follows:

- Pacific Northwest National Laboratory, Richland, WA

- Oak Ridge National Laboratory, Oak Ridge, TN

- Stanford University, Stanford, CA

- Massachusetts Institute of Technology, Boston, MA

- IBM Corporation, Almaden Research Center, San Jose, CA

- Woods Hole Oceanographic Institute, Woods Hole, MA

- Commissariat à l’Energie Atomique (CEA) Cadarache Research Facility, France.

Information collected via this benchmarking exercise included successful infrastructure planning and implementation processes and procedures, such as facility modernization planning and design, mission compatibility, land-use planning, financial mechanisms, research atmosphere, relevant policies and procedures, employee concerns, community involvement, waste management, and space management. In conducting this benchmark study, researchers also considered other similar studies conducted at the INL and by DOE and independent organizations. The conclusions of this study suggest that achieving world-class status involves many aspects of the laboratory, including the people, policies and procedures, mission alignment, and research culture, as well as infrastructure.

Specific conclusions identified through this benchmarking study are as follows; more detailed conclusions appear in Section 5 of this report.

- The "connectivity" of the campus is critical both internally to the campus as well as externally to the surrounding community.

- Attractive "common spaces" should be incorporated into both campus and building designs to foster social interactions and research collaborations.

- "Green spaces" should be incorporated into the campus design to unify the campus community with the physical environment.

- Leadership in Energy and Environmental Design guidelines should be followed for all new construction and campus modifications. 
- "Adaptable" laboratory designs support reconfiguration for varying research needs and should provide movable and reusable components to accommodate individual laboratory needs.

- Laboratories should be designed to be in close proximity to offices.

- Access to natural, day lighting and external landscape should be maximized for both laboratories and office space.

- Successful world-class research organizations are focused on unique and compelling research agendas and are moving away from the isolated engineering and science disciplines to more interdisciplinary efforts.

- Vision, mission, and objectives of the infrastructure modernization program must be clearly defined early in the process.

- A detailed campus plan that matches the organization's mission must be in place before initiating conversations with architects or proceeding with the detailed design.

- A centralized, computerized management system can improve space and equipment utilization.

- The physical work environment should be designed to create a positive research culture, including state-of-the-art equipment; modern, reconfigurable facilities, and a strong link to the natural environment.

- Collocation of researchers from different departments and research disciplines should be strongly considered to facilitate research collaboration, strengthen interdisciplinary interactions, promote the development of new ideas, and enhance research results.

- Successful infrastructure modernization programs require "ownership" and leadership by senior management.

To achieve the vision for the laboratory, the INL must modernize and optimize its facility use and create an environment that fosters world-class research and academic, industrial, government, and international collaborations. As the INL moves forward in the design and construction of its new research campuses, it is important that the INL learn from the practices of others and incorporate these lessons into its infrastructure development efforts. 


\section{Contents}

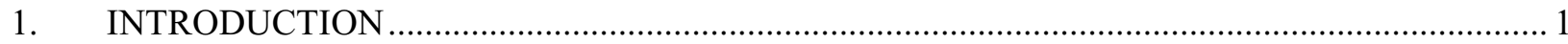

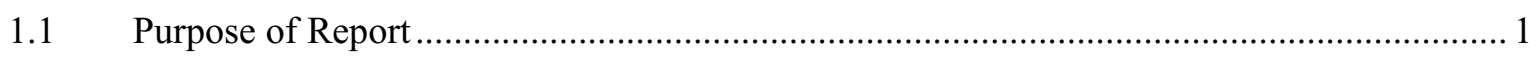

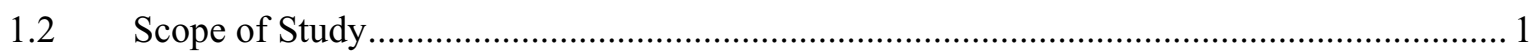

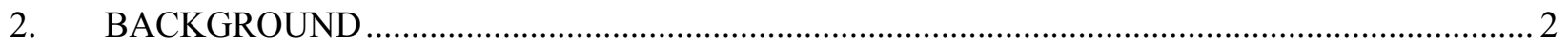

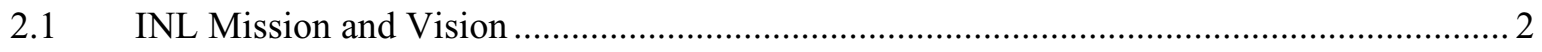

2.2 National Research Council / NERAC / FEMP / GAO / Recommendations ........................ 3

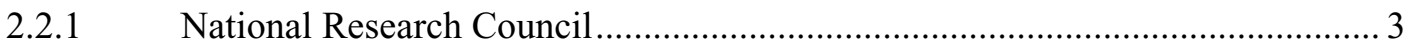

2.2.2 Nuclear Energy Research Advisory Committee .......................................... 4

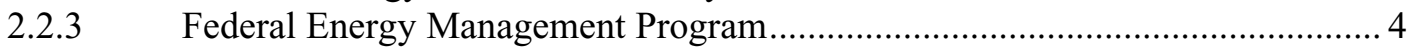

2.2.4 Government Accountability Office …...................................................... 5

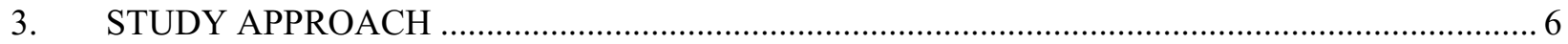

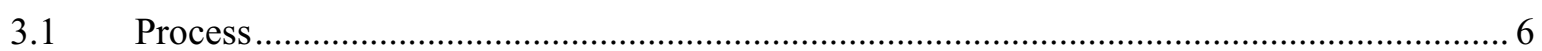

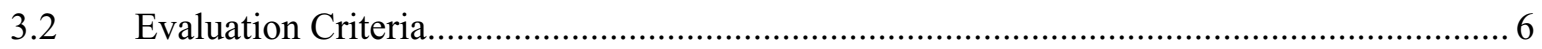

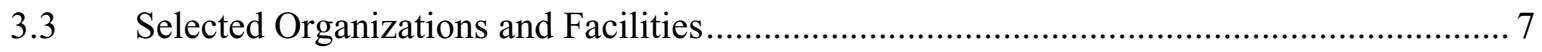

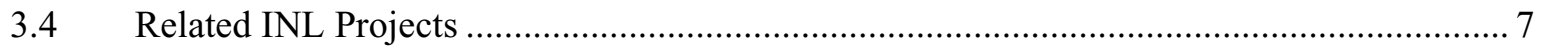

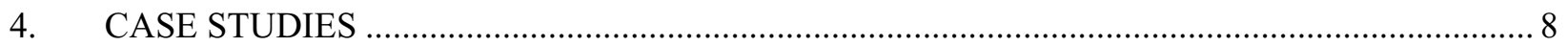

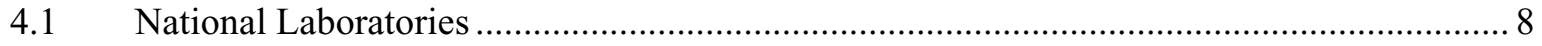

4.1.1 Pacific Northwest National Laboratory.......................................................... 8

4.1.2 Oak Ridge National Laboratory ….............................................................. 13

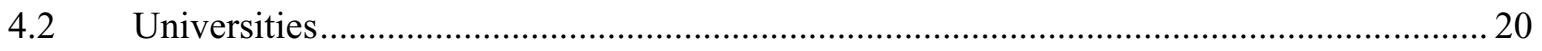

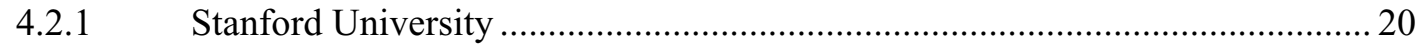

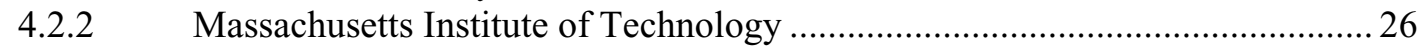

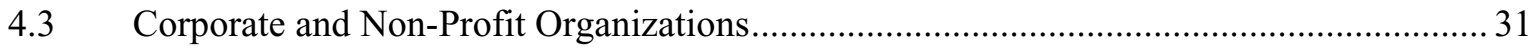

4.3.1 IBM Corporation - Almaden Research Center ................................................ 31

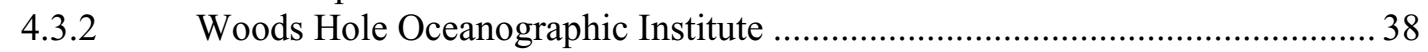

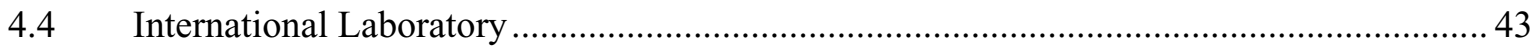

4.4.1 Commissariat à l`Energie Atomique (CEA) -

Cadarache Research Center............................................................................ 43

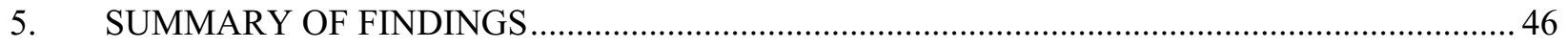

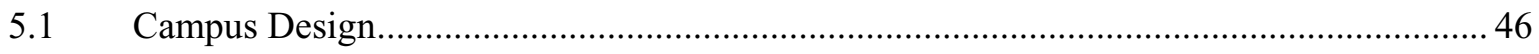

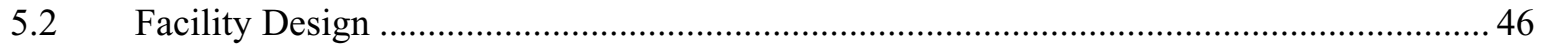

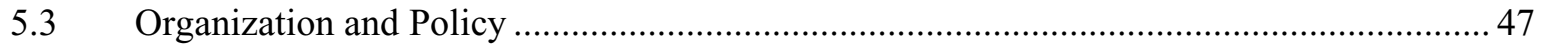

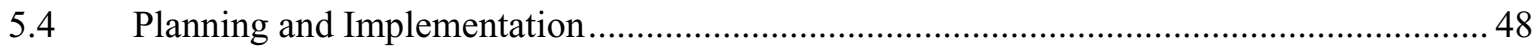

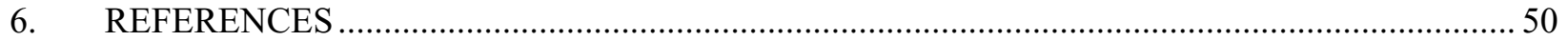


This page intentionally left blank. 


\section{INTRODUCTION}

\subsection{Purpose of Report}

This report presents information about the best practices of select world-class research organizations in the area of infrastructure planning and implementation. The findings of this study are intended to provide insight to Idaho National Laboratory (INL) management as the INL embarks on its modernization task to achieve the U.S. Department of Energy (DOE)'s vision of three INL campuses conducting world-class research.

\subsection{Scope of Study}

This project benchmarked infrastructure vision, planning, and implementation processes and other characteristics of world-class research and development institutions to identify areas where effective changes can be implemented at the INL. Research organizations were selected from the DOE National Laboratory complex, commercial organizations, universities, private non-profit institutes, and international laboratories. The selected laboratories have maintained and/or modernized their infrastructure to attract new business as well as creative and innovative personnel. In addition, other factors that contribute to their world-class status were identified and documented.

Information collected via this benchmarking exercise included successful infrastructure planning and implementation processes and procedures, such as facility modernization planning and design, mission compatibility, land-use planning, financial mechanisms, research atmosphere, relevant policies and procedures, employee concerns, community involvement, waste management, and space management. 


\section{BACKGROUND}

\subsection{INL Mission and Vision}

The DOE designated the INL to be the national lead laboratory for nuclear energy research, development, and demonstration. As a multi-program National Laboratory, INL will also serve as a major center for national security and environmental technology development and demonstration.

DOE's vision is that by year 2015 the INL will:

- Become the preeminent, internationally-recognized nuclear energy research, development and demonstration laboratory

- Become a major center for national security technology development and demonstration

- Become a multi-program national laboratory with world-class capabilities

- Foster academic, industry, government, and international collaborations to produce the investment, programs, and expertise needed to ensure the vision.

To achieve the vision for the laboratory, the INL has identified six critical attributes necessary to achieve the laboratory's preeminent status. The six critical attributes for INL include:

- Nuclear Programs - A robust portfolio of nuclear science and technology programs

- Synergistic Programs - A synergistic portfolio of national and homeland security, energy, and environmental programs

- Science Base - A robust science base to attract the best staff and create a culture of scientific inquiry

- Revitalize Education - A central role in revitalizing nuclear science and engineering education

- Partner/Collaborate - Extensive national and international collaboration

- Modern Infrastructure - Forefront research facilities, support infrastructure, and management systems.

This project is focused on the sixth critical attribute - Modern Infrastructure.

To achieve the vision for the laboratory, the INL must modernize and optimize its facility use and create an environment that fosters world-class research and academic, industrial, government, and international collaborations. A challenge facing the INL is the fact that the laboratory's assets are dispersed across a secure but remote 890 square-mile desert site and in the southeastern Idaho community of Idaho Falls. The INL will be comprised of three modern campuses that are necessary to achieve the DOE objectives. These campuses include the Science and Technology Campus, the Reactor Technology Complex, and the Materials and Fuels Complex. As the INL moves forward in the design and construction of these new campus designs, it is important that the INL learn from the practices of others and incorporate these lessons into its infrastructure development efforts. 


\subsection{National Research Council / NERAC / FEMP / GAO / Recommendations}

In conducting this benchmark study, researchers considered other similar studies conducted by DOE and independent organizations. Specifically, researchers looked at four studies conducted by the National Research Council, a DOE Nuclear Energy Research Advisory Committee (NERAC) subcommittee, the DOE Federal Energy Management Program (FEMP), and the Government Accountability Office (GAO).

Among the top nine priority NERAC recommendations was one to benchmark several world-class laboratories to identify and replicate polices, best practices, and cultural aspects that contribute to worldclass stature. The findings of the National Research Council, NERAC subcommittee, FEMP, and GAO studies all support identifying and implementing best practices (such as those identified by this benchmarking study) as a key method to achieving excellence. The above studies also support this project's conclusions that achieving world-class status involves many aspects of the laboratory, including the people, policies and procedures, mission alignment, research culture, as well as infrastructure. Further, FEMP suggestions for sustainable green designs for new facilities were well supported by the finding of the benchmarking project. The following recommendations were excerpted and/or paraphrased from the actual reports.

\subsubsection{National Research Council ${ }^{[1]}$}

The National Research Council was contracted by DOE in 2001 to assess the steps DOE is taking to upgrade is aging facilities and infrastructure. The evaluation was conducted by the Committee on the Renewal of DOE Infrastructure under the auspices of the National Research Council's Board on Infrastructure and the Constructed Environment. The evaluation was divided into four tasks. Task 1 included assessing DOE's facilities and infrastructure managing practices and initiatives and providing recommendations for areas requiring additional focus. The Council's evaluation found that although policies for facilities management that are characteristic of high-performance organizations have been put into place, application of these policies is inconsistent across program offices and sites. As a result, a unified and effective approach to facilities management has not been implemented. Task 2 was to identify or develop "best-practice" tools and techniques for DOE real property asset management in many areas, such as site planning, maintenance, space and land utilization, etc. The Council found that there is no single set of practices that can be used by all DOE sites. Rather, they found that each facility must identify the approaches that will work best for its unique circumstances and apply them consistently throughout the organization. In Task 3 , the Council was asked to develop guidelines for deciding when to repair, renovate, or replace DOE buildings and facilities based on agency mission and return on investment. The Council found that a life-cycle systems model is appropriate for these decisions, and provided an example that can be tailored to DOE needs. Factors such as mission requirements, facility condition, and available funds are part of such decisions. In Task 4, the Council was asked to define performance metrics that integrate budget with expected outcomes and ensure accountability. The Council proposed a facilities management system that links all facilities management activities based on the asset condition and mission, and provides alternative strategies to identify the option that provides the best return on investment.

Based on their study, the National Research Council committee concluded that long-term improvement of DOE facilities and infrastructure will "require cultural and organizational changes, improved planning and budgeting procedures, and the development of improved performance measures." The Council further added that facilities and infrastructure stewardship must be explicitly recognized in DOE's strategic plan and in DOE's budget requests. Implementing improvements will also require a 
dedicated, concerted effort from DOE and contractor management to include facilities and infrastructure improvements as high-priority items; maintenance and improvements cannot be deferred, but must be performed as a strategic business decision to ensure the success of DOE's mission. Since many DOE facilities are DOE-owned but contractor-operated, the Council recommends that DOE include a performance-based incentive fee tied to the stewardship of facilities using metrics that assess performance. The Council suggests that this approach will integrate life-cycle facilities and infrastructure management into the DOE system to facilitate the required upgrades.

\subsubsection{Nuclear Energy Research Advisory Committee ${ }^{[2]}$}

As part of the INL's return to nuclear technology development as its primary mission, DOE requested NERAC to establish a subcommittee on Nuclear Laboratory Requirements. The subcommittee's goals were to identify the "characteristics, capabilities, and attributes a world-class nuclear laboratory would possess." It was also asked to become familiar with the practices, culture, and facilities of other world-class laboratories and use this knowledge to recommend what needs to be implemented at Idaho. The subcommittee developed this definition of a world-class research and development organization:

A world-class research organization is one that is recognized by peers, customers, and competitors as among the best in the field on an international scale.

The subcommittee concluded that, "the capabilities, qualifications, focus, and drive of the scientific, technical, and other professional staff of the laboratory are absolutely critical to a laboratory being, and being recognized as, among the best in the world." Another essential factor that the subcommittee identified is a strong commitment by sponsors and stakeholders that provides sustained allocation of resources (funding, people, and facilities) to implement the laboratory's mission, goals, and objectives.

The subcommittee further identified six key areas required for achieving excellence and a worldclass status. They are customer focus, resource and capabilities, strategic vision, value creation, quality focus, and sound governance. The subcommittee went on to define the common attributes of world-class research laboratories and presented 28 recommendations for DOE and the INL to achieve world-class status.

\subsubsection{Federal Energy Management Program ${ }^{[3]}$}

Executive Order 13123, Section 403(d), instructs federal agencies to develop sustainable design principles and use them in planning and building new facilities. This order also instructs agencies to optimize life-cycle costs and other environmental and energy cost associated with the construction, lifecycle operations, and decommissioning of a facility. These activities are aimed at reducing greenhouse gases, increasing water conservation, and ensuring the cost-effective use of renewable energy. FEMP has supported several federal facilities in working to meet these goals through a process called "greening." To transfer the energy and environmental technologies used, FEMP issued a report entitled "Greening Federal Facilities." This report describes a wide range of effective, environmentally conscious actions that include selecting non-polluting materials; recycling; conserving energy and water; improving landscaping; and purchasing energy-efficient lighting, heating, and cooling equipment. The report also highlights best practices to:

- Invest in improvements that have quick paybacks and make economic sense

- Increase the productivity, comfort, and health of employees and building occupants 
- Maximize innovative financing and partnering opportunities

- Facilitate interagency cooperation

- Work within the ongoing operations

- Reduce environmental impacts.

The report highlights practical, cost-effective actions that federal facility managers can take to increase energy and resource efficiency, cut waste, and improve the performance of federal buildings and facilities.

\subsubsection{Government Accountability Office ${ }^{[4]}$}

In a summary report of its Forum on High-Performing Organizations, the GAO states that the federal government faces a range of new challenges for the $21^{\text {st }}$ century that it must confront to enhance performance, ensure accountability, and position the nation for the future. To meet these challenges, the federal government must strive to build high-performing organizations by using best practices. In addition, the federal government needs to change its culture to become more result-oriented, client- and customer-focused, and collaborative in nature. The GAO held a forum on November 6, 2003, to discuss what metrics, means, and mechanisms a federal agency should use to optimize its influence and contribution to nationally important results and outcomes. As a result of the forum, the participants agreed upon the key characteristics and capabilities of high-performing organizations. The four themes identified are as follows:

- A clear, well-articulated, and compelling mission

- $\quad$ Strategic use of partnerships

- Focus on the needs of clients and customers

- Strategic management of people. 


\section{STUDY APPROACH}

\subsection{Process}

This benchmarking project and data collection involved several steps. Initially, a meeting was held with INL Fellows and Infrastructure Optimization, Integration, and Planning (IOIP) management to define the project scope, direction, and potential research organizations to include in the study. Internet searches were used to gather preliminary data and identify contacts at the facilities. Evaluation criteria were identified, and a questionnaire (see appendix) was developed to assist with data collection. Identified sites were contacted to confirm willingness to participate and arrange site visits. The final list of selected facilities was based on willingness to participate and schedules, and was kept small to improve the cost-effectiveness and timeliness of the project. Site visits were then conducted to meet with staff, conduct tours, and gather data. In some cases (Oak Ridge National Laboratory [ORNL] and Commissariat à l’Energie Atomique [CEA]), INL staff had recently toured the facilities, so the information they had gathered was used rather than conducting another site visit. Using electronic sources, site visits, and hard copy data, a case study was written describing each research organization. The case studies and project findings were then compiled into this report.

\subsection{Evaluation Criteria}

The evaluation criteria were developed based on discussions with INL Fellows and IOIP team members, and were intended as a guide. Evaluation criteria were as follows:

- Facility Planning (facility modernization, mission compatibility, space utilization, and flexibility of the space to be modified for changing missions)

- Facility Design (energy efficiency/conservation, green buildings, landscape design, communication systems, impact of facility on the efficiency of workers (office/lab relationship), HVAC, filtration systems, and one large vs. many small buildings)

- Land-use Planning (footprint management [reduction/expansion], land-use categories, and preservation of/integration with natural environment)

- Financial Mechanisms (For facilities/infrastructure: private investment, public funding, \% public/private, and innovative financing methods. For Laboratory equipment: linking multiple funding sources, lease/purchase, and equipment sharing. In general: historic research budgets, stability of research budgets over long term, and responsibility for obtaining research funding.)

- Research Atmosphere (research culture, researcher attitudes and motivation level, research culture vs. public face, access/ease of movement and interactions, state of the art equipment, and equipment storage)

- Policies and Procedures (operating policies and procedures, barrier removal approaches, and procedures for assigning lab space)

- Employee Concerns (common use space [copy centers, etc.], cafeterias, child care centers, wellness centers, exercise areas, conference rooms, and casual meeting areas) 
- Community Involvement (public use, user-facilities, common space, transportation, and visitors)

- Waste Management (pollution prevention and material reuse/recycle)

- Space Management (philosophy, use gridlines, assignment criteria, daily move activity, facility maintenance, user return policy, pay-for-space criteria, security, campus amenities, and future vision).

\subsection{Selected Organizations and Facilities}

The facilities selected were based on recommendations from the INL Fellows and IOIP management. The final selection was based on willingness to participate, schedules, and a desire to have a mix of types of research organizations. The selected institutions were as follows:

\section{National Laboratories}

- Pacific Northwest National Laboratory, Richland, WA

- Oak Ridge National Laboratory, Oak Ridge, TN

\section{$\underline{\text { Universities }}$}

- Stanford University, Stanford, CA

- Massachusetts Institute of Technology, Boston, MA

\section{Corporate and Non-Profit Organizations}

- IBM Corporation, Almaden Research Center, San Jose, CA

- Woods Hole Oceanographic Institute, Woods Hole, MA

\section{International Laboratory}

- Commissariat à l’Energie Atomique (CEA) Cadarache Research Facility, France.

\subsection{Related INL Projects}

This infrastructure benchmarking project is being conducted in conjunction with several related projects within the IOIP department and other departments at the INL. One related project identified guidelines for "green" buildings at the $\mathrm{INL}^{[5]}$. Another project is considering space utilization (i.e., designated space planning based on needs and resources) for the overall INL campus, and still another is considering workplace design (i.e., the furniture, finish, design standards, and layout) to ensure that the interior of each facility optimizes practical functionality while being aesthetically pleasing. A fourth team is conducting a benchmarking study of energy facilities (similar to the benchmarking study described herein) to provide a basis for decisions on the future Center for Advanced Energy Studies (CAES) facility at the INL. 


\section{CASE STUDIES}

\subsection{National Laboratories}

\subsubsection{Pacific Northwest National Laboratory}

4.1.1.1 Introduction. The Pacific Northwest National Laboratory (PNNL) is one of nine DOE multiprogram national laboratories. The DOE Office of Science, acting as the Principal Secretarial Office for PNNL, is responsible for the overall management of the laboratory. DOE has contracted with Battelle to perform and manage the day-to-day operations of the laboratory. Battelle has been the operating contractor at PNNL for DOE since the laboratory was created in 1965.

The mission of PNNL is to perform basic and applied research to deliver energy, environmental, and national security for our nation. More specifically, PNNL provides science-based solutions to the challenges of expanding energy, protecting national security, conducting world-class scientific research, and resolving the environmental legacy of the Cold War. In addition to the DOE, PNNL also performs work for other government agencies and industries.

PNNL is located in Richland, WA, adjacent to the DOE Hanford Reservation. Currently, PNNL has a staff of approximately 4,000 personnel. PNNL has a diverse customer set including the DOE; other federal, state, and local agencies; universities; and industry sponsors. PNNL's annual business volume was estimated at $\$ 638$ million for fiscal year $2004^{[7]}$.

\subsubsection{Site/Campus Level Considerations.}

Facility Planning and Modernization - Laboratory modernization is central to the entire laboratory. The immediacy of this modernization effort was prompted by the DOE decision to close the Hanford 300 Area, thus forcing PNNL staff out of older DOE laboratories. PNNL is planning to vacate approximately $700,000 \mathrm{ft}^{2}$, involving 19 buildings, by 2009 . This will involve $45 \%$ of their experimental laboratories, $75 \%$ of the federally owned facilities, $100 \%$ of the radiological laboratories, and $100 \%$ of the fresh water laboratories. Approximately 1,000 staff, or $25 \%$ of the workforce, will be impacted ${ }^{[7]}$.

PNNL intends to replace the facilities that will be closed at the 300 Area and the capabilities that will be lost. In addition, PNNL's new development will also accommodate space needs required for anticipated business growth. To support the campus-level planning, PNNL conducted a functional analysis (i.e., Capability Transition Plan), which defined the needed space and capabilities. Based on this analysis, PNNL plans to develop an additional $700,000 \mathrm{ft}^{2}$ by 2009 . Multiple buildings are now being planned, which tie the buildings back to customer sponsors so that each customer would have a building for their investment. Larger buildings with more flexible space appear to be the plan.

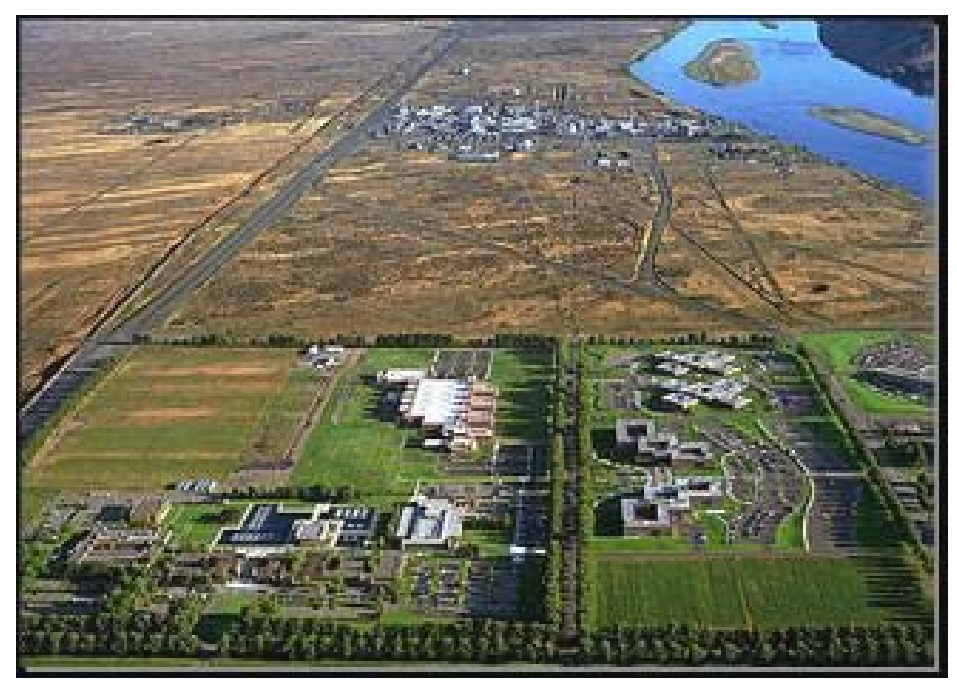

Aerial view of PNNL campus. (Photo courtesy of PNNL) 
The entire effort is being managed as a single project, and all projected construction is included in a Conceptual Design (CD-1) package. Once the acquisition strategy is determined, project construction will be broken out individually by fund-source ${ }^{[8]}$.

Land Use Planning - PNNL, although in close proximity to the DOE Hanford site, does not have a direct contractual responsibility for the long-term management of the site. The legacy management responsibilities (i.e., long-term monitoring and stewardship obligations) for the Hanford site are the responsibility of other site contractors. PNNL may provide services and technologies but does not have a landlord responsibility. PNNL land use considerations are therefore limited to their immediate campus.

The PNNL campus is generally accessible to the public (i.e., conference facilities are available for use); however, the buildings are not open and require security badges for access. Building security is controlled via "proximity" cards. No guards were observed.

Landscape Architecture - The campus landscape consists of large grass areas between buildings and tree-lined roads. The individual buildings are all well landscaped. The campus landscape is noticeably distinct from the surrounding natural desert setting. No "natural" vegetative areas were evident on the campus, which was quite lush and green. The campus is walkable with a considerable number of walking paths and sidewalks between buildings. While the campus is relatively isolated (i.e., located several miles from Richland), no biking or mass transit alternatives were evident. Parking is available at all buildings giving the campus more of an upscale industrial complex feel rather than a university campus feel.

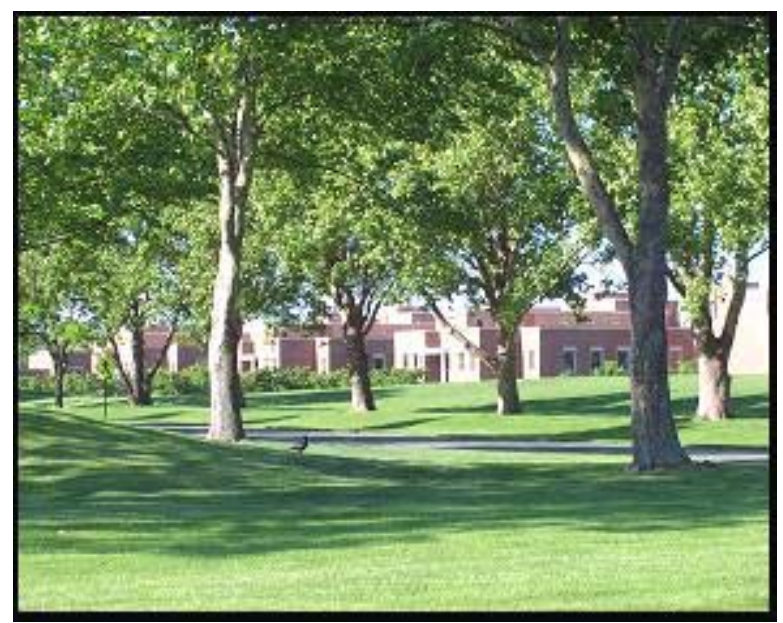

PNNL landscape with EMSL in the background. (Photo courtesy of K. Kostelnik)

Financial Mechanisms - To achieve the current and proposed "campus of the future," Battelle has applied several different financial approaches. These include federally funded buildings on federal land, Battelle buildings on Battelle land, and leased buildings on Battelle land. Generally, Battelle prefers to use a 25-year "lease-to-own" operating lease split into two terms. Third-party funding is critical for the proposed PNNL development, accounting for approximately $55 \%$ of the facility development ${ }^{[8]}$. Battelle has drafted "Principles for Government Use," which describes their policy for developing buildings and then making those facilities available to the government at no economic benefit to Battelle.

\subsubsection{FacilitylLaboratory Level Considerations.}

Facility/Laboratory Designs - The PNNL campus is comprised of facilities constructed during different time periods, thus they exhibit unique although compatible appearances. Few details were available regarding the energy efficiency goals of the campus facilities.

The showcase facility on the PNNL campus is the William R. Wiley Environmental Molecular Sciences Laboratory (EMSL). EMSL is a 200,000 $\mathrm{ft}^{2}$ DOE-owned national user facility, which opened in 1997. The two-story building houses advanced scientific instrumentation and computing resources, dry and wet laboratories, a state-of-the-art auditorium, office space, and conference rooms. 
In addition, PNNL has a User Housing Facility for visiting researchers and guests. The facility is well maintained although it appears to be underutilized. Use limitations appear to be related mainly to the remote location of the laboratory, thus there are not many additional amenities or recreational activities in the general area after normal work hours.

Equipment Management - As a national user facility, EMSL is open to the international research community. Use proposals undergo a peer review. Selected users need to have secured their own funding for their time and materials although access to EMSL is free if the users agree to publish their work in the open literature. In support of EMSL

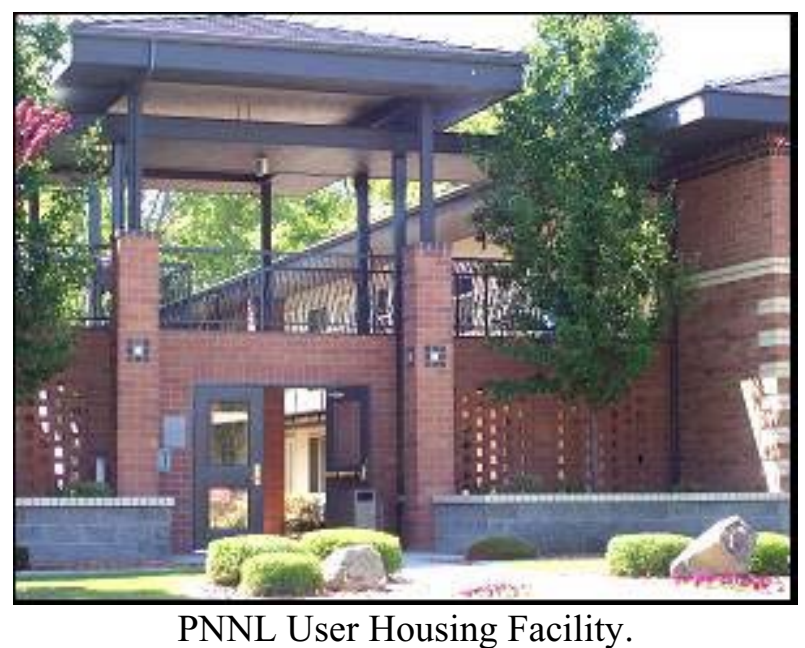

(Photo courtesy of K. Kostelnik) operations, DOE provides an annual operating budget via the DOE Office of Science. As such, EMSL maintains state-of-the-art process, computing, and support equipment.

PNNL uses a dual equipment and space management approach. Resources and equipment have one responsible manager, while the space and laboratories have a second responsible manager. In addition, EMSL has a centralized management of all facility related efforts. For example, shipping and receiving is centralized for EMSL as is waste handling, energy management, space management, etc.

PNNL is developing criteria and procedures to better determine if and when they should move equipment from the 300 Area or buy new equipment (i.e., a cost benefit analysis tool for the 4,000 pieces of equipment at the 300 Area).

Space Management/Utilization - PNNL currently estimates 97\% total space utilization, including $100 \%$ utilization for laboratories. The current office configurations are primarily hard-wall offices, although new facilities are anticipated to move away from hard walls and have a more open group plan. PNNL has used architectural engineering services of CUH2A in Princeton and Chicago.

The EMSL facility is fully utilized at this time. For example, EMSL is currently occupied by 360 staff and researchers where it was originally designed to hold $280^{[8]}$. In addition to visiting researchers, local PNNL investigators are permanent residents of EMSL, which appears to take up much of the available office space.

The EMSL laboratories were designed to be somewhat flexible in their configuration. These laboratories have a centralized HVAC system with movable components to accommodate individual laboratory needs. EMSL has a utility corridor between the laboratory corridors to house much of the operating equipment, chemical storage, and excess equipment. In addition, numerous equipment storage cabinets are available for the researchers throughout EMSL.

\subsubsection{Social Considerations.}

Research Atmosphere/Culture - The research culture at PNNL appears to be very positive and confident. All researchers, managers, and support staff had positive comments regarding the PNNL management and the overall research climate. The laboratory morale and attitudes were also very positive. 
Visitors are allowed, and collaborative research is strongly encouraged. Unannounced visits are generally not encouraged.

Employee Amenities - The PNNL campus is modern and user friendly. The entire campus is wireless, providing easy access for the researchers. Individual laboratories can be configured with cameras so that researchers can observe their space from offices and/or resident housing facility.

EMSL has several open, common work areas. These areas are well lighted and have ample work and meeting space.

EMSL has a cafeteria and a small, state-of-the-art conference facility. The PNNL campus also has a larger conference facility, which can be accessed by the public for special events.

Shower facilities are generally not included in the newer facilities due to DOE financial concerns. Shower facilities are, however, included when necessary to satisfy collective bargaining agreements. Older and private facilities tend to have smaller shower facilities.

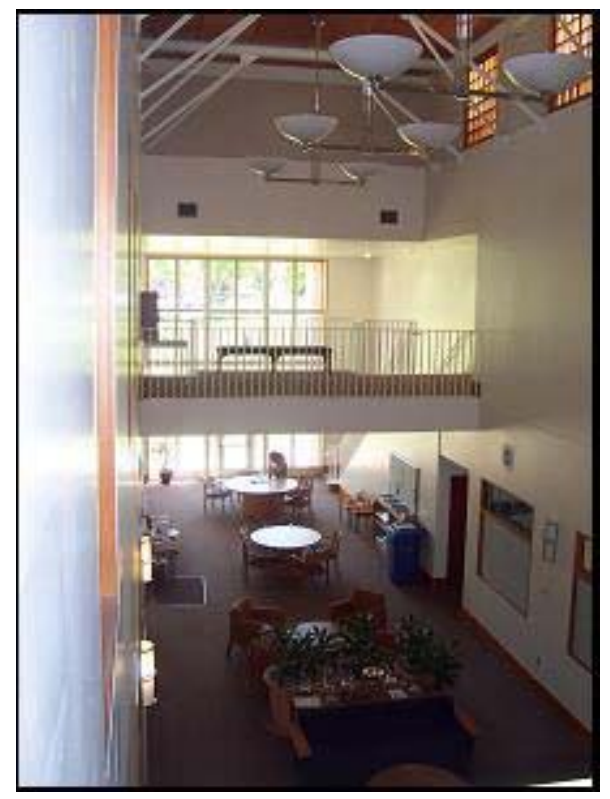

EMSL common space areas. (Photo courtesy of K. Kostelnik)

Operating Policies/Procedures - The policies and procedures, particularly at EMSL, appear to be designed to support the researchers while maintaining adequate safety and management oversight. Ease of movement was observed to be very good. The EMSL facility is setup as a national user facility. The goal is to have all visitors able to access their laboratories within two hours of arrival. This goal is achievable because training and security issues are resolved prior to visitor arrival.

Several support systems have been developed for various purposes ${ }^{[9]}$. Examples include:

- EMSL Resource System (ERS) - is an internal resource management system. Resources are defined as equipment systems. EMSL has identified resource (i.e., equipment) custodians as well as laboratory custodians. The system tracks equipment use, service, schedules, etc.

- EMSL User System (EUS) - is a workflow tracking and research management tool. This system starts with users submitting EMSL use proposals. The system includes links to available equipment (ERS) and space and, thus, serves as a scheduling tool. It also links to proposal review and approvals as well as to issued publications, funding, and other metrics.

- Integrated Operations System (IOPS) - is a management tool designed to help qualify potential EMSL users. IOPS serves as an automated Integrated Hazards Review system that links security, safety, and environmental training to the hazards associated with a given space and activities. Researchers, space managers, and resource managers are all linked. The system is capable of initiating automated prompts for required training and self-assessments, and it subsequently tracks completion.

- Wireless Tablets - EMSL has wireless tablets for performing self-assessments. This automated system is directly linked to the action tracking system and "must do lists," and eases data entry requirements. 
4.1.1.5 Summary. PNNL, operated by Battelle, is a DOE national laboratory sponsored by the DOE Office of Science. The laboratory was established in 1965 and is currently planning a major infrastructure modernization campaign. Approximately 700,000 $\mathrm{ft}^{2}$ of vintage laboratory and office space will be replaced with modern facilities by 2009 .

The campus, located near Richland, WA, contains a collection of modern laboratories, administrative offices, and support facilities. The research culture at PNNL was found to be very positive and confident with the workforce displaying positive morale.

The EMSL facility is a showcase national user facility at PNNL that is financially supported through the Office of Science. Keys to the success of this operating laboratory are the user-friendly and modern laboratory facility itself; the state-of-the-art equipment; and the dedicated, resident research staff, which provides valuable operating experience to visiting researchers.

\section{William R. Wiley Environmental Molecular Sciences Laboratory (EMSL)}

EMSL, a 200,000 $\mathrm{ft}^{2}$ DOE-owned national user facility, opened in 1997 and is the newest building at PNNL. EMSL is located in the heart of PNNL's main research campus. The two-story building houses advanced scientific instrumentation and computing resources, dry and wet laboratories, a state-of-the art auditorium, office space, and conference rooms. Hundreds of scientists from around the world travel to EMSL annually to conduct research in the facility's collaborative environment; others take advantage of EMSL's unique electronic capabilities to pursue projects from offsite locations via the Internet. Although research conducted at EMSL supports all of DOE's mission areas, most of the facility's work is focused in basic science disciplines.

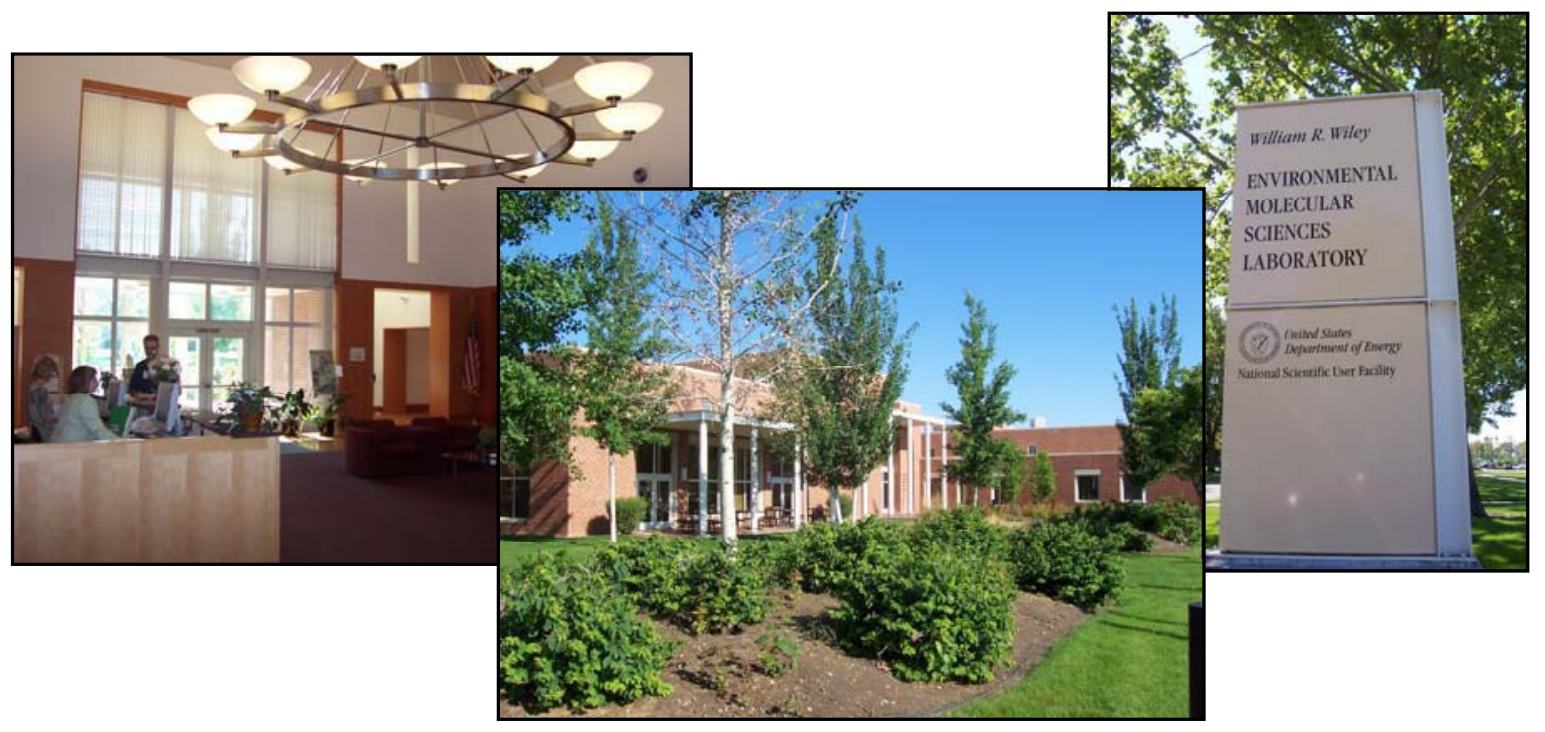

(Photos courtesy of K. Kostelnik) 


\subsubsection{Oak Ridge National Laboratory}

4.1.2.1 Introduction. ORNL, located near Knoxville, TN, is one of the DOE's national laboratories. With an annual budget of about $\$ 1$ billion, ORNL is DOE's largest science and energy laboratory ${ }^{[10]}$. ORNL's six major scientific competencies include neutron science, energy, high performance computing, complex biological systems, advanced materials, and national security ${ }^{[13]}$. ORNL employs about 3,700 people $^{[10]}$, who are housed in over 272 buildings on its 4,250 -acre site ${ }^{[12]}$. The 4,250 acres are located within the larger DOE Oak

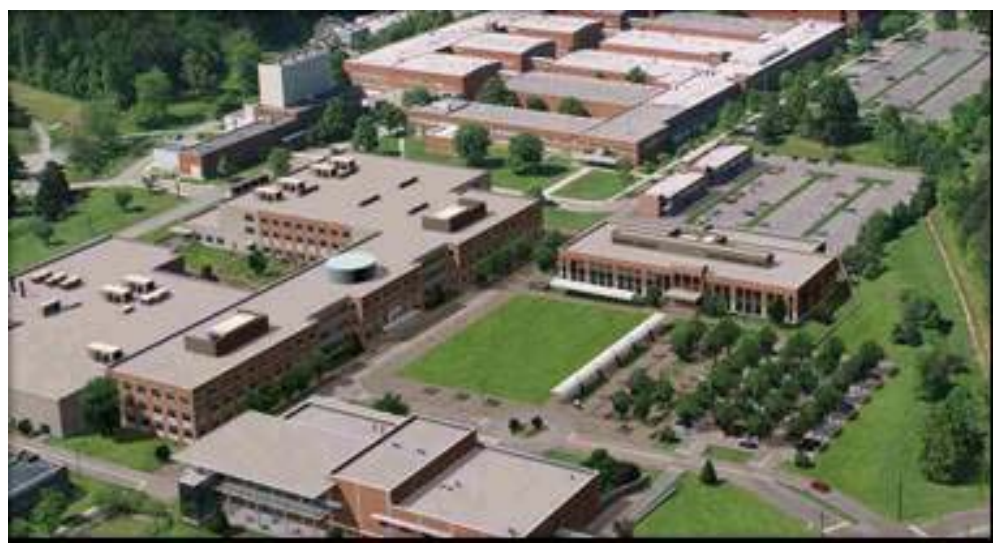

ORNL East Campus Plan for FY05

(Image courtesy of ORNL) Ridge Reservation of 34,000 acres of federally owned lands; 20,000 acres of this are designated as the Oak Ridge National Environmental Research Park, an outdoor laboratory ${ }^{[12]}$. ORNL has 18 user facilities and hosts an average of 3,000 research guests annually ${ }^{[13]}$. ORNL is managed by a partnership of the University of Tennessee and Battelle (UT-Battelle). ORNL is supported primarily by the DOE Office of Science, with significant other sponsors from the Department of Defense, National Aeronautical Space Administration, Environmental Protection Agency, National Science Foundation, and Nuclear Regulatory Commission $^{[11]}$.

The ORNL infrastructure mssion is to transform ORNL into a modern research campus for the $21 \mathrm{st}$ century that:

- Possesses world-class technical and support facilities that attract the best and brightest

- Is seen as a vibrant campus setting where staff have opportunities to interact and conduct multidisciplinary science

- Offers on-site, short-term housing for a growing user community

- Has sufficient maintenance investments to sustain the facilities and infrastructure ${ }^{[10]}$.

The ORNL Master Plan, which guides the site revitalization, was created by the University of Tennessee's Graduate School of Architecture. Program requirements that were defined in the ORNL Institutional Plan were used as a guide. In addition, the following guiding principles were used to develop the Master Plan:

- Creation of an open research campus

- Use of energy efficiency/sustainability as a major design principle

- Establishment of a flexible structure that allows for phased program growth

- Establishment of a campus center ${ }^{[10]}$. 


\subsubsection{Site/Campus Level Considerations.}

Facility Planning and Modernization - ORNL is in the final stages of a $\$ 300$ million modernization program that involved building 13 new facilities ${ }^{[13]}$. ORNL's modernization plan involved three primary steps: (1) consolidating at the main site, (2) vacating older space, and (3) building new and refurbishing key facilities ${ }^{[10]}$. The modernization introduces significant new technical capabilities and facilities in the areas of environmental and life science, neutron science, materials science, and computational science. Among the new facilities are the Functional Genomics Center; the Center for Nanophase Materials Science; the Advance Materials Laboratory, and the joint institutes for Computational Science, Biological Science, and Neutron Science. Recently built facilities include a Computational Sciences Building $\left(137,000 \mathrm{ft}^{2}\right)$, an Energy Technology Facility $\left(98,000 \mathrm{ft}^{2}\right)$, and a Research Office Building $\left(140,000 \mathrm{ft}^{2}\right)$, which contains 406 offices, 14 conference rooms, and a "Main Street" area that houses employee amenities (credit union, etc.) and is designed to create staff interaction opportunities. The Engineering Technology Facility includes 35 laboratories, two high bays, five clean rooms, and 96 offices $^{[10]}$.

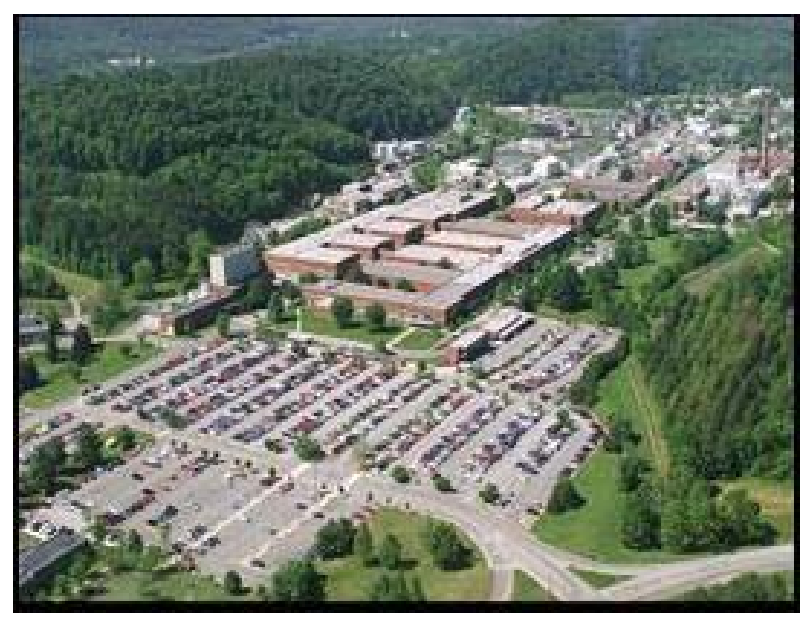

ORNL East Campus as it appeared in March 2002

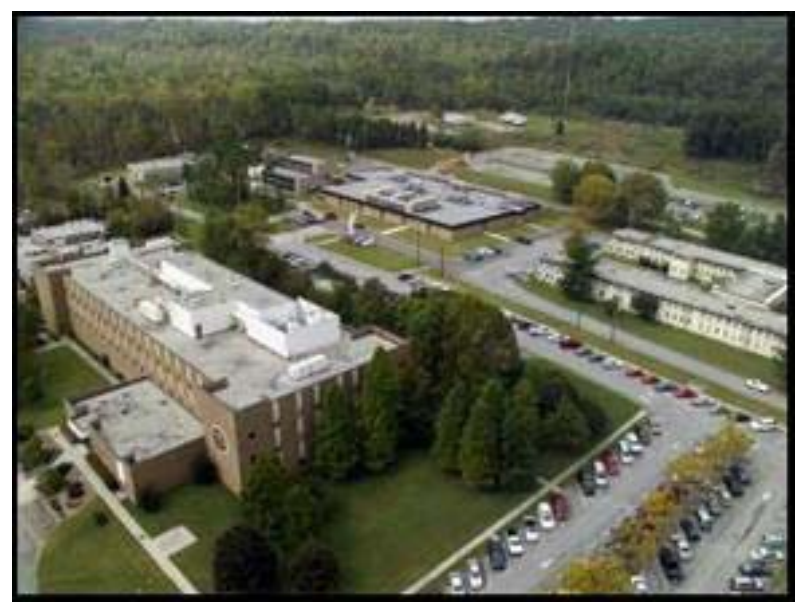

Environmental and Life Sciences West Campus Today

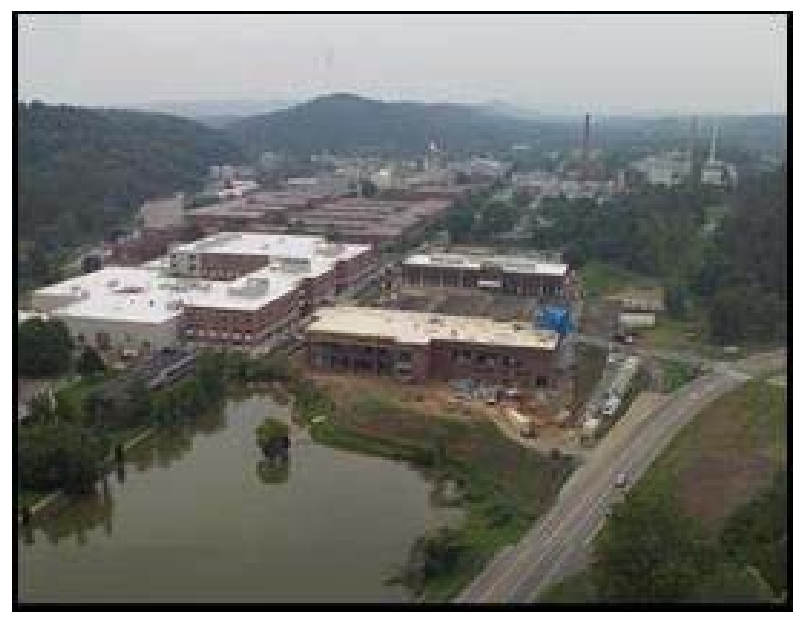

ORNL East Campus in September 2004

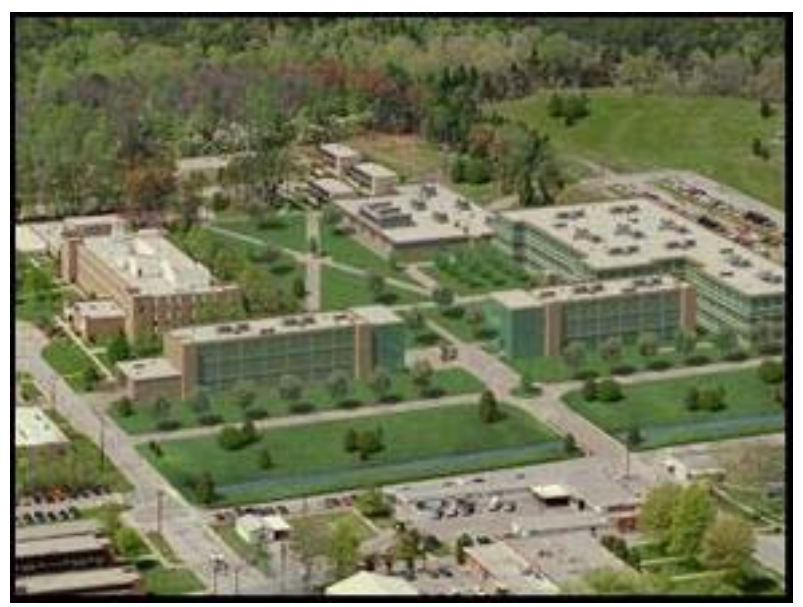

Environmental and Life Sciences

West Campus Vision

(Photos and images courtesy of ORNL) 
To facilitate communication and research collaborations, the facilities include multiple telecommunications rooms with different levels of security. The facilities were designed with expansion in mind, and include an unfinished shell build-out and the option to expand to a $4^{\text {th }}$ story to accommodate and anticipated 250 future staff. The new Research Support Center, located adjacent to the composite facility, houses a visitor center, cafeteria, and conference center. Another new facility, the Joint Institute for Computational Sciences and Oak Ridge Center for Advanced Studies (52,000 $\mathrm{ft}^{2}$ ), was also recently completed $^{[10]}$.

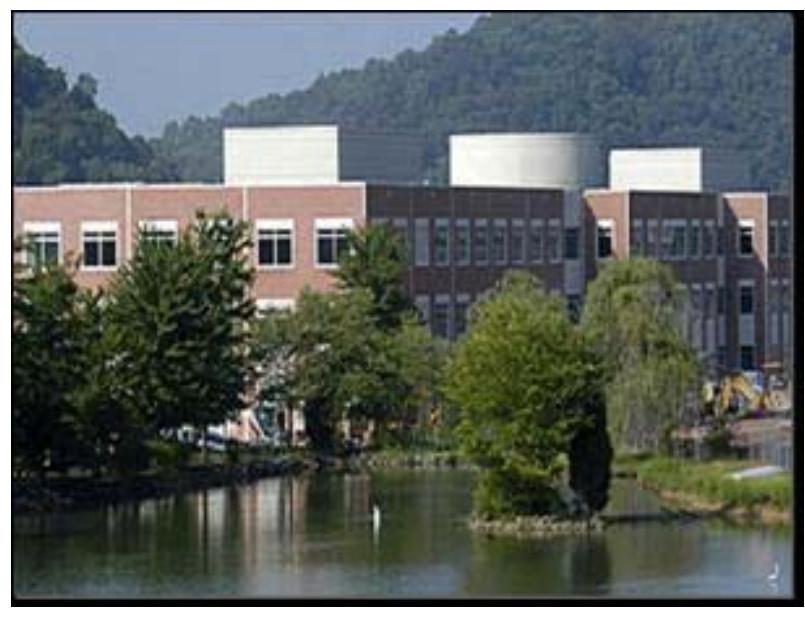

First LEED-certified facility in Tennessee

(Photo courtesy of ORNL)

SustainabilitylEnergy Conservation - A major focal point of ORNL's modernization is sustainability, requiring all new buildings to meet sustainability goals. ORNL built the first three Leadership in Energy and Environmental Design (LEED)-certified facilities in Tennessee, and there are now five new ORNL buildings with LEED certification (Silver or Gold) ${ }^{[10]}$. LEED guidelines employed by ORNL include energy efficient roofs, low emission materials, recycled-content materials, and native landscaping, which all contribute to sustainability.

Land Use Planning - ORNL was established in 1943 as part of the Manhattan Project to pioneer a method for producing and separating plutonium ${ }^{[13]}$. Because of this history, ORNL has many older facilities that are no longer needed for the current mission, as well as some radiological controlled areas. Approximately $80 \%$ of the existing space is more than 30 years old ${ }^{[11]}$. The overall goal is to reduce the infrastructure footprint by $25 \%$, from 4.4 million $\mathrm{ft}^{2}$ to 3.2 million $\mathrm{ft}^{2}{ }^{[10]}$. This change will include vacating 1.8 million $\mathrm{ft}^{2}$ and new construction totaling 0.6 million $\mathrm{ft}^{2}$. Vacating the older facilities is needed because the aging infrastructure impacts the ability to perform science. Factors include the functionality, high operating and maintenance costs, utility systems that are non-compliant with current regulations, legacy materials that need disposition, and increasing difficulty in maintaining a safe work environment. Although ORNL has demolished many facilities, ORNL indicated that footprint reduction and legacy management are areas that are not sufficiently funded and will require additional funding in the future $^{[10]}$.

ORNL has a Land Use Planning organization that identifies and prioritizes needs for stewardship and preservation of reservation land to meet the requirements of existing and future missions across the site. Proposed projects are screened based on priorities of preserving and protecting the land to meet

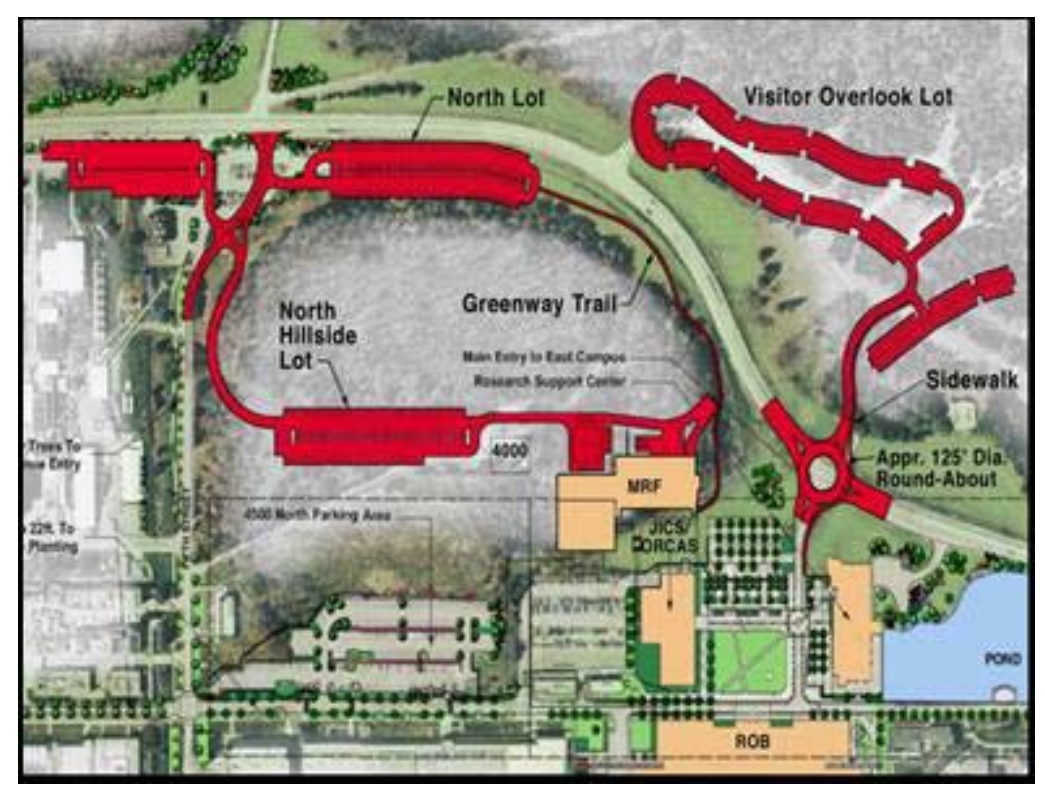

An Aerial Diagram of ORNL (Image courtesy of ORNL) 
environmental research and science needs and on allowing uses that are compatible with DOE missions. This organization guides which projects are conducted on the site, especially in the 20,000-acre Oak Ridge National Environmental Research Park. The National Environmental Research Park is an ORNL user facility that was used by more than 900 users from 120 colleges, universities, industries, ORNL, and other State and federal agencies over the five years from 1998 to 2003. This area allows DOE to support major field experiments that could not be conducted if it had not been protected for such long-term studies. Fundamental questions about the effects of energy related activities on ecological systems are studied here ${ }^{[12]}$.

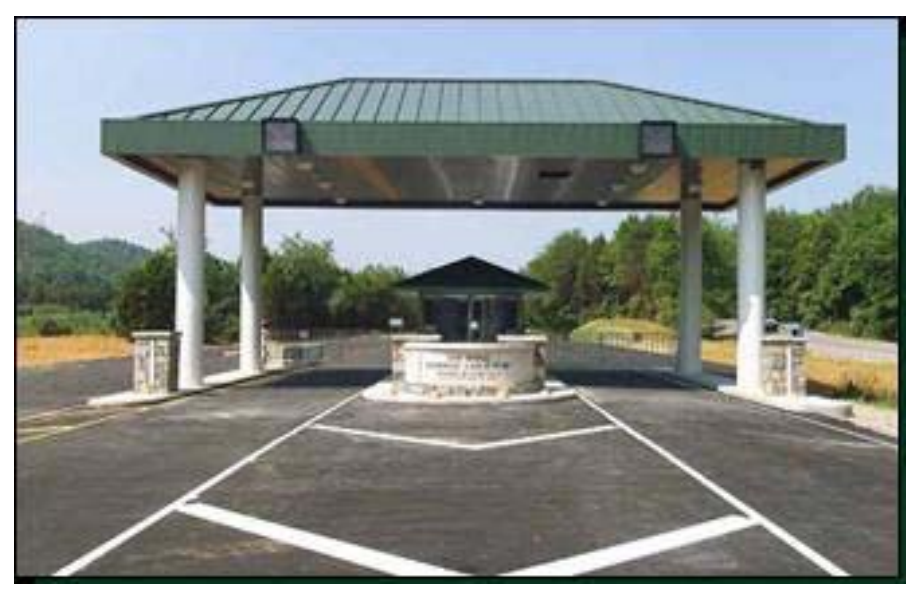

Access Portal

(Photo courtesy of ORNL)
Landscape Architecture - When new buildings are planned, an important factor ORNL considers is how they will fit into the existing infrastructure. Efforts are made to ensure that new buildings blend well with existing buildings and other features. The landscaping and new building designs are also receiving additional attention. A greenway trail has been added to connect the facilities and parking lot areas and provide a scenic overlook from the visitor parking lot. ORNL has also changed the access approach (i.e., access portals on Bethel Valley Road) to the site, presenting a new image of an open campus $^{[10]}$ to visitors and guests.

Waste Management - ORNL has responsibility for conventional waste, including sanitary/industrial wastes, process wastewater, and stormwater. A separate contractor, Bechtel Jacobs Company, is responsible for remediation systems and operations of low-level radioactive, transuranic, hazardous, mixed, and toxic waste disposal $^{[10]}$.

Financial Mechanisms - ORNL combines DOE, state, and private-sector funding to accomplish its infrastructure modernization mission. DOE funding was used for major science structures and infrastructure improvements, state funding was used for the Joint Institutes with university partners $(\$ 18 \mathrm{M})$, and private-sector funding was used for commercial laboratory and office space (\$73M).

ORNL utilized a unique process to accelerate its modernization plan via the private sector. This process involved DOE transferring land to UT-Battelle via a "quitclaim deed." Then the land was leased to a developer for the facility construction. The constructed facility was then leased back to UT-Battelle (i.e., 10-yr operating lease, with three 5-year options to renew).

This approach provided advantages for the government in terms of cost savings and quick development to fuel the modernization project. Three important considerations in the financing and development were that DOE guaranteed the lease,

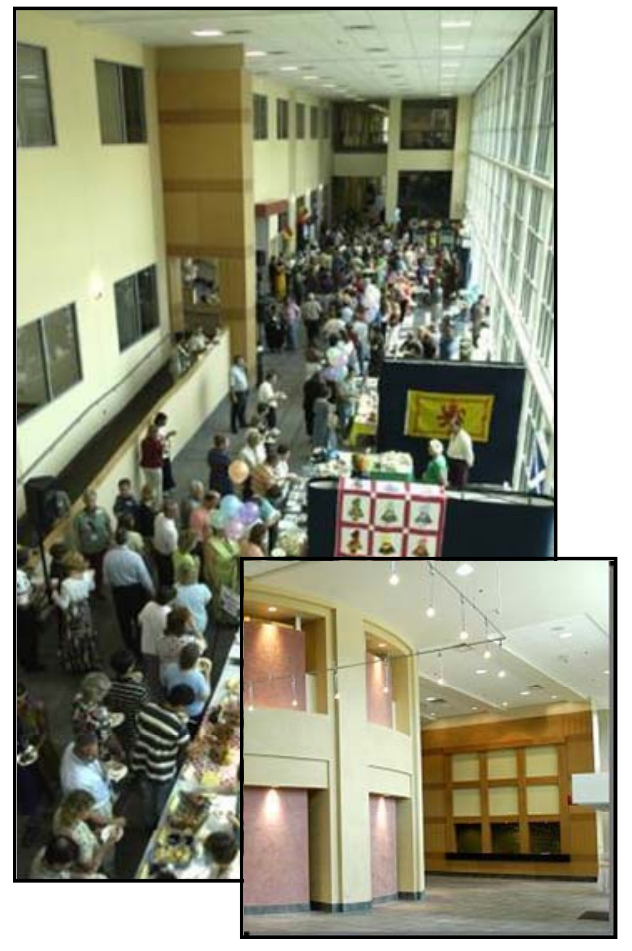

Main Street and Front Lobby (Photos courtesy of ORNL) 
that the new facilities be essential to the laboratory's continuation, and that there be alternate uses for the facilities in the future ${ }^{[10]}$.

Space Management/Utilization - The new buildings are being constructed to maximize sustainability and flexibility through use of open office space and demountable walls ${ }^{[10]}$.

\subsubsection{Social Considerations.}

Research Atmosphere/Culture - In general, ORNL's modernization has created a spirit of innovation and excitement within the laboratory and community. One key aspect of ORNL's modernization effort was to reduce number of staff offsite and consolidate staff in the main buildings, resulting in over 400 employee moves ${ }^{[10]}$. However, as some employees moved to the newer facilities and other employees remained in the older facilities, a "have vs. have-not" culture has emerged.

Employee Amenities - Many amenities are provided for employees of ORNL. For example, the new Research Office Building has a "Main Street", which houses a credit union, cafeteria, coffee stand, and lounge area. Additional areas within the ORNL site are being landscaped with courtyards and walkways to create a campus feel. The greenway, which connects the parking areas to the facilities, provides an area for walking, exercise, and connection with the outdoors, including a waterfall.

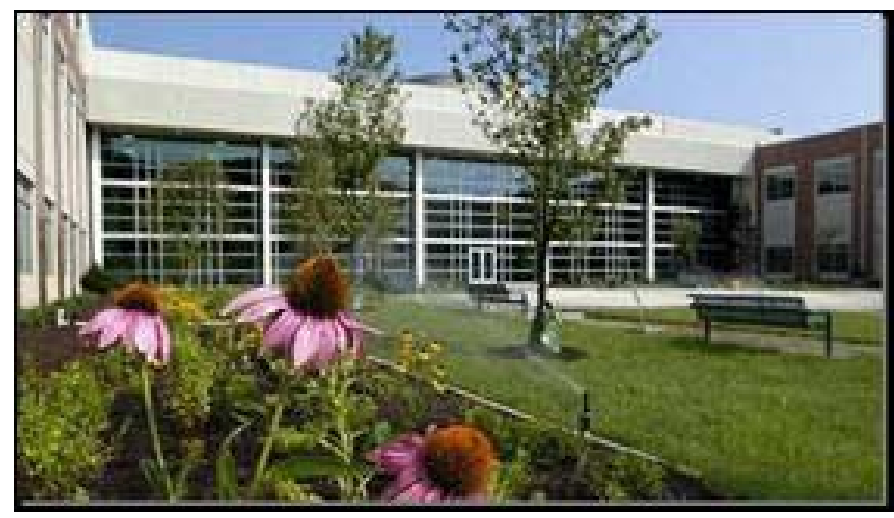

Courtyard for Events

(Photo courtesy of ORNL)

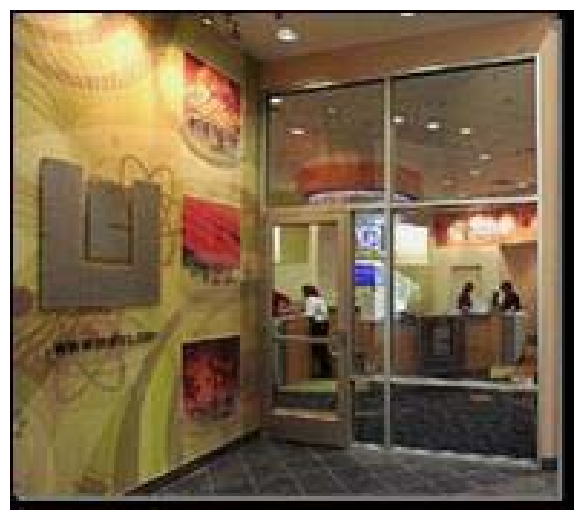

Credit Union

(Photo courtesy of ORNL)

Operating Policies/Procedures - ORNL has streamlined their visitor security approval process, making it easier to host visitors and encouraging collaborations. Key to the success of their system is a centralized department that provides visitor services and contacts. ORNL's Visitor Center, located in Research Support Center, provides a comfortable place to meet visitors while complying with security requirements. Visitor requirements are easy to obtain via ORNL's website, which includes contacts for prospective visitors, as well as information about ORNL user facilities, collaborations, travel, and local amenities. In the future, ORNL plans to build visitor housing to encourage visitors and research collaborations.

4.1.2.4 Summary. ORNL is currently DOE's largest science and energy research laboratory, with an annual budget of about $\$ 1$ billion. ORNL is focusing on six major competencies: neutron science, energy, high performance computing, complex biological systems, advanced materials, and national security. ORNL's 4,250-acre site is located within a larger DOE reserve of 34,000 acres. ORNL employs about 3,700 people and hosts an additional 3,000 visiting researchers annually in their 18 user facilities. Funded primarily by the DOE Office of Science (DOE-SC), ORNL is managed by a partnership between the University of Tennessee and Battelle. 
ORNL's current infrastructure mission is to transform ORNL into a modern research campus that possesses world-class facilities, encourages multi-disciplinary science, and attracts world-renowned researchers. ORNL's $\$ 300$ million modernization program, which is nearing completion, is being guided by a Master Plan that was developed by the UT Graduate School of Architecture. The modernization plan involves three primary steps: (1) consolidating at the main site, (2) vacating older space, and (3) building new and refurbishing key facilities. Along with building 13 new facilities and refurbishing others, upgrades are being made to key site-wide infrastructure components, such as HVAC, plumbing, and wiring.

Several underlying principles have guided ORNL's modernization effort. The modernization is being done so it facilitates communication and research collaborations in the facility and campus design. A streamlined visitor security approval process has been established to encourage collaborations and international use of the user facilities. Another major focal point of ORNL's modernization is sustainability, wherein all new buildings must meet sustainability goals. As a result, ORNL built the first three LEED-certified facilities in Tennessee. ORNL manages the site as a whole, with short and longrange plans documented for each facility and land-use area. This approach ensures the necessary facilities are in place and enables preservation of land and resources to meet the requirements of current and future research. ORNL's modernization has also provided improved employee amenities, newer office space, state-of-the-art equipment, and conveniences like an on-site credit union. To accomplish the modernization, ORNL combined DOE, state, and private-sector funding in innovative ways. 


\section{Spallation Neutron Source}

The Spallation Neutron Source (SNS), a $\$ 1.4$ billion facility, is scheduled for completion in $2006^{[14]}$. Six national laboratories partnered to design and build the SNS. The SNS will provide the most intense pulsed neutron beams in the world for scientific research and industrial development. The baseline design calls for an accelerator system consisting of an ion source, full-energy linear accelerator (linac), and an accumulator ring that combine to produce short, powerful proton pulses. These proton pulses impinge onto a mercury target to produce neutrons through the spallation nuclear reaction process.

The SNS will attract 1,000 to 2,000 scientists and engineers each year from universities, industries, and laboratories in the United States and other nations, making ORNL the world's foremost center for neutron science research ${ }^{[14]}$.

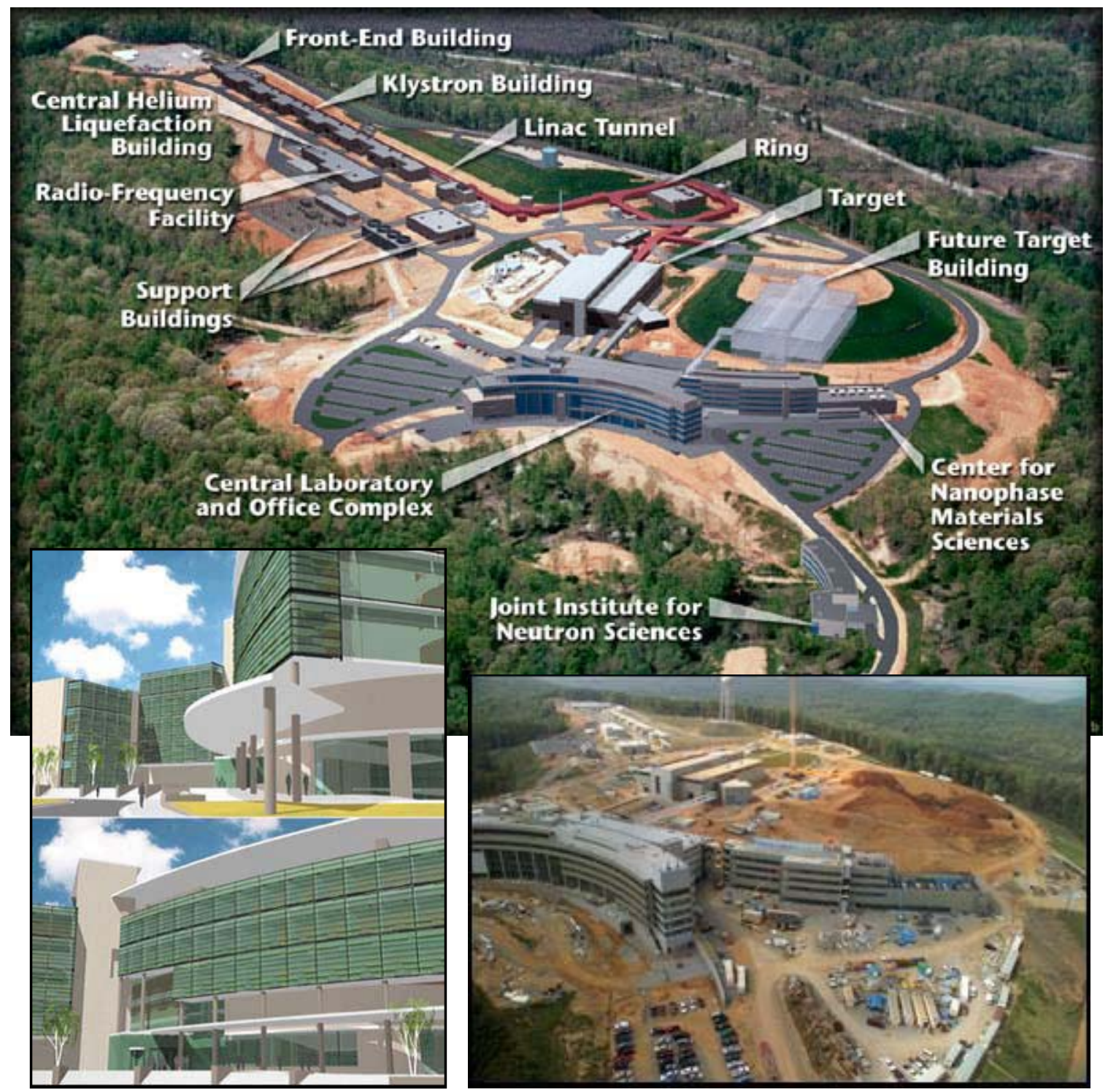

(Photos and images courtesy of ORNL) 


\subsection{Universities}

\subsubsection{Stanford University}

4.2.1.1 Introduction. Stanford University, located about 50 miles south of San Francisco, CA, is a large multidisciplinary institution of higher education and research. Stanford's faculty currently includes 16 Nobel laureates, four Pulitzer Prize winners, and 24 MacArthur Fellows ${ }^{[15]}$. Stanford faculty and alumni have started numerous successful businesses, including e-Bay, Google, HewlettPackard, Charles Schwab \& Co., The Gap, Nike, and Silicon Graphics. Many ideas created at Stanford have changed the world.

Situated on 8,180 acres, Stanford has 678 major buildings, comprising approximately 12.6 million $\mathrm{ft}^{2}$. These facilities include the colleges of medicine, law, business, education, engineering, earth sciences, humanities, and science, as well as a medical center and two hospitals. In addition to the educational and research facilities, Stanford houses $94 \%$ of undergraduates, $52 \%$ of graduates, and $30 \%$ of the faculty on campus. Stanford's 2004-2005 budget was $\$ 2.6$ billion, not including capital expenditures ( $\$ 169$ million), or the hospital and clinic budgets ${ }^{[15]}$.

\subsubsection{Site/Campus Level Considerations.}

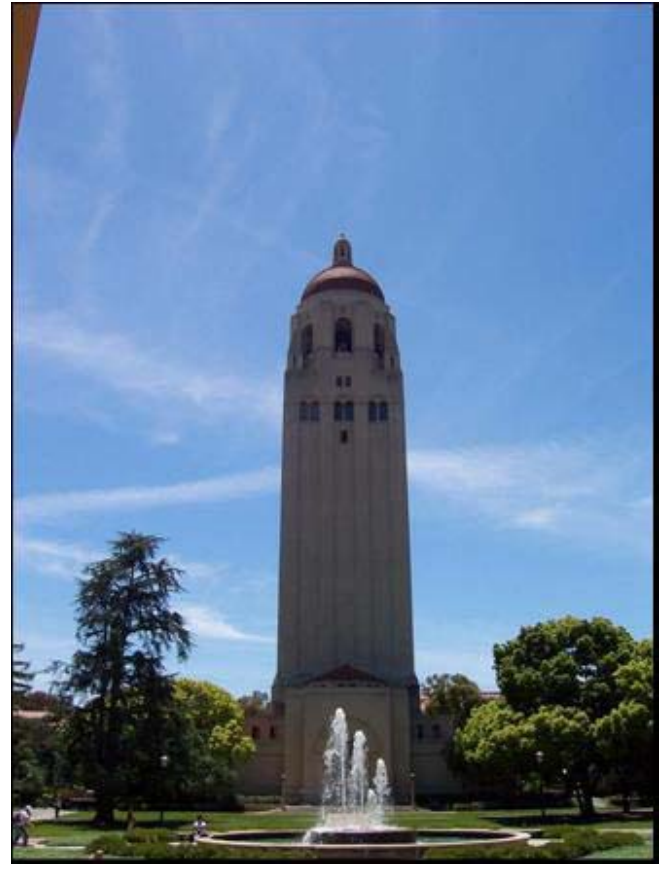

Stanford University

(Photo courtesy of K. Kostelnik)

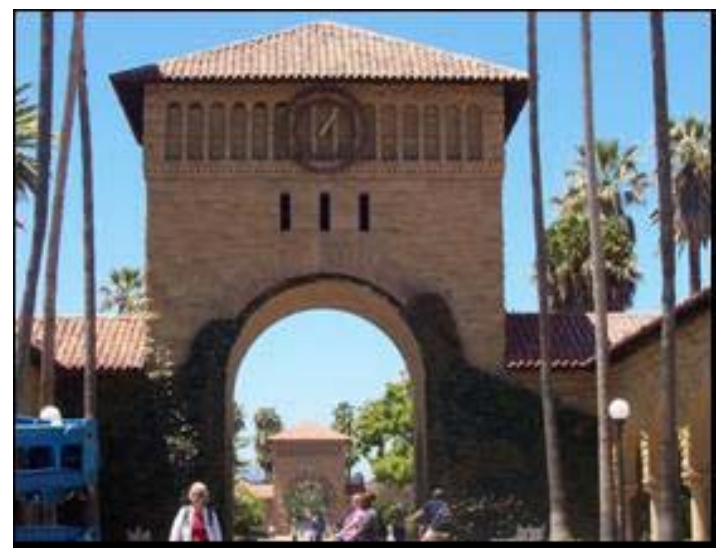

Stanford's historic design style

(Photo courtesy of K. Kostelnik)
Facility Planning and Modernization - When it first opened in 1891, Stanford's design and architecture teams settled on a California mission style with yellow sandstone arches and red tile roofs ${ }^{[15]}$. Throughout the years, Stanford has maintained much of the historic campus look while incorporating modern buildings by using a standardized architectural design style that ties the campus together.

The original campus master plan included having a separate quadrangle for each college, but over time, variations of this concept have been built. There is currently an effort underway to restore the original campus design vision.

Based on agreements with the local government and community, Stanford's expansion is limited to a maximum of 2 million $\mathrm{ft}^{2}$ over the next 10 to 20 years ${ }^{[16]}$. Because of this limitation, Stanford first looks to renovation and more effective utilization of existing facilities, rather than new construction. Most of the new construction is done to replace existing facilities. Stanford also limits vertical expansion to three stories and focuses instead on underground space.

Stanford's Capital Planning Department assists with space planning tasks and questions, and has a Space Planning Guidelines document that guides their work. Capital Planning's role includes assessing 
existing space usage, translating program plans into space needs, improving efficiency and space capacity, design space renovations, and "right size" offices and other spaces.

Energy Conservation/Sustainability - Stanford has extensive campus-wide energy conservation and sustainability programs. These concepts are incorporated into most campus areas, including facility planning, landscape design and maintenance, and waste management.

Stanford defines "sustainable buildings" as those that use energy, water, and other natural resources efficiently and provide safe and productive indoor environments. Stanford has documented their approach for sustainability of buildings in their "Guidelines for Sustainable Buildings" booklet. This booklet provides details about how to include sustainability into all steps of the project process, from scoping to construction, and includes specific sustainability goals for each project phase. It also provides technical guidelines, which are organized into five categories: (1) site design and planning; (2) energy use; (3) water management; (4) materials, resources; and waste; and (5) indoor environmental quality ${ }^{[17]}$.

All proposed new projects are required to meet energy efficiency standards and practices. When renovating buildings, Stanford follows the intent of the LEED program for energy star certification, but doesn't certify or reuse construction materials. This approach allows them to meet the intent of the program with less administrative cost. Stanford is currently building a "green" dormitory as an experimental facility.

Stanford employees are encouraged to use public transportation systems to prevent undue environmental impact on the campus habitat and to allow for efficient access to university facilities. Train, metro-bus, campus shuttles, bikes, and vehicle access are all available options. Employee start and end times are also staggered to prevent undue burden on public transport systems.

\section{Landscape Planning - A Geographical} Information System (GIS) is used to map and track space and features across campus. The detail of this system allows for specific identification and location of all elements, including vegetation type and placement ${ }^{[16]}$.

\section{Landscape Architecture - Stanford's} landscape is designed to be sustainable and easily maintained, using indigenous plants that are water and care conservative. Stanford is a certified green business, and environmentally friendly controls are used for weeds and pests. For example, weeds are controlled through steam and flame-throwers, rather than

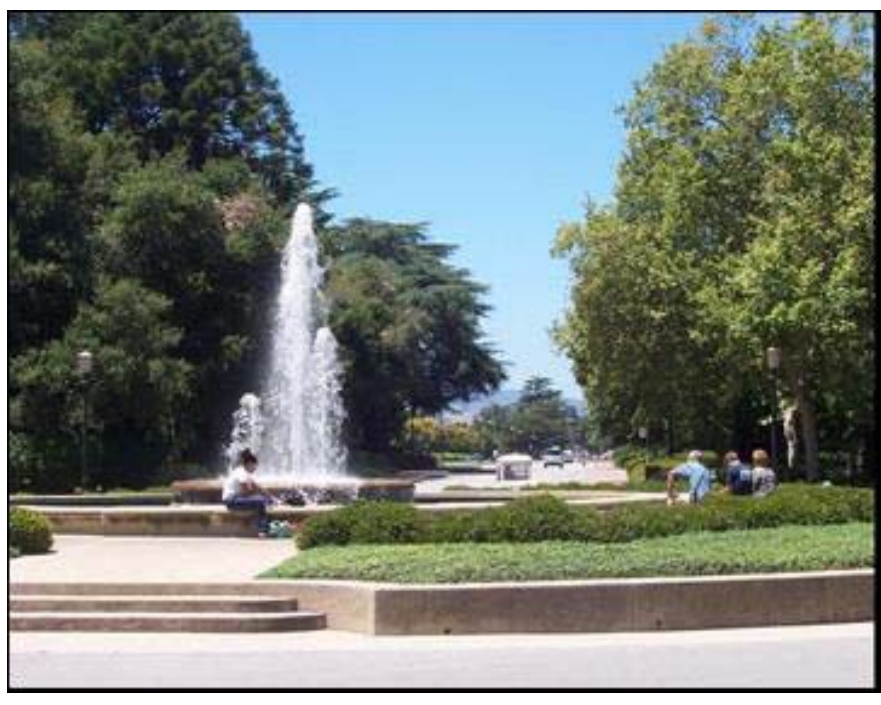

Groomed Landscaping

(Photo courtesy of K. Kostelnik)

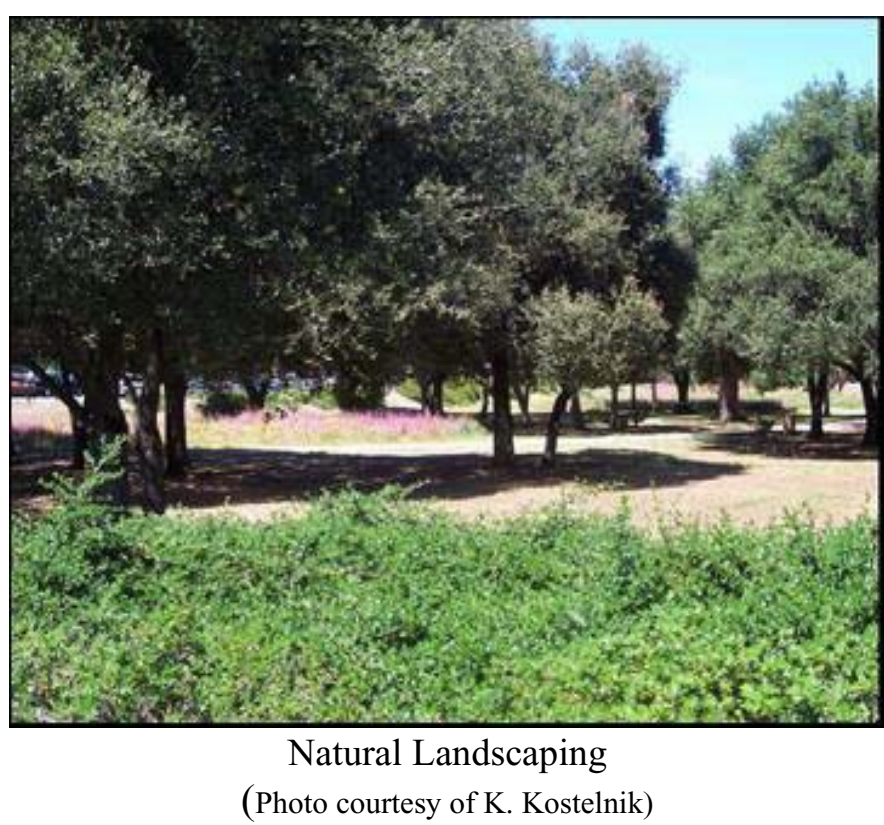


herbicides, and pests are controlled through plantings that are not susceptible to pests, and other methods such as soaping, and predator pests. The landscaping includes many areas that are in their natural state. These areas blend well with the groomed and planted areas, which are well-maintained and inviting.

Waste Management - Stanford has a comprehensive waste management program. Sixty percent of Stanford's waste stream is recycled, including food, greenery, construction/demolition materials, cardboard, paper, and plastics. These recycling efforts are largely voluntary and implemented through individual users in facilities. Styrofoam and computers are diverted to offsite vendors for processing, while sharing and storage of chemicals is universally managed through a campus-wide database that helps eliminate waste.

Financial Mechanisms - A significant amount (75\%) of financial support is from private investors, with public funds being contributed in the form of grants and contracts $(25 \%)^{[16]}$. Funding profiles vary with the economy. Gift funding and endowments are sought after and used but are not predictable or reliable as a consistent source of funding. Overhead taxes are used to support new capital improvements. Multiple funding sources (both private and public) are linked and used, and mechanisms are in place to facilitate this.

Stanford has found that project renovation costs have ranged from $\$ 244 / \mathrm{ft}^{2}$ for office renovations to $\$ 500 / \mathrm{ft}^{2}$ for laboratory space renovations or historic preservation projects. Building new space costs even more, ranging from $\$ 336 / \mathrm{ft}^{2}$ for office space to $\$ 600 / \mathrm{ft}^{2}$ for laboratory space ${ }^{[18]}$. These numbers represent total project costs, including space development, construction costs and fees, permits, furniture, equipment, etc.

\subsubsection{Facility/Laboratory Level Considerations.}

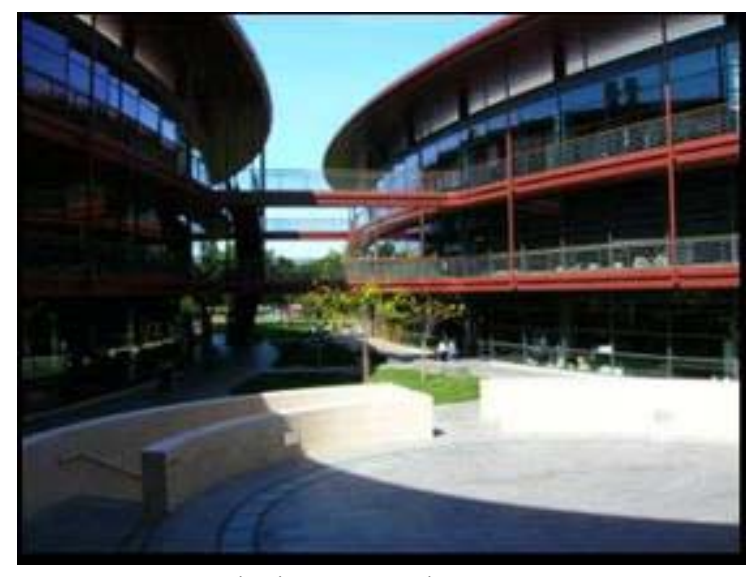

Clark Research Center

(Photo courtesy of Stanford University)

Facility/Laboratory Design - Stanford has numerous laboratory facilities with varying levels of modernization. The Clark Research Center, Stanford's newest addition, is a showcase modern laboratory featuring flexibility, open architecture, and innovative approaches to space utilization.

Laboratory space is allocated based on project priority and importance, and is directly tied to the amount of outside funding the project secures. This approach rewards performance by providing more resources to those generating new business and funding. Laboratory space is not available for use by external entities. Laboratory space is at a premium and every part of the facility is used to accommodate research. Space is allocated for equipment storage, but the indication is that there is never enough storage space ${ }^{[16]}$.

Space Management/Utilization - Stanford's Capital Planning Department provides guidance to allocate and efficiently use space. Their guiding document, Stanford's Space Planning Guidelines ${ }^{[19]}$, provides recommendations about the allowable amount of office space based on rank. Different levels of campus management, faculty, staff, and students are allowed defined amounts of office space based on their classification. Suggested office lay-outs are also provided. In addition, the document provides guidelines for laboratory designs and lay-out, focusing on modularity, flexibility, and zoning. The laboratories are classified as computer, wet, dry, studio, teaching, or special large equipment laboratories. 
Lastly, the document provides guidelines for classrooms and conference rooms, designating the required number of desks, chairs, tables, and computers along with suggested layouts.

In the newly built or remodeled facilities, interchangeability of functions as well as flexibility in space utilization is common. The older facilities are less flexible because of their original design and intended functionality.

\subsubsection{Social Considerations.}

Research Atmosphere/Culture - Stanford embraces an open research atmosphere, where innovation and creativity are encouraged. The University is known for its openness to new ideas and interdisciplinary approach.

Employee Amenities - Stanford provides many amenities to facilitate combining education and research with other needs. For example, there are many cafeterias and snack shops that make it convenient to get food near your work place. Numerous casual gathering places, both indoor and out, foster interactions and study. The campus design includes many inviting, open spaces with a lot of light for study or creative thought. The conference rooms, plug-and-work areas, and computers are available for use by all. Stanford faculty, staff, and students all

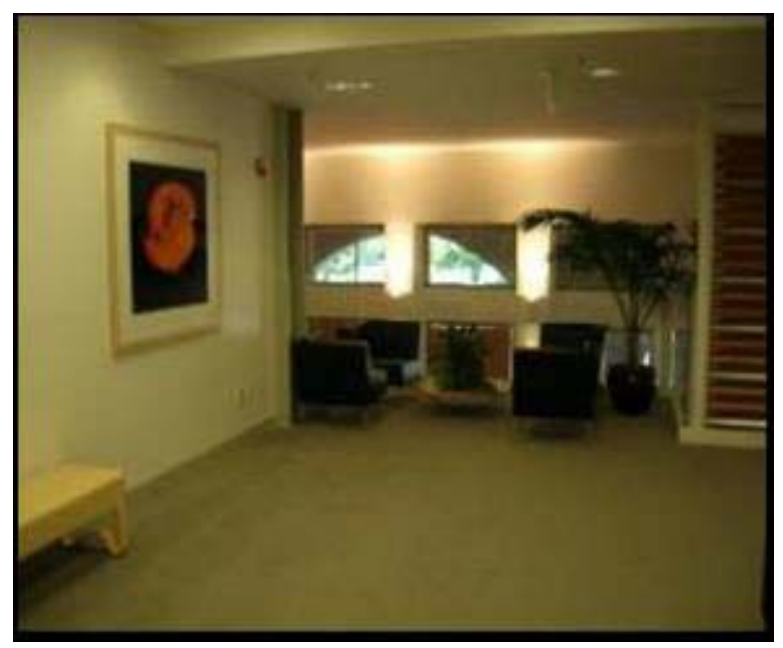

Open areas for study

(Photo courtesy of L. Stephenson) have access to wellness and athletic facilities on campus. In addition to the physical amenities, policies, such as flexible work schedules, are aimed at meeting people's needs. Stanford opened an on-site childcare center, but it was not heavily utilized. Stanford found that the employees valued flexibility in their schedule to meet family needs more than a child-care center, so administrators disbanded the child-care center and made policy changes to allow more flexible work schedules.

Community Involvement - The public is welcome and encouraged to share the campus, and the community is invited to participate in campus interactions. Even within campus facilities, access to use

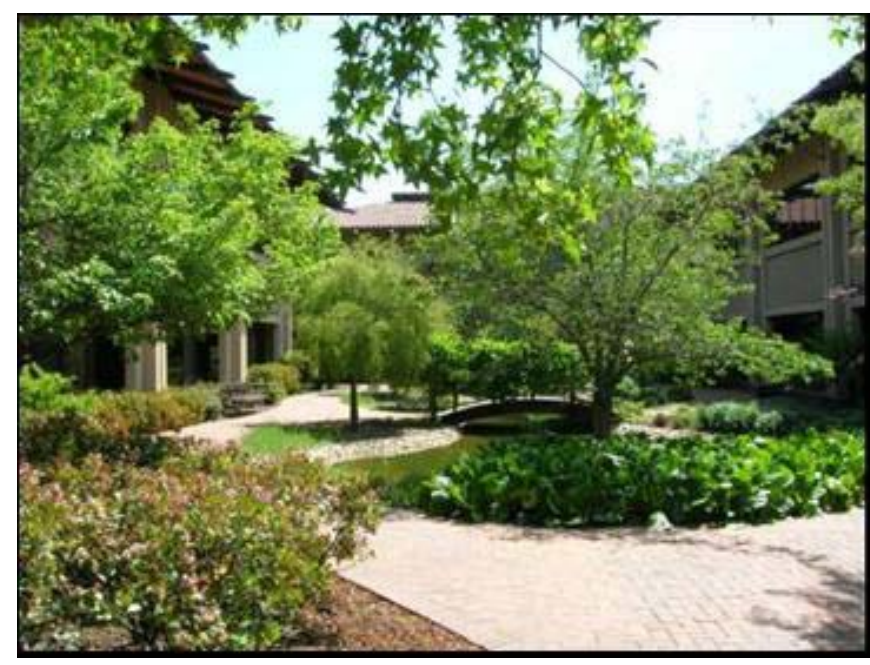

Courtyard at Stanford

(Photo courtesy of L. Stephenson) of rooms, equipment, and facilities is

encouraged. This open approach works well as individual laboratories and/or buildings can be secured. Security issues do not appear to be a great concern.

4.2.1.5 Summary. Stanford University, located about 50 miles south of San Francisco, $\mathrm{CA}$, is known for its award-winning faculty and research results. Numerous revolutionary ideas, inventions, and successful businesses have been initiated by Stanford faculty, students, and alumni. Stanford is known for its interdisciplinary approach and fostering intellectual creativity. 
Stanford's campus and laboratory designs, as well as ongoing modernization projects, are aimed at creating an environment that encourages significant research results. For example, the award-winning Clark Research Center is a multidisciplinary facility where medicine, engineering, biology, and physical science researchers are collocated to facilitate collaborations. The Clark Research Center features a striking, open building design where glass-walled laboratories face an open courtyard. The laboratories are open, modular, and immensely flexible.

Modernization efforts such as the Clark Research Center are made within a framework of limited growth and maintaining the historic campus look. Throughout campus, in modernization efforts, landscape design, and policies/procedures, Stanford focuses on sustainability and environmentally conscious actions. In addition to the environment and facilities, Stanford provides many amenities to faculty, staff, and students to facilitate education and research.

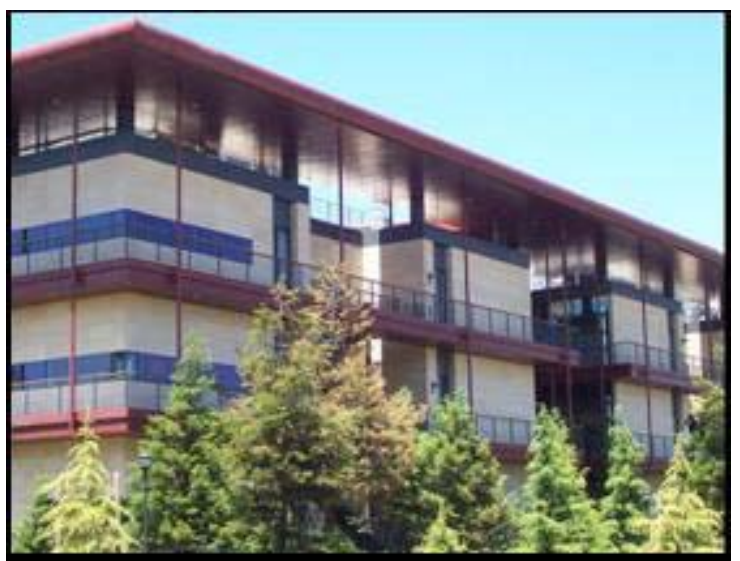

Exterior of Clark Research Center (Photo courtesy of K. Kostelnik) 


\section{Clark Research Center}

The Clark Research Center is the centerpiece of Stanford's new Bio-X program - an innovative campus-wide initiative designed to foster interdisciplinary research in medicine, biology, engineering, and physical sciences. The $146,000 \mathrm{ft}^{2}$ facility houses 42 interdisciplinary faculty members, 700 people overall, an underground auditorium, conference and lecture rooms, two cafeterias, and an administrative area. The building design includes an open courtyard where three stories of curved, glass-walled research laboratories are connected by balconies and walkways. The open building design and collocation of different departments is hoped to result in unprecedented interdisciplinary interactions and research results.

The Clark Center's most arresting feature is its open laboratory design. The laboratories are modular and immensely flexible, with wheeled workstations that connect to overhead utilities that are suspended from a Unistrut ceiling and racks, and threaded through removable stainless steel guides. The drop-down utilities include gas, air, vacuum, electricity, communication, and water. Sinks are the only non-mobile items. The lab zones consist of two $10,000 \mathrm{ft}^{2}$ areas per floor. Most of the fume hoods for common use are located in alcoves in support zones near the rear of the laboratory space. Pl's offices are located inside the laboratory.

Because of its innovative design, modular laboratories, and interdisciplinary approach, Stanford's Clark Research Center received R\&D Magazine and the Scientific Equipment and Furniture Association's (SEFA) 2004 Lab of the Year Award, and has become the benchmark for modern, modular laboratory buildings ${ }^{[20]}$.

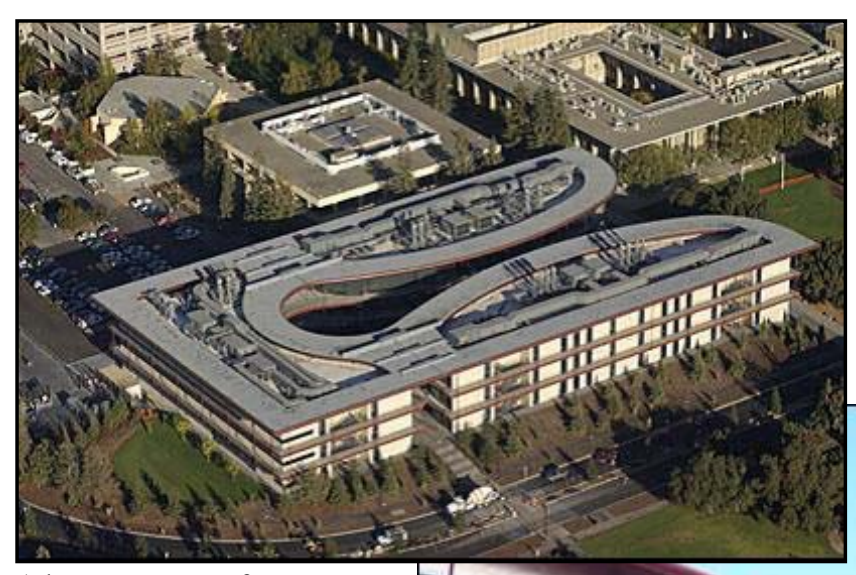

(Photo courtesy of Stanford University)

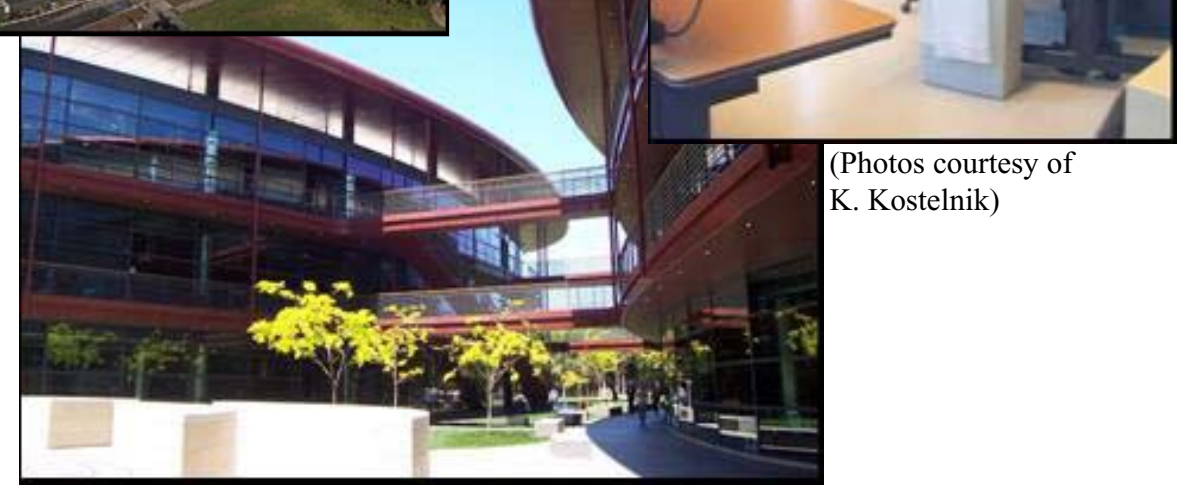




\subsubsection{Massachusetts Institute of Technology}

4.2.2.1 Introduction. The Massachusetts Institute of Technology (MIT) is a world-class educational institution located adjacent to the Charles River in Boston, MA. MIT was founded in 1861 and admitted its first student in 1865. MIT was founded by William Barton Rogers to serve as an independent educational institution that coupled teaching and research focused on real-world problems. Today, MIT remains an independent, coeducational, and privately endowed institution. The MIT mission is "to advance knowledge and educate students in science, technology, and other areas of scholarship that will best serve the nation and the world" ${ }^{\prime[23]}$.

MIT is comprised of five schools (School of Architecture and Planning; School of Engineering; School of Humanities, Arts and Social Sciences; Sloan School of Management; and the School of Science), one College (Whitaker College of Health Sciences and Technology), and numerous interdisciplinary Centers that work across traditional departmental boundaries $^{[22]}$.

The MIT research community involves approximately 17,000 individuals. This includes approximately 1,000 faculty members and 10,000 students $(60 \%$ graduate and

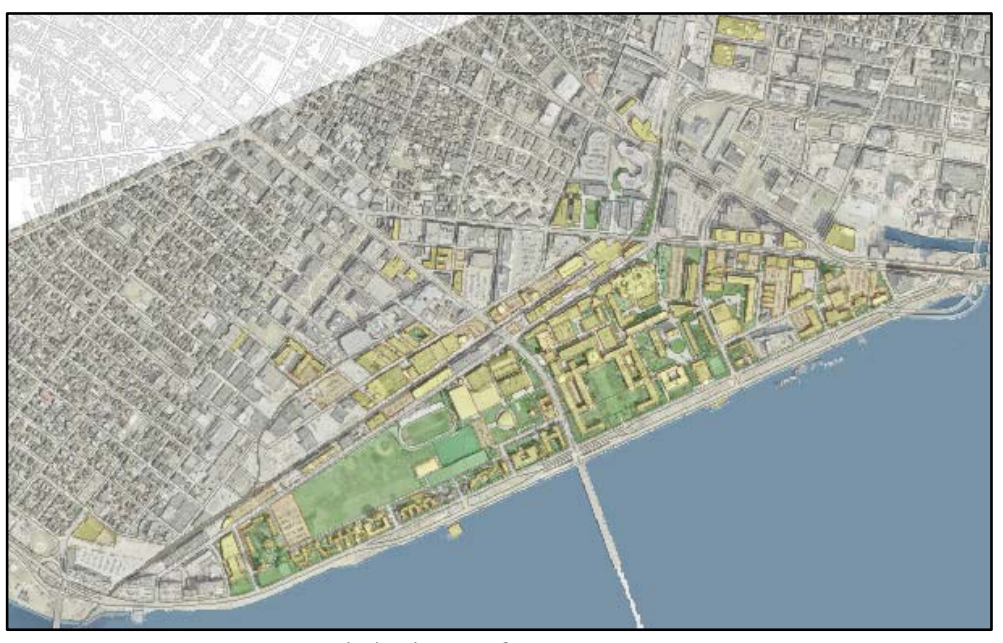

Aerial view of MIT campus

(Photo courtesy of MIT; color added) $40 \%$ undergraduate). The highly distinguished faculty includes 73 members belonging to the National Academy of Engineering and 72 members of the National Academy of Science. In addition, eight current MIT faculty members have won the Nobel Prize, totaling 59 present and former MIT faculty members that have won the coveted honor ${ }^{[23]}$.

\subsubsection{Site/Campus Level Considerations.}

Facility Planning and Modernization - The MIT campus encompasses 168 acres. The original central group of interconnecting buildings was commissioned in $1916^{[23]}$, and additional buildings of varying styles have been added over the past 90 years. Currently, the campus includes 158 buildings, which encompass 11 million $\mathrm{ft}^{2}$ of space. Approximately half of this space is dedicated to academic purposes while the remaining space supports residences and administrative functions ${ }^{[24]}$.

MIT is nearing completion of an aggressive infrastructure modernization campaign that began in 1999. Over the past 5 years, nearly 2 million $\mathrm{ft}^{2}$ of space has been renovated or modernized. MIT anticipates adding an additional 1 million $\mathrm{ft}^{2}$ of space over the next decade ${ }^{[24]}$.

The vision guiding MIT's modernization program is "the creation of an infrastructure for invention that fosters the unfettered cross-fertilization of ideas" ${ }^{26]}$. New facilities are being designed to bring together colleagues in related fields, thus strengthening interdisciplinary programs to support the development of new ideas for research and teaching. New laboratory facilities are being added to support emerging research demands, and new residence halls and common spaces are being designed and built to foster collaborations. 
MIT facility staff noted that for these types of development efforts to be successful they require the "ownership" and leadership of senior management. This includes fully understanding and developing the strategic vision before engaging in discussions with architectural engineers.

Land Use Planning - MIT has developed a "Framework for Campus Development" document ${ }^{[26]}$ that defines the campus development consistent with the institutional priorities. It also defines the principles that will guide the MIT development progress of its evolving campus.

The connectivity of the campus is an important element of the MIT Framework. This connectivity includes internal issues relative to the campus itself (e.g., MIT's "Infinite Corridor" [see explanation below]) as well as connectivity with its surrounding neighborhoods (i.e., Cambridge, Boston). The MIT campus is generally accessible to the public although individual buildings or laboratories can be secured.

The MIT Framework identifies several deficiencies that exist with the current campus as well as plans to correct these conditions. Noted deficiencies include a scarcity of common spaces that are needed to foster more social interactions and a "crisis of landscape."

Landscape Architecture - The urban environment dominates the MIT campus. However, MIT's approach to campus modernization now involves a perspective of sustainability and the incorporation of environmentally "green" areas. Several landscaping projects, planned walkways, and common spaces are being designed to reunify the campus physically, aesthetically, and socially.

MIT's "Infinite Corridor" connects many of the buildings through a series of corridors, tunnels, and overpasses. While the connectivity of the new buildings is still being practiced, MIT is attempting to enhance these corridors. In addition, MIT

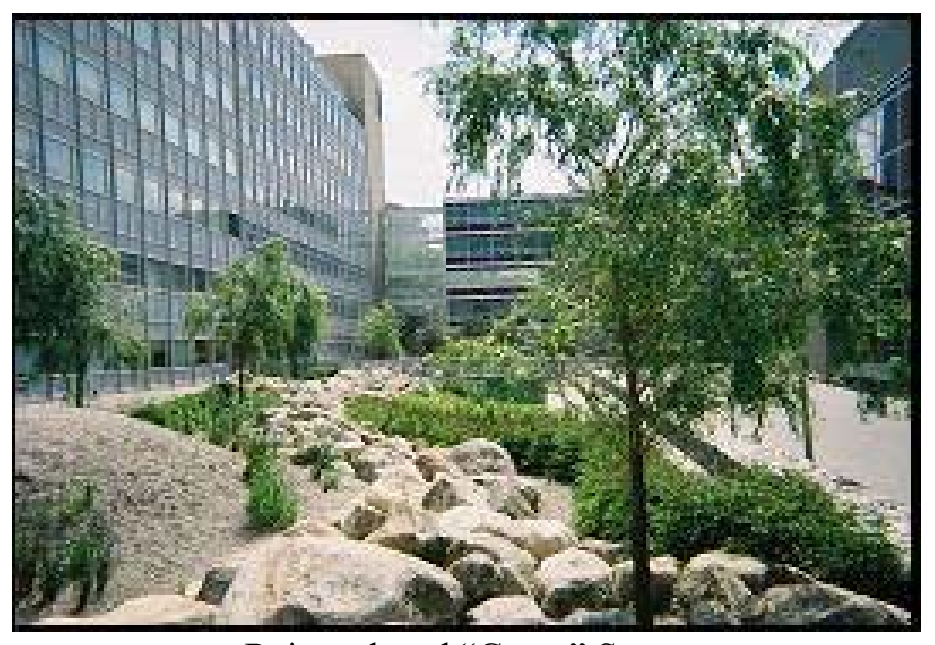

Reintroduced "Green” Space

(Photo courtesy of K. Kostelnik) recognizes the need to enhance its exterior, street-level walkways. Streets and student walkways are being reconfigured in partnership with the Cambridge community, and vegetative areas are being recreated on campus and incorporated into new building designs ${ }^{[26]}$.

MIT's “Framework for Campus Development" serves as the Institute's Master Plan ${ }^{[26]}$. Supporting this plan are Landscaping Standards that define the types of sidewalk pavers to be used, standardize campus signs, and describe vegetative recommendations.

Financial Mechanisms - MIT is an independent, coeducational, and privately endowed institution. Like other similar institutions, MIT obtains it operating budget through tuition revenue, private endowments, gifts, loans, and research grants.

MIT's research is sponsored by a variety of organizations, including the U.S. Department of Health and Human Services (31\%), the U.S. Department of Defense (16\%), the DOE (13\%), and the National Science Foundation (12\%). Other federal, state, and local agencies and industry sponsor research at MIT. MIT's annual research funding was estimated at $\$ 530$ million for fiscal year 2004 . This does not include other MIT affiliated organizations such as the Lincoln Laboratory ${ }^{[23]}$. 


\subsubsection{FacilitylLaboratory Level Considerations.}

Facility/Laboratory Designs - The MIT campus is comprised of facilities constructed during different time periods, thus they exhibit unique appearances. Current MIT facility designs are exhibiting a stronger linkage between landscape architecture and architectural engineering and large, multi-disciplinary buildings are now being constructed on the MIT campus.

MIT has established a Green Building Task Force to work with MIT environmental experts, clients, and design teams from the earliest stages of every building project to achieve the Institute's "green" goals. Enhancing the functionality of the building while remaining environmentally conscious, and achieving LEED Silver classification are currently the goals for all new buildings.

A number of new "signature" buildings are being designed and built at MIT. These signature buildings, in addition to their academic or educational mission, will serve as recognizable landmarks for

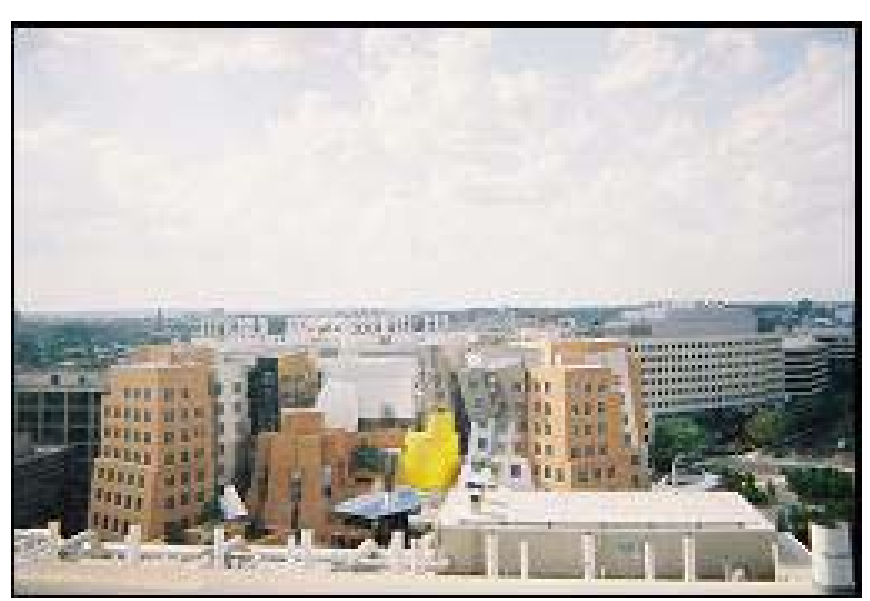

The Ray and Martha Stata Center (Photo courtesy of K. Kostelnik) the Institute. MIT believes that not all buildings need to be "signature" buildings. Therefore, "background" but fully functional buildings are also being incorporated into the campus development.

A new signature showcase facility on the MIT campus is the Ray and Maria Stata Center for Computer, Information, and Intelligence Sciences. The building houses MIT's Computer Science and Artificial Intelligence Laboratory, the Laboratory for Information and Decision Systems, and the Department of Linguistics and Philosophy. Over 1,000 students, faculty, and staff are resident within the $720,000 \mathrm{ft}^{2}$ facility $^{[22]}$.

Equipment Management - There appear to be varying approaches to the management and maintenance of laboratory and research equipment at MIT. For example, during new building design and construction, permanent laboratory equipment is included in the construction budgets. Specialized laboratory equipment, whether permanent or temporary, is expected to be financed by the programs requiring this equipment. Building renovations, including equipment upgrades, are cost shared between the University, the Department, and the programs.

The maintenance of equipment is not centralized and remains the responsibility of the users since they are considered the "owners" of the equipment. As such, preventative maintenance is often an issue.

Space Management/Utilization - MIT currently estimates $100 \%$ space utilization of its 11 million $\mathrm{ft}^{2}$ of space ${ }^{[22]}$. MIT's philosophy towards space management is to provide the researchers with the space that is required to accomplish their research. Therefore, MIT does not have a standardized formula for allocating space. The space is "owned" by the Departments, Centers, and Institutes who manage its use.

MIT is in the process of modernizing facilities for successful researchers and Centers that have outgrown their limited and outdated spaces. There is also a move to collocate related Centers and Departments to foster more interdisciplinary collaboration. 


\subsubsection{Social Considerations.}

Research Atmosphere/Culture - The research culture at MIT is rich in confidence and accomplishments. All researchers, managers, and support staff had positive comments regarding MIT's overall research climate and its future potential. The underlying attitudes of the University were all very positive.

MIT continues to operate at a world-class level. Keys to that success, as expressed by its researchers, are that the MIT administration supports (financially, infrastructurally, politically, etc.) a strong, cutting-edge research agenda that retains and attracts eminent scientists and promising students. This research agenda is generally initiated by the research faculty and supported by the administration through the formulation of Centers (physical and virtual), joint faculty appointments, and research grants.

Employee Amenities - The MIT campus contains all of the expected employee and student amenities commonly found at major U.S. university campuses. These include on-campus housing, cafeterias, recreational facilities, lecture halls, research laboratories, auditoriums, etc. MIT is an open, urban campus, and community events are frequently scheduled at MIT facilities. The campus is moving to a wireless network although a number of the older facilities have not yet been converted.

Because of MIT's urban setting, transportation remains an important employee and student concern. MIT is attempting to address this issue in several ways. For example, MIT provides on-campus shuttle service for employees and students. MIT also works with the local municipalities to arrange and coordinate public transportation alternatives, such as buses and subway service, and MIT subsidizes these services for its employees and students.

Operating Policies/Procedures - MIT's operating policies and procedures do not appear to be centralized but rather are developed and maintained by the Departments, Centers, and Institutions that require them. As such, the researchers and principal investigators appear to have considerable freedom in establishing applicable operating procedures for their specific area of research. For example, there is no centralized procurement system in place. As such, individual researchers are able to procure their required materials and chemicals without having to access a centralized system. The downside of this approach, as noted by the administration, is the reduced ability to control recycle and reuse of excess materials. The disposal and handling of hazardous materials was noted to be centralized as MIT subcontracts this service from a certified hazardous waste handler.

4.2.2.5 Summary. MIT continues to be recognized as a world-class research institution. Established in 1861, MIT today involves a research community of approximately 17,000 individuals on a 168 -acre area with 158 buildings encompassing 11 million $\mathrm{ft}^{2}$ of space. To maintain its leadership position, MIT has aggressively strived to modernize its infrastructure. Over the past 5 years, approximately 2 million $\mathrm{ft}^{2}$ of space has been renovated or modernized. MIT anticipates adding an additional 1 million $\mathrm{ft}^{2}$ of space over the next decade.

The MIT administration supports its world-class research agenda through financial, infrastructure, and political means. This approach continues to retain and attract eminent scientists and promising students. The MIT Brain and Cognitive Sciences Project facility (see inset) is an example of how MIT is planning to maintain its leadership position. This facility will integrate MIT's neuroscience, cognitive science, imaging technology, genetic science, and molecular and cellular biology programs to position MIT for the growing biotechnology market. 


\section{Brain and Cognitive Sciences Project}

MIT's Brain and Cognitive Sciences Project (BCSP) is a model facility that showcases the way related research disciplines will intersect on emerging scientific topics. MIT expects the BCSP to become the world's leading center of brain research and bring together scientists and engineers from a variety of fields with a common goal: better understand the human mind.

Projected to open in the fall of 2005, the BCSP will integrate the study of neuroscience, cognitive science, imaging technology, genetic science, and molecular and cellular biology. The interdisciplinary BCSP will serve three primary groups:

- The Department of Brain and Cognitive Sciences, headed by Mriganka Sur, Sherman Fairchild Professor of Neuroscience

- The McGovern Institute for Brain Research at MIT, directed by Phillip Sharp, winner of the 1993 Nobel Prize for his work in physiology and medicine

- The Picower Center for Learning and Memory, led by Susumu Tonegawa, winner of the 1987 Nobel Prize for his work in immunology.

This $400,000 \mathrm{ft}^{2}$ building, estimated to cost $\$ 156$ million, is an example of MIT's financial commitment to maintaining its leading research position.

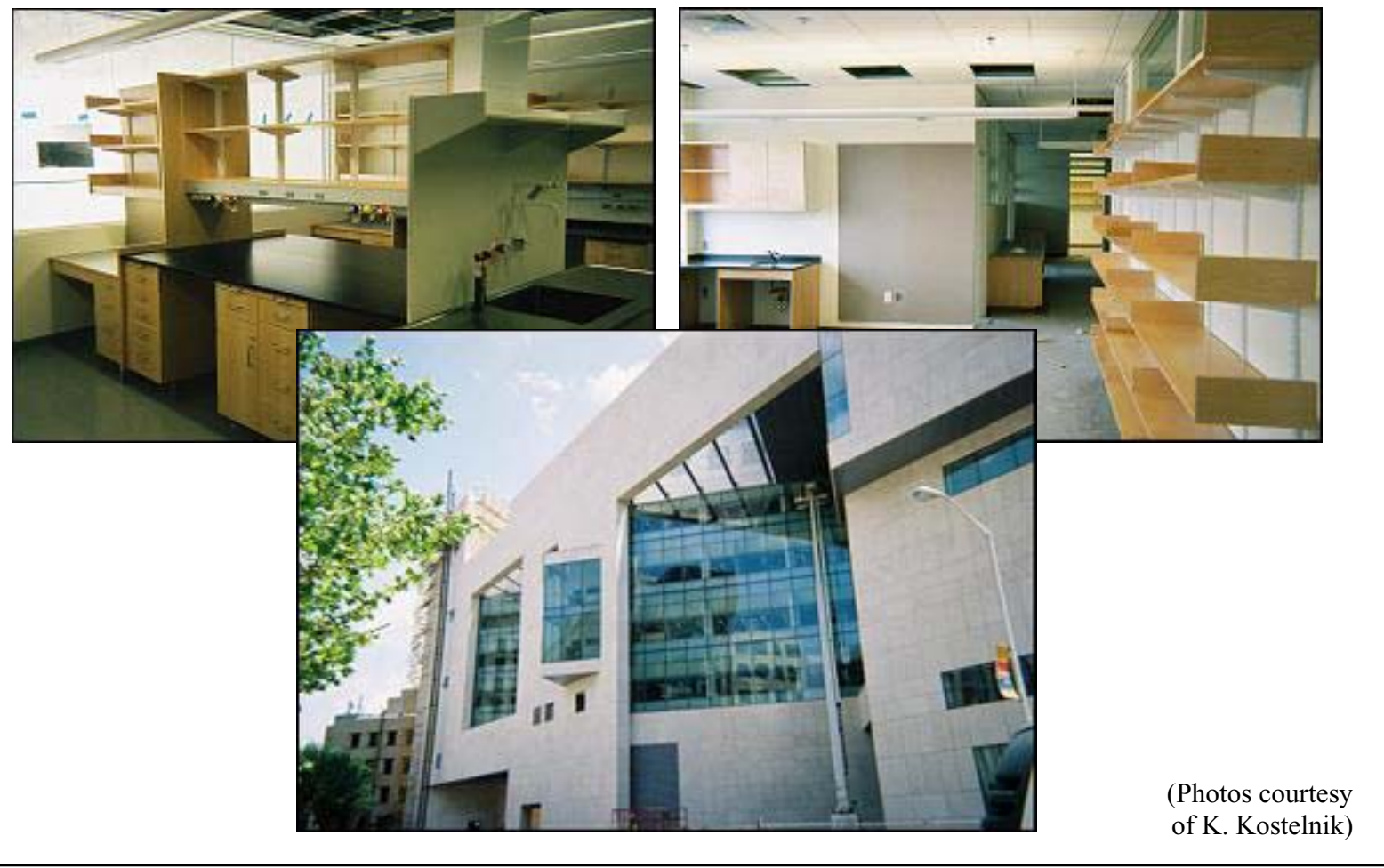




\subsection{Corporate and Non-Profit Organizations}

\subsubsection{IBM Corporation - Almaden Research Center}

4.3.1.1 Introduction. IBM's Almaden Research Center (ARC) in San Jose, CA, is one of IBM's eight research laboratories. The 30-acre fenced and developed site is situated within a 690 -acre area on an undeveloped hilltop, surrounded by Santa Theresa County Park. The $540,000 \mathrm{ft}^{2}$ facility houses about 1,000 people, including 500 scientists. Thirty percent of IBM's Fellows are located at ARC. For the past 12 years, IBM has led in the number of U.S. patents awarded, receiving more patents than the next 10 companies on the list, combined. ARC has over 600 ongoing research projects in a broad range of areas. Their research departments include Computer Science Software, Computer Science Storage Systems, and Science and Technology. The research conducted includes both pure basic research and research more directly applicable to market needs ${ }^{[27]}$.

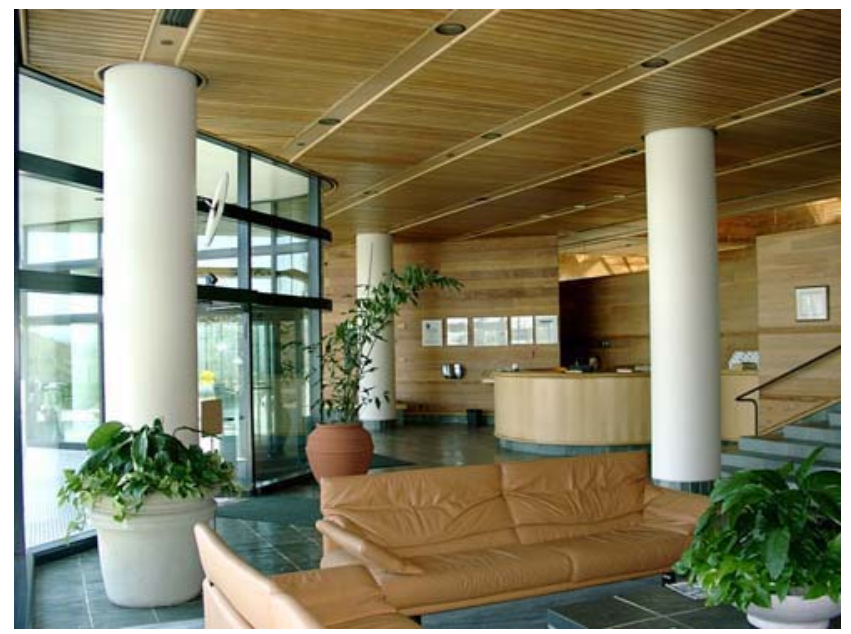

Almaden Lobby

(Photo courtesy of IBM)

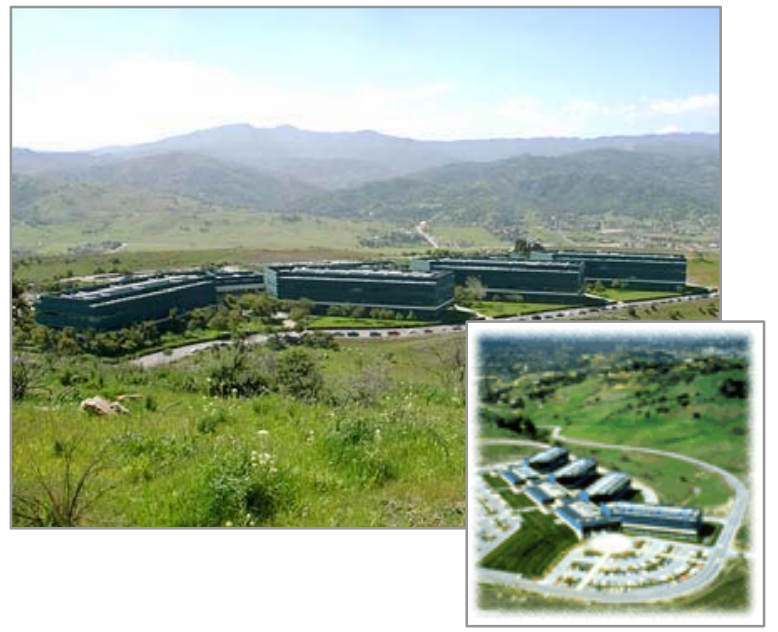

IBM's Almaden Research Center (Photo courtesy of IBM)

Two key factors in ARC's success have been integrating research and development with manufacturing, and using market needs and future trends to direct research. ARC works closely with IBM's product development and manufacturing plants, and integrates employees from development facilities into ARC's research projects to ensure applicability of the results. This close link with manufacturing also helps ARC gain insight into future market needs. ARC uses this and other information about upcoming market needs to guide their research. For example, ARC is now shifting its product development focus to support the service sector, since many of the world's economies are shifting away from manufacturing to service, and toward scaling out (adding modules) rather than scaling up (increasing equipment complexity) to allow for easy expansion and modularity of computer hardware systems. ARC's close interaction with IBM's product development organizations and their keen insight into future needs are key factors in their success.

\subsubsection{Site/Campus Level Considerations.}

Facility Planning and Modernization - ARC was built in 1985, and there are no immediate plans for facility additions or significant modernization projects. However, the facility was designed to accommodate two additional wings, and the HVAC system and other support systems are large enough to support these, if built. For instance, when ARC was built, an extra chiller was installed to accommodate the potential new wing. Although they provide an excellent back-up system for equipment failures, these 
systems are expensive to maintain, so ARC employees recommend allowing room for expansion, but not installing the equipment until needed.

Energy Conservation/Sustainability - IBM has a corporate-wide energy conservation program, which includes the following key factors:

- Understanding and reporting energy use patterns

- Implementing energy conservation and cost avoidance

- Incorporating energy efficiency in building design

- Energy awareness for employees

- Strengthening relationships with energy supplier

- Working with government efficiency and conservation plans

- Developing an Energy Master Plan based on past and predicted future use.

Based on this policy, IBM corporate has established four primary goals:

- Use energy responsibly

- $\quad$ Reduce energy use by $4 \%$ per year

- Achieve $10 \%$ energy cost avoidance per year

- Favor renewable energy use.

In accordance with this program, ARC has implemented numerous energy conservation projects and has successfully lowered their energy use by $4 \%$ per year for several years. This was accomplished by changing the chiller set points and introducing variable frequency drives on the fans, pumps, and condensers in the HVAC system. ARC has also avoided 10\% of their previous year's energy cost by reducing peak energy use. Based on past and expected future energy use, ARC developed an Energy Master Plan that helped them achieve their energy conservation goals. The total site-wide energy use is reported to IBM corporate each month. Locally, ARC tracks energy use to 10 sub-levels site-wide meaning, for example, that they can track the energy use for each of the research wings ${ }^{[27]}$.

ARC believes that a key component in the success of an energy conservation program is having excellent working relationships with the local power company. They have worked diligently to achieve this, and have agreements with the local utilities that ARC will reduce their energy use by $20 \%$ during rolling black-outs. The power company will then reciprocate by exempting them from the complete black-outs $^{[27]}$.

ARC was designed and built before the LEED program existed, and IBM has not attempted LEED certification. Newer IBM facilities, such as one recently built in Texas, have been LEED certified, which accelerated the permitting time by 6 months. 


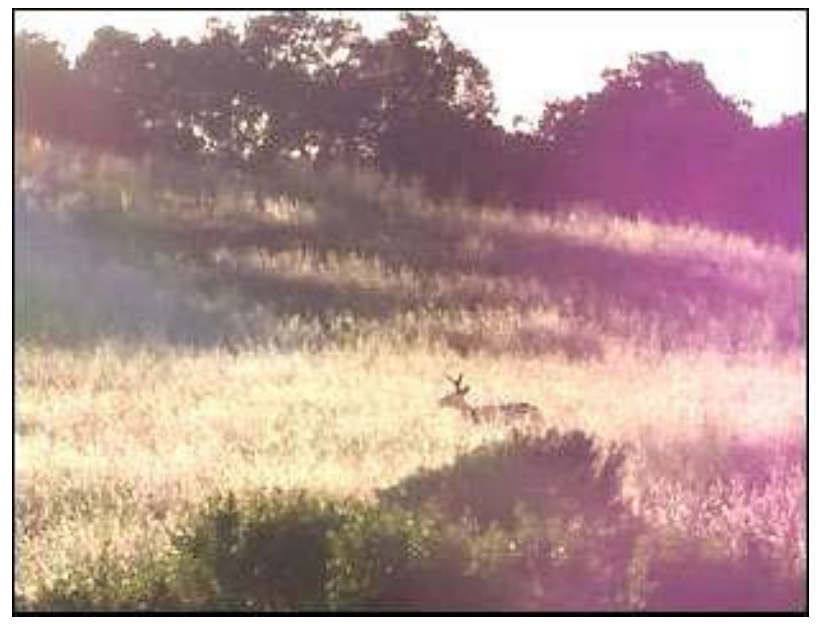

Santa Theresa County Park

(Photo courtesy of K. Kostelnik)
Land-use Planning - In exchange for access to build the road to the site, ARC gave a portion of land to the Santa Theresa County Park when ARC was constructed. IBM still owns 690-acres (30acres are fenced and developed), and this area is managed in cooperation with Santa Theresa County Park $^{[27]}$. ARC helps maintain the land through programs like an annual adopt-a-creek day where ARC employees remove litter from the creek.

Many site management services are outsourced, including facility maintenance, grounds maintenance, janitorial services, procurement, and moving/warehouse services. Services that are still handled in-house include land management, city relations, space planning, and systems engineering.

Landscape Architecture - ARC fits well into its natural undeveloped setting, with green anodized aluminum tubular siding and a complementary design. Within the ARC perimeter fence, the grounds are landscaped with grass, trees, and shrubs. Landscaped areas separate the parking area from the ARC buildings, enhancing the view from inside the building and drawing people through the landscaped area as they walk daily to and from the building. Outside the cafeteria, a patio covered with flowering vines provides an outdoor eating area. The areas between the research wings are landscaped courtyards with picnic tables, benches, and even ping-pong tables.

Because ARC is located in the middle of Santa Theresa County Park, landscaping has been a challenge because wild animals from the park tend to destroy the plantings. Wild pigs overturn the grass to eat roots, and deer eat many of the plants. As a result, ARC piloted a test garden with deer resistant plants. After a successful 1-year test period, these types of plants will be used in the general landscaping. ARC is also a certified Western Bluebird Habitat and works to keep that status with all landscaping changes. Employees are encouraged to participate in environmentally friendly

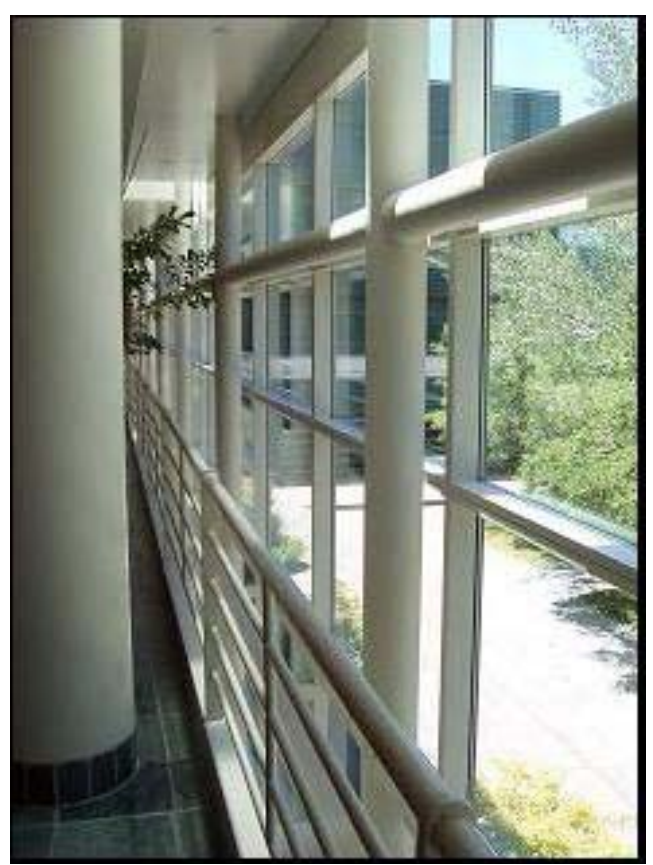

Large windows provide views onto landscaped courtyards (Photo courtesy of K. Kostelnik) activities, and have assisted with projects such as setting up bat nursery houses.

Waste Management - ARC has extensive waste management plans and requirements for all effluents from the site. The programs include Hazardous Waste Management, Hazard Communications and Incident Response, Solid Waste Management, Air Emissions, Industrial Waste Water Permits, Storm Water Management, Groundwater Management, Spill Prevention Controls, Regulatory Reviews, Chemical Management, and Environmental Impact Statements. ARC is ISO 14001 certified, and their energy management program includes annual ISO audits. ARC recycles all industrial waste-water by filtering it, then using it in the HVAC cooling towers. They also make their own de-ionized water for laboratory use. A bar-code tracking system is used for all Hazardous Waste containers (see additional details in the Chemical Management section of this case study). 
Eighty percent of the solid waste on site is recycled. Recycling is done at all possible levels, including a composting program for food scraps. All recyclable wastes are collected in one blue trash can in each office and segregated later. Switching to this system, where employees do not have to segregate paper from aluminum cans, etc., improved participation in the program significantly.

$\mathrm{ARC}$ is in the process of receiving certification as a Bay Area Green Business based on their environmental regulatory compliance, natural resource conservation, pollution prevention, and waste minimization programs.

Financial Mechanisms - ARC's research is funded by IBM corporate and is large enough to complete significant research in numerous areas. Funding levels for specific projects are determined by line management, and research funding appears to be stable, particularly when the research has a defined market or end-use.

\subsubsection{FacilitylLaboratory Level Considerations.}

\section{Facility/Laboratory Designs - The} building design works well to support the research mission. The four research wings are connected by a central building that houses support functions. These include a cafeteria, library, computer servers, machine shop, auditorium, customer center, lounge areas, vending machines, and conference rooms. Within the wings, hardwall offices line the exterior of the building, providing window offices for each of the researchers. The center of each wing houses laboratory space that is divided by a large central utilities corridor. The corridor is designed to allow utility isolation of each lab, so if piping or electrical modifications are made to the utilities entering one lab, adjacent labs are unaffected by the

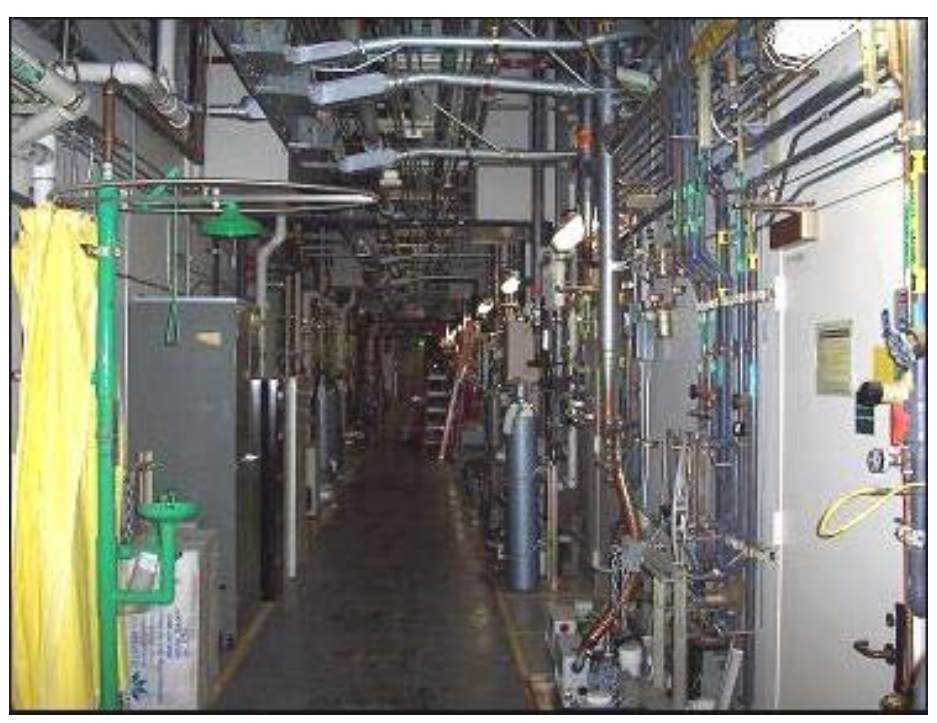

Utility corridor behind laboratories (Photo courtesy of K. Kostelnik) construction. The corridor includes a removable floor providing access to water supply and exit lines. The corridor also provides a second emergency exit for each of the labs. The hallways between the labs, and the hard-wall offices are equipped with air inlet ducts near the floor and outlet ducts near the ceiling to provide emergency removal of any airborne chemicals. The labs include wet, dry, and hazardous material labs. Within the wet labs, each hood is equipped with an automatic airflow control valve, so when the hood door is opened, the system immediately compensates to create the airflow required for venting. In addition to the local digital display of airflow, these hoods are all monitored and tracked remotely. Laboratory benches and cabinets are permanently mounted in the labs. Hard walls separate the individual labs and are moved when changing missions justify the construction. The Facilities Engineering group performs most design changes in-house, but larger construction/modification projects are out-sourced.

ARC employees believe that the central location of the labs to allow window offices for the researchers has been an effective design. However, if they build a new wing, they are considering a modified design that maintains the centralized lab space, but has an open walkway along the windows with cubicles between the windows and laboratories. This design would allow more employees to enjoy natural lighting and an outdoor awareness from their office area, and would allow for a larger volume of 
offices in the lab building. ARC would also include "virtual offices" with plug-and-work connections for employees who are frequently on travel, such as sales and marketing, to allow more efficient use of office space.

Chemical Management - ARC is designated as a chemical Large Quantity Generator, not a storage facility. ARC uses over 17,000 chemicals, handling 24,720 containers per year. The site has 13 chemical storage rooms and six hazardous material storage rooms ${ }^{[27]}$. A bar-code chemical tracking system is used to track chemicals, and physical inventory of all chemicals is performed twice a year. A real-time, online, corporate-wide system is used for Material Safety Data Sheets. ARC has recently worked to remove chemicals not in use from long-term storage. Common chemicals are stocked, and special order chemicals are available with a 24 hour turn-around-time.

Space Management/Utilization - The labs are fully utilized, and negotiations for changing ownership of lab space are handled within management. If a lab is underutilized, it is re-assigned by management. Space is charged to the home organization, with office, wet, and dry lab space charged at different rates.

\subsubsection{Social Considerations.}

Research Atmosphere - The positive, innovative research culture at ARC is evident from the number of patents and successful research conducted. Researchers are dedicated, and working over weekends is a common occurrence. All employees are given complete flexibility in their work schedules. ARC actively works with other organizations, such as Stanford University, on integrated research projects. Although some areas are restricted from visitors, access to the designated visitor areas is possible with minimal paperwork, which facilitates national and international research collaborations. ARC regularly holds classes and seminars that include off-site collaboration.

Employee Amenities - ARC has a vast number of programs aimed at enhancing the work climate and employee well being. These programs focus on increasing morale, innovation, interactions among employees, and fun. ARC uses a cost-benefit analysis approach to determine which programs to implement. Most of these programs are administered centrally by one department with site-wide support from "spirit teams."

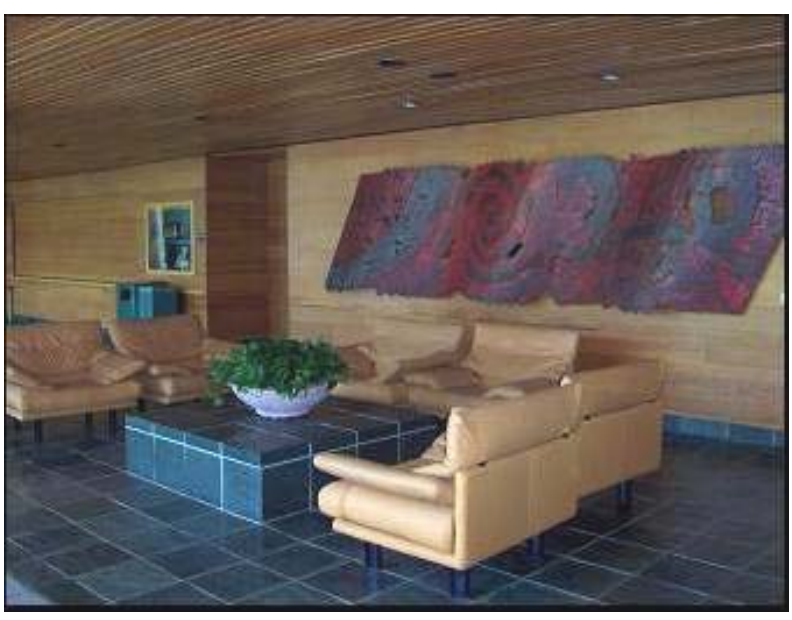

Lounge at Almaden (Photo courtesy of K. Kostelnik)

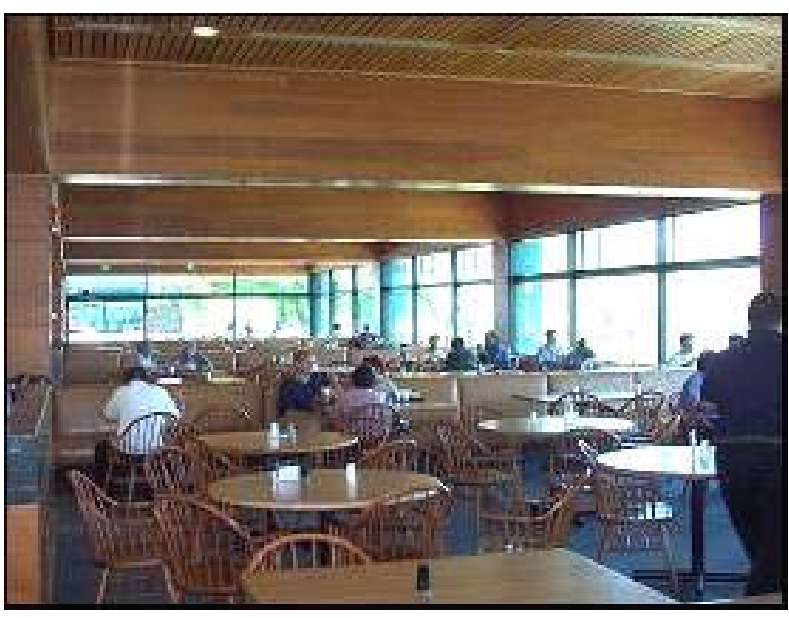

Almaden Cafeteria (Photo courtesy of K. Kostelnik)

ARC held an event called Innovation Days in 2003, which has now been replicated at five other IBM sites. The goal of this program was to foster a culture of innovative thinking and actions, and 
encourage risk-taking. This five-day event included a "wild ideas" forum with prizes for the most creative ideas; an "innovation challenge" (moving water over a barrier), where employees competed with senior management; a "solve an innovation puzzle with your colleagues" event; free lunches; entertainment; and awards for participants. As a result of this program, an innovation category was added to the employees' annual performance appraisal form, and managers host weekly innovation office hours.

ARC also has a commute alternatives program to help people get to work in energy-conservative ways. They provide a free shuttle service from the mass transit end-point to ARC, free county-wide mass transit passes to all employees, shower/locker rooms for people who want to bike to work, a guaranteed ride program that ensures any employee will be given a ride home in case of an emergency, and an annual bike to work day. Because of programs like these, they are in the running for the "Bay Area Best" award. ARC believes that these programs are the right thing to do for the environment and the employees.

To maintain employee health and wellness, ARC provides on-site health education, immunizations, medical services, health fairs, and blood drives free of charge. Employees can also participate in on-site exercise classes and Weight Watchers for a fee. ARC hosts on-site massage therapy, which employees can use for $\$ 1 /$ minute, and the cafeteria provides family take-home meals for purchase on Wednesdays.

ARC provides free coffee in the cafeteria at 4:00 every day to encourage employee interactions. They regularly host site socials with free meals; monthly lunch scrambles, where employees gather to solve brain-teaser puzzles; and health and education focused activities. For example, they host "poker walks" where employees walk around campus to exercise as they gather a poker hand and some environmental information at each station.

Activities aimed at making ARC a family-friendly, fun place to work include an evening of Art at Almaden showcasing employees' art, an on-site spring egg hunt, an on-site haunted house, an annual car show, and an annual family campout on the Almaden grounds. They have also hosted piano recitals, Godiva chocolate/Starbuck's coffee tasting, and take-your-child-to-work day.

Operating Policies/Procedures - ARC is a non-union facility that works to streamline required reporting programs and make processes quick and easy for employees. Examples include the corporatewide on-line move and maintenance request forms. Whenever possible, computer systems are linked to reduce work so that, for example, the on-line phone book automatically updates when move requests are processed.

4.3.1.5 Summary. IBM's Almaden Research Center (ARC) in San Jose, CA, is one of IBM's eight world-wide research laboratories. The 30-acre groomed portion of the 690 -acre site is located on a hilltop surrounded by Santa Theresa County Park. ARC employs about 1,000 people, including 500 scientists conducting over 600 research projects. The primary research areas are computer software, hardware, and science and technology. Two key factors in ARC's success are their market-driven research and close integration with IBM development and production facilities. Innovation is enabled through streamlined procedures and encouraged using special programs. Extensive employee amenities and programs demonstrate the importance of employee satisfaction and well-being at ARC. ARC focuses on environmentally conscious operation and sustainability through its energy conservation and waste management programs. 


\section{Almaden Visitor Center}

The Almaden Research Center features a central building with a visitor center and employee services. The center includes an auditorium with a wireless projection system, several conference rooms with video and phone connections, and lounge areas. The area doubles as the central location for emergency services, in the event of an evacuation or similar emergency. IBM Almaden also hosts seminars and classes for off-site collaborators, as well as in-house training for employees. The proximity of the cafeteria, snack shop, and lounges make this area a central location for employees to meet.

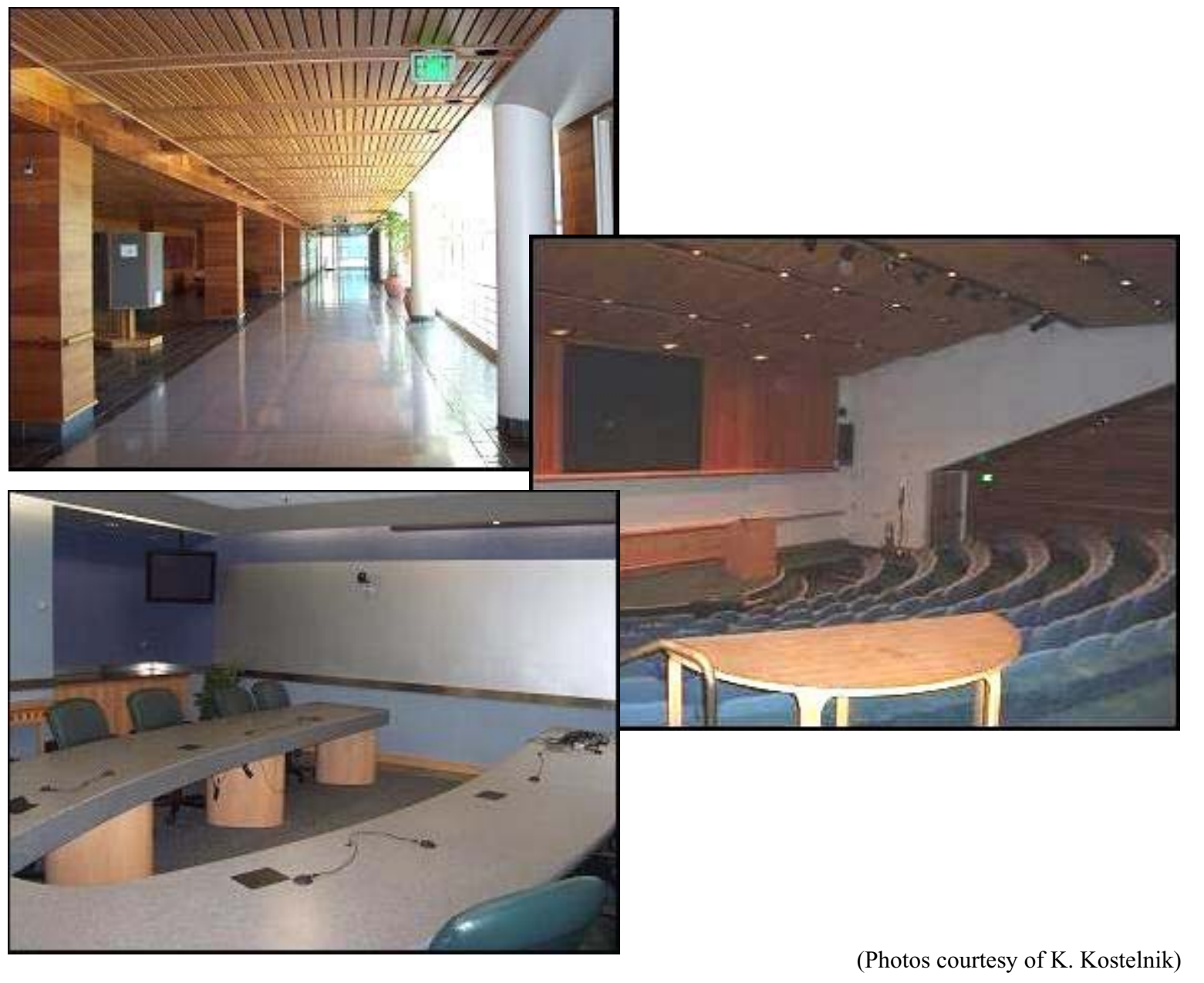




\subsubsection{Woods Hole Oceanographic Institute}

4.3.2.1 Introduction. The Woods Hole Oceanographic Institution (WHOI) is an independent, private, not-for-profit research and higher education institution. The Institute is located southeast of Boston on Cape Cod in the village of Woods Hole, MA. Established in 1930 from a \$3 million grant from the Rockefeller Foundation, WHOI is today the largest independent oceanographic research institute in the United States $^{[31]}$. The WHOI organization is comprised of more than 1,092 staff as of 2004. This includes 142 Tenure-track Scientists, 38 Scientists Emeritus, 55 Postdoctoral researchers, and approximately 142 students $^{[29]}$.

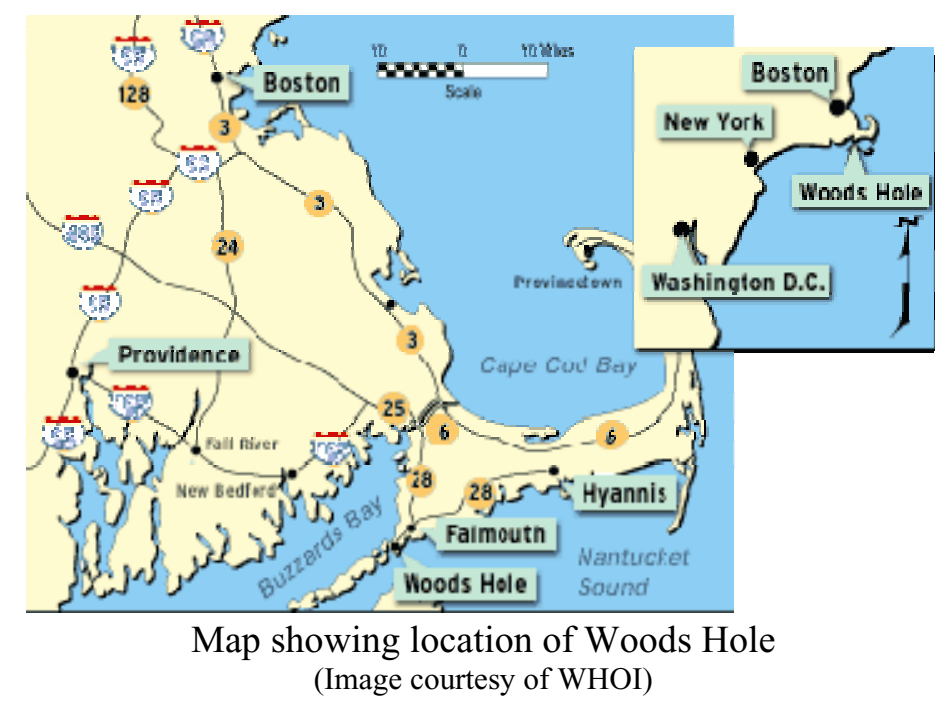

The primary mission of WHOI is "to develop and effectively communicate a fundamental understanding of the processes and characteristics governing how the oceans function and how they interact with the Earth as a whole" ${ }^{\mathrm{[30]}}$.

The goal of the Institution is "to be a world leader in advancing and communicating a basic understanding of the oceans and their decisive role in addressing global questions." To achieve this goal WHOI believes they must:

- Recruit, retain, and support the highest quality staff and students and provide an organization that nurtures creativity and innovation

- Stress a flexible, multidisciplinary, and collaborative approach to the research and education activities of its staff within an equitable working environment

- Promote the development and use of advanced instrumentation and systems (including ships, vehicles, and platforms) to make the required observations at sea and in the laboratory

- Make the results of its research known to the public and policymakers and foster its applications to new technology and products in ways consistent with the wise use of the oceans

- Secure the essential resources to sustain these activities, a responsibility that the trustees and corporation members must jointly share with management and staff.

WHOI is organized into five research departments: Applied Ocean Physics and Engineering, Biological Oceanography, Geology and Geophysics, Marine Chemistry and Geochemistry, and Physical Oceanography. In addition to these departments, a considerable amount of interdisciplinary research is being conducted at WHOI. To facilitate this work, WHOI also maintains a number of multidisciplinary Centers and collaborative research institutes. 


\subsubsection{Site/Campus Level Considerations.}

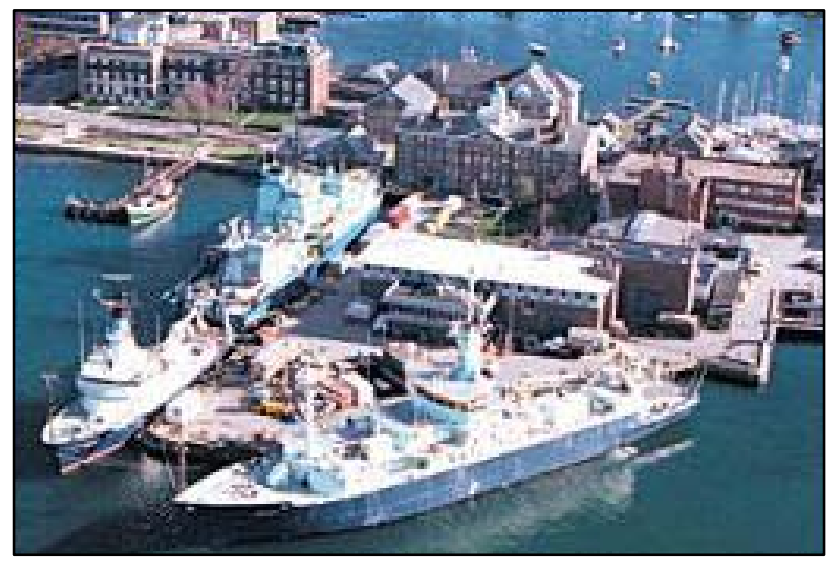

WHOI research vessels at Woods Hole port

(Photo courtesy of WHOI).
Facility Planning and Modernization - WHOI is comprised of shore-based facilities and oceanbased research vessels. The ocean-based vessels serve as floating laboratories and are a unique infrastructure feature in that they are truly international "user-facilities." These ships carry researchers around the globe for diverse studies that range from tracking large and small currents and investigating coastal pollution to studying the earth's crust beneath the seafloor and examining marine animals from whales to microbes ${ }^{[30]}$.

WHOI's shore-based facilities were historically located solely within the port village of Woods Hole. However, WHOI expansion needs and development restrictions within the village have forced WHOI to relocate a portion of their shorebased operations. Today, WHOI shore-based facilities are located in the village of Woods Hole (50\%) as well as at the nearby Quissett campus (50\%). These facilities encompass 219 acres of land and waterfront and 58 buildings and laboratories.

The current modernization plan is to relocate most of the WHOI shore-based research functions to the Quissett campus while leaving the vessel-support functions at the port location. As these relocations occur, in-village facilities will be converted from administrative and laboratory space to student housing.

\section{Land Use Planning - WHOI's Quissett} campus is located in a forested-setting overlooking Nantucket Sound. The native forest has been preserved, adding to the aesthetics of the campus.

Transportation routes to and on the campus were modified in 2002 to form a perimeter around the campus. This access approach allowed WHOI to begin clustering their facilities in the center of campus, which supported the development of a more "walkable" campus with expanded "social space." The transportation routing also eliminated lighting impacts to surrounding neighbors, which was viewed very positively by the local community.

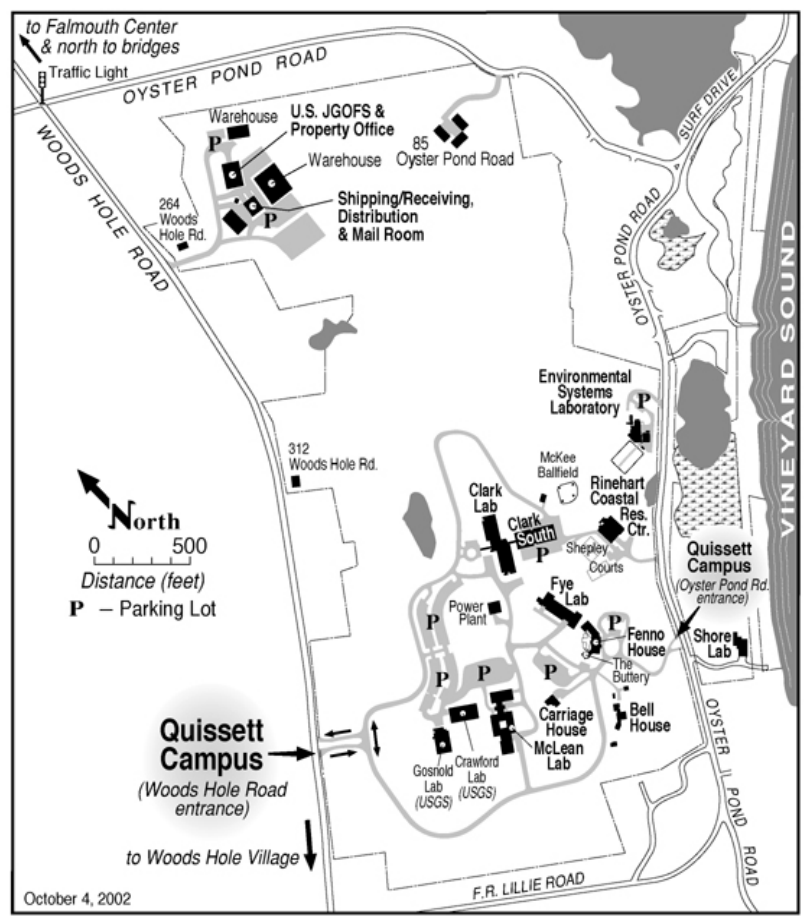

WHOI Quissett Campus Map (Image courtesy of WHOI)

Landscape Architecture - The forested environment dominates the WHOI Quissett campus. WHOI's campus modernization involves a perspective of environmental sustainability, which complements its organizational mission. New facilities are being constructed at the Quissett campus and incorporate environmentally "green" areas into their landscape designs. 
Financial Mechanisms - WHOI is an independent, non-for-profit, private research institution. Like other similar institutions, WHOI obtains its operating budget through private endowments, gifts, loans, and research grants. The $2004 \mathrm{WHOI}$ budget totaled approximately $\$ 120 \mathrm{M}$ for 865 individual research projects. The primary sponsor of WHOI is the National Science Foundation, accounting for approximately $\$ 50 \mathrm{M}$ in $2004^{[30]}$; WHOI's private endowment currently exceeds $\$ 300 \mathrm{M}^{[32]}$.

An important aspect of WHOI is its educational opportunity. WHOI offers a joint program with MIT. This program enrolls approximately 140 masters and doctoral students.

Infrastructure construction is financed through third-party bonds. $75 \%$ of the interest on these bonds appears to be charged back to grants and research proposals in terms overhead rates ${ }^{[32]}$.

\subsubsection{FacilitylLaboratory Level Considerations.}

Facility/Laboratory Designs - All shore-based facilities, infrastructure, and physical plant features are managed by the WHOI Facilities Department. Functions performed include site security, skilled crafts, facility maintenance, and renovations as well as new infrastructure construction.

Equipment Management - WHOI operates four research vessels (two large, one intermediate, and one small). Additionally, WHOI operates the submersible Alvin, a remotely operated and autonomous vehicle, as well as several small surface craft and a series of oceanographic instruments. WHOI scientists, as well as scientists from many other research laboratories, use these state-of-the-art vessels, vehicles, and instruments for exploration and research in all the basic marine disciplines. Operated in an "international-user" manner, access to these resources is a competitive process. Proposers must obtain their own independent funding and then obtain WHOI ship/equipment time.

The responsible Department or Center within WHOI manages equipment. A number of vessels, vehicles, and equipment are customer-owned but WHOI-maintained through grants/contracts.

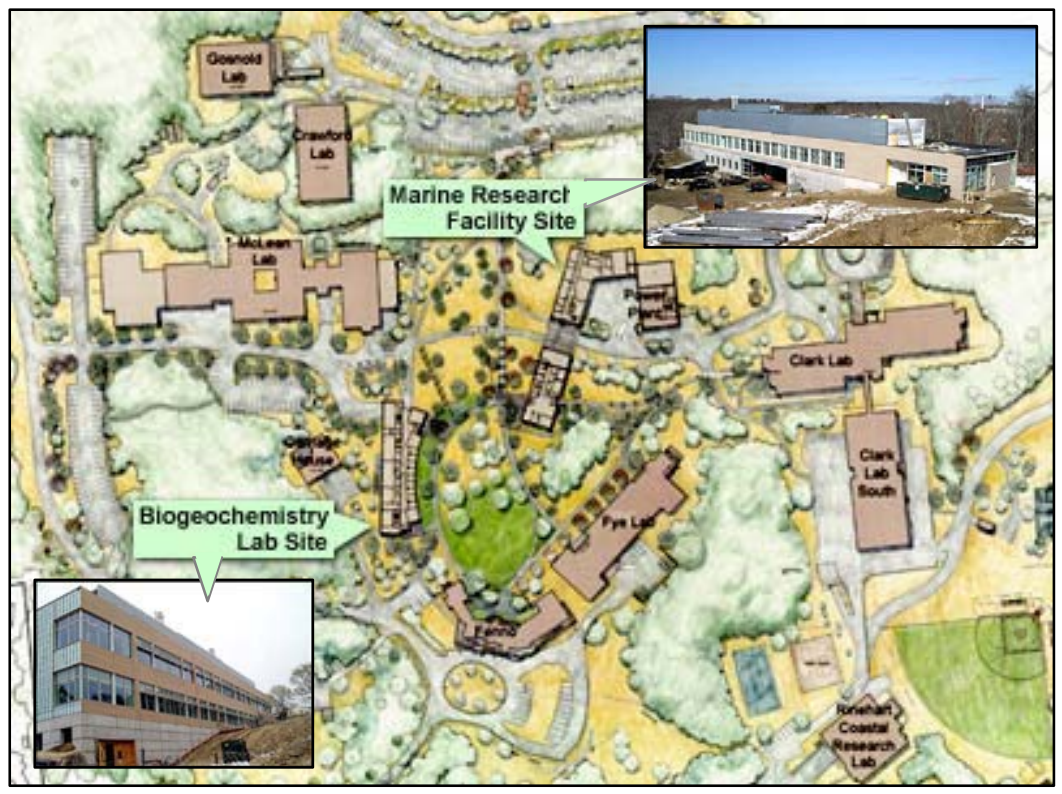

Infrastructure modernization at Quissett Campus (Photos and image courtesy of WHOI)
Space Management/Utilization

- WHOI space is a collection of laboratories and offices constructed throughout its 70-year history. Many of the scientists and staff located at the village campus are operating in offices and laboratories modified out of older homes.

WHOI is currently expanding its Quissett campus to support the collocation of select organizations (i.e., organizations currently with poor work space and organizations performing interdisciplinary work) and replace the older village laboratories and administrative space. Currently, WHOI space utilization is near $100 \%$. 
Two buildings, the Marine Research Facility and the Biogeochemistry Building, are currently under construction at the Quissett campus, involving approximately $80,000 \mathrm{ft}^{2}$. This space includes a combination of office space and adjacent laboratory space with an estimated construction cost of $\$ 32 \mathrm{M}^{[33]}$. Also included in this estimate is a 7,500 $\mathrm{ft}^{2}$ addition to the current facilities central plant.

Although WHOI does not have a standardized formula for allocating space, generally research scientists are allocated $120-150 \mathrm{ft}^{2}$ for an office. Additional laboratory and office space is available if it is required to accomplish their research.

\subsubsection{Social Considerations.}

Research Atmosphere/Culture - WHOI continues to attract the world's best oceanographers and related scientists. Researchers and scientists are attracted to the Institute because of the current expertise of its staff and its historic reputation. As such, WHOI continues to operate at a world-class level. Keys to WHOI success, as expressed by its researchers, are the people and the freedom to do cutting-edge research work.

The research culture at WHOI is an entrepreneurial one. Principal investigators are responsible for managing their own projects, budgets, etc. WHOI tenure (after 8-10 years and a 65\% success rate) and promotion are based on publications, the reputation of the scientist being evaluated, and the impact of his/her work. The funding record of the individual is not taken into account. WHOI also believes in the value of mentoring and invests substantial human resources in their mentoring program. New and young research staff members at WHOI are mentored by 2-3 senior staff members until tenure is granted or denied.

All researchers, managers, and support staff had positive comments regarding WHOI's overall research climate and its future potential. The underlying attitudes of the Institute were all very positive.

Employee Amenities - The WHOI Quissett campus contains many of the expected employee and student amenities commonly found at smaller U.S. university campuses. These include cafeterias, recreational facilities (baseball field, walking trails), lecture halls, research laboratories, a small auditorium, computing capabilities, and shuttle service to Woods Hole village.

The campus is open to the community, and families (and pets) of staff are frequently present on campus.

\section{Operating Policies/Procedures - WHOI} appears to have achieved a unique operating posture in that the researchers and Departments maintain individual freedom to control their research agenda, projects, and resources while the WHOI administration serves as a useful "support" organization. As such, although policies and procedures also appear to be centralized, they appear to offer the individual researchers adequate flexibility in terms of implementation. Thus, researchers and principal investigators appear to have considerable freedom in establishing applicable

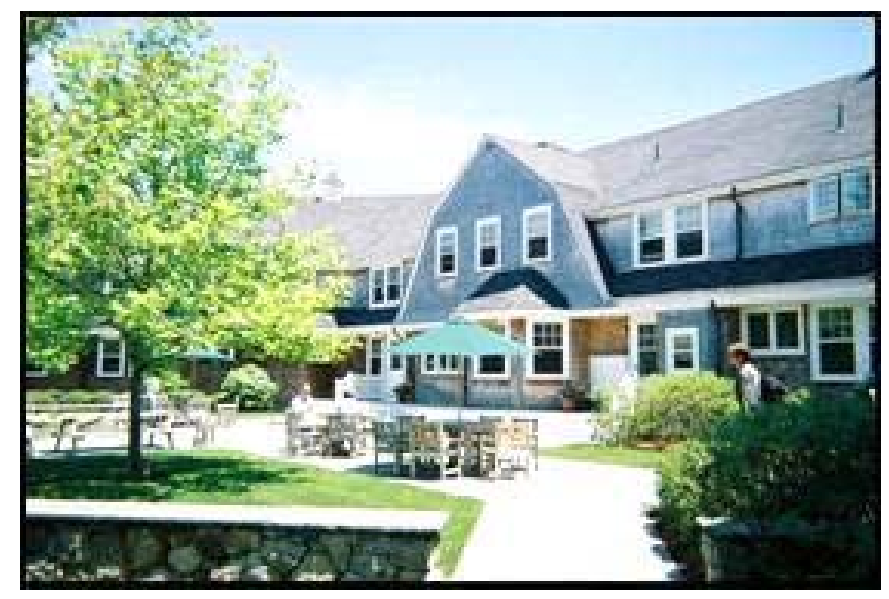

Cafeteria seating and common space at

Woods Hole Quissett Campus (Photo courtesy of K. Kostelnik) operating procedures for their specific area of research. 
4.3.2.5 Summary. The Woods Hole Oceanographic Institution (WHOI) is an independent, private, not-for-profit research and higher education institution located in the village of Woods Hole, MA. Established in 1930, WHOI is today the largest independent oceanographic research institute in the United States, employing 1,092 staff. During 2004, WHOI performed approximately $\$ 120 \mathrm{M}$ of research involving approximately 865 individual research projects.

WHOI is comprised of shore-based facilities and ocean-based research vessels. WHOI's shorebased facilities encompass 219 acres of land and waterfront and include 58 buildings and laboratories. Shore-based facilities are split between the Woods Hole Village Campus and the nearby Quissett campus.

WHOI is currently expanding its Quissett campus to support the collocation of select organizations (i.e., organizations currently with poor work space and organizations performing interdisciplinary work) and replace the older village laboratories and administrative space.

WHOI continues to attract the world's best oceanographers and related scientists. Researchers and scientists are attracted to the Institute because of the current expertise of its staff and its historic reputation. Keys to WHOI success are the people and the freedom to do cutting-edge research work. 


\subsection{International Laboratory}

\subsubsection{Commissariat à I’Energie Atomique (CEA) - Cadarache Research Center}

\subsubsection{Introduction. Cadarache, the research} center of the Commissariat à l'énergie atomique (CEA), is one of the largest technological research and development centers for energy in Europe. Cadarache is located in Saint-Paul-Lez-Durance (Bouches-duRhône), 40 miles north of Aix-en-Provence, France. A fenced area encloses 900-hectares (3.47 square miles) of the 1,600-hectare (6.17 square mile) site. The center employs over 4,100 people, 2,300 of whom are CEA employees. Another 860 are employees of Technicatome, Cogema, and the Institute of Radioprotection and Nuclear Safety (IRSN). Another 870 are employees from other companies, French and foreign research organizations, and universities. Approximately 80 are doctoral students ${ }^{[34]}$.

Nuclear energy is the predominant energy source in France, where 58 reactors provide nearly $80 \%$ of the electricity consumed. In addition, nuclear energy drives France's military submarines and

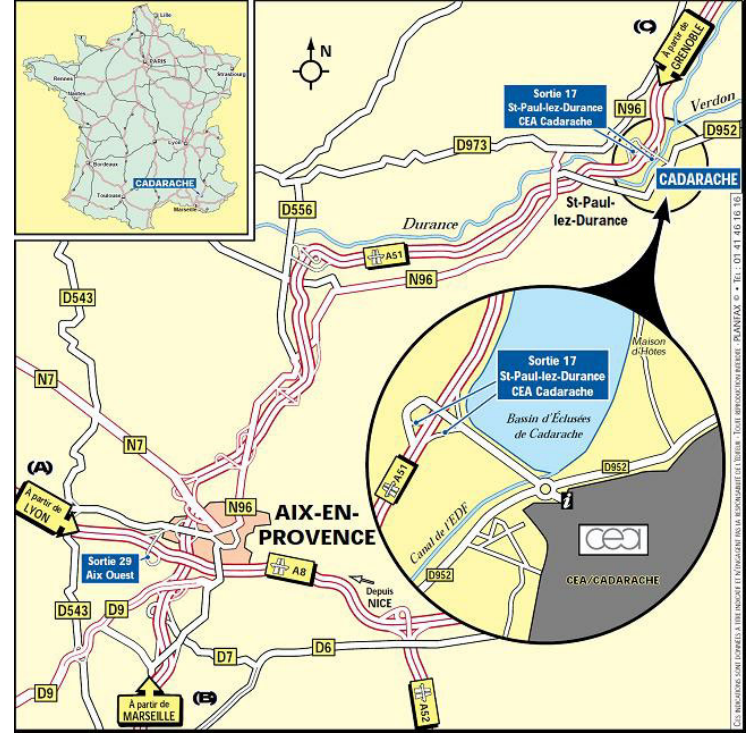

Cadarache is about 40 miles north of Aix-en-Provence (Image courtesy of CEA) aircraft carriers. First established in 1959, Cadarache has been involved in most of the scientific breakthroughs that have resulted in developing the first two generations of nuclear reactors operating in France ${ }^{[34]}$. They are now focused on the third generation European Pressurized Reactor (EPR) and on the international effort to develop the fourth generation of nuclear reactors, which are expected to be operational around 2040.

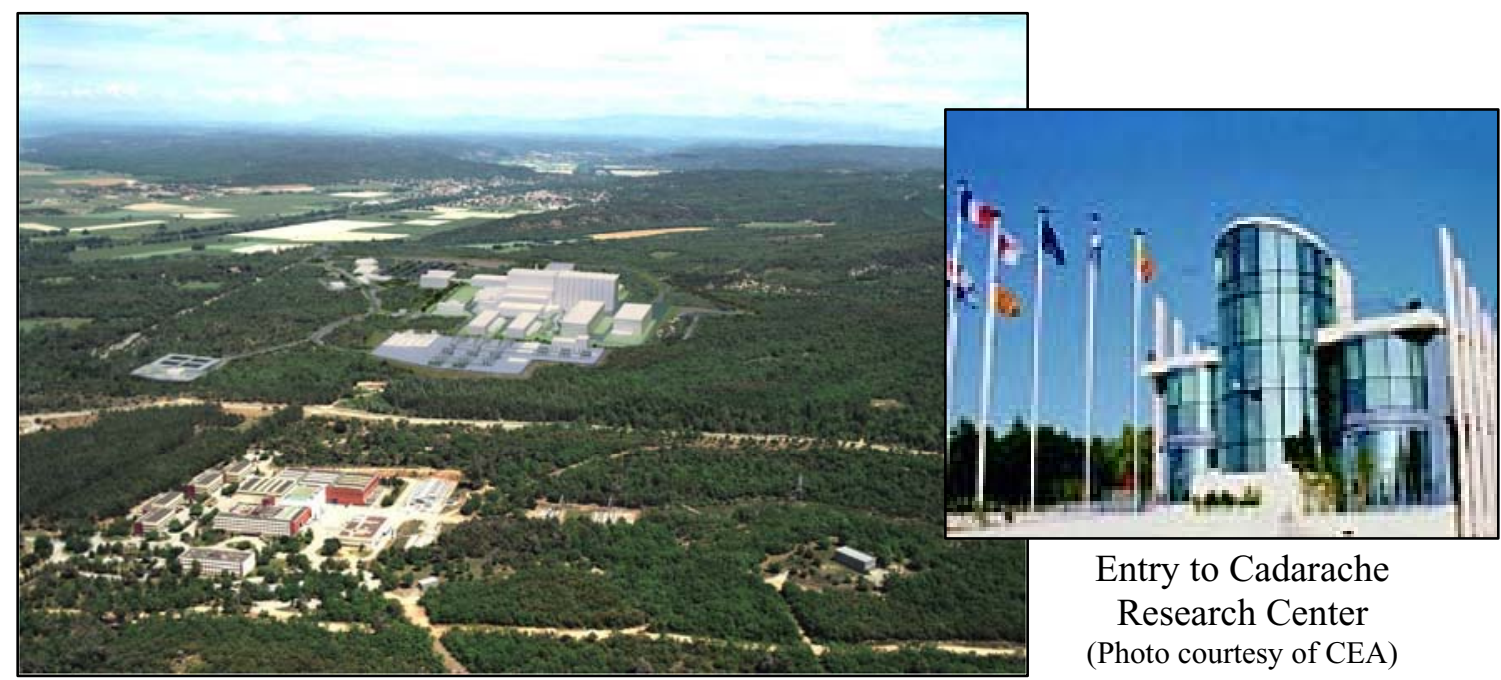

An aerial view of CEA's Cadarache Research Center (Photo and conceptual insert courtesy of CEA)

The research at Cadarache is organized into five platforms: Fission, Fusion, Services, New Technologies for Energy, and Plant Ecophysiology and Microbiology. The primary research focus of 
Cadarache is on nuclear energy, with about 2,600 personnel working on fission research, while 300 personnel work on fusion research. Fission research is primarily aimed at optimizing existing nuclear reactors and replacing them with safer reactors. Cadarache has numerous experimental and test facilities and research reactors to accomplish these goals. Numerous international collaborations (with U.S., Russia, Japan, China, South Korea, and Europe) are also involved in completing this work. Fusion research has been ongoing for over 20 years, involving about 50 foreign scientists and international facilities, including construction of the Tore Supra Tokamak at Cadarache ${ }^{[34]}$.

The services platform provides services required by the nuclear facilities and those necessary for the management of nuclear materials, wastes, and nuclear facility releases, as well as surveillance of the facilities, environment, and safety. The New Technologies for Energy platform performs research in the areas of solar energy and biomass, while Plant Ecophysiology and Microbiology platform studies the effects of radiation on plant life.

\subsubsection{Site/Campus Level Considerations.}

Facility Planning and Modernization - CEA has made significant ongoing investments in large experimentation facilities that are not available elsewhere in the world. These investments are made with longer-term goals in mind. Sometimes capabilities are included in smaller-scale versions to allow opportunity to test that capability for use in a larger-scale version. For example, when CEA built the Tore Supra Tokamak, they invested in a superconducting magnet and actively cooled, plasma-facing component system, which, although not needed for this scale version, provided a roadmap for how to accomplish this when a larger-scale unit is built in the future ${ }^{[35]}$.

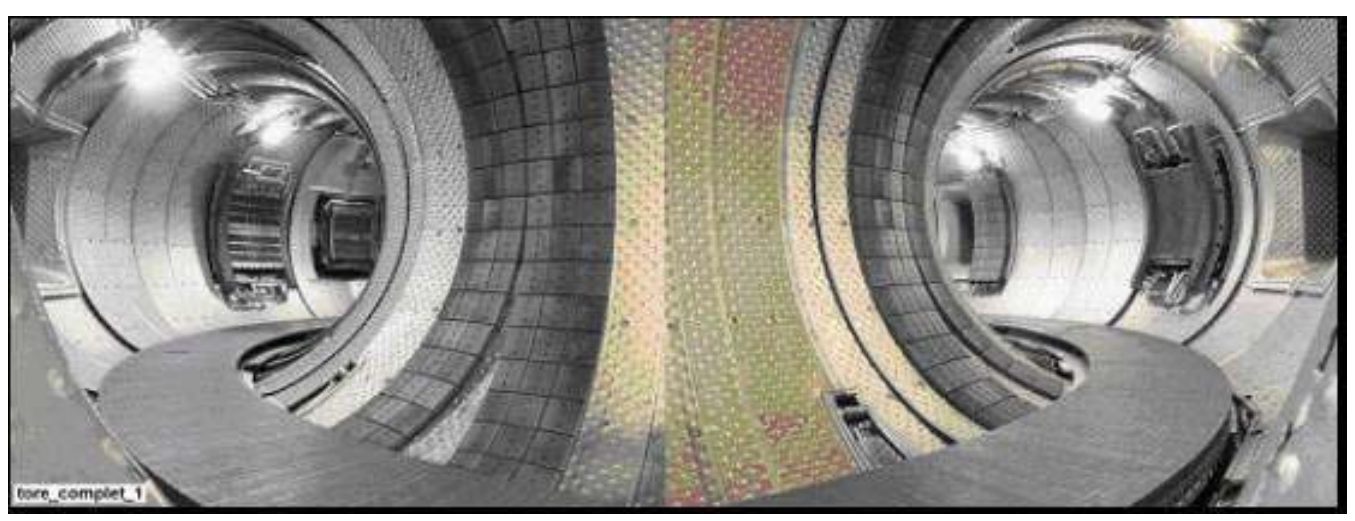

The Tore Supra Tokamak ${ }^{\mathrm{a}}$

(Photo courtesy of CEA)

\subsubsection{FacilitylLaboratory Level Considerations.}

Facility/Laboratory Design — In the hot laboratory facility for the study and examination of advanced fuels (LECA-STAR) at Cadarache, CEA made a strategic decision that put them on the fast-track to world-class status by installing state-of-the-art equipment to enable cutting-edge research in existing hot cells. Although the hot cells are old and are currently being upgraded, the internal capabilities are far beyond those of other facilities world-wide. LECA-STAR's destructive and non-destructive examination equipment allows a complete characterization of fuel materials ${ }^{[35]}$. Further, the LECA Micro-Analysis

a Tokamak, the Russian acronym of Toroidalnaya Kamera Magnitinymi Katushkami (toroidal chamber and magnetic coil): a machine in the shape of a torus, or donut, using a superconducting magnet to generate the magnetic field used for confinement. 
Area provides a set of shielded analytical equipment able to characterize highly irradiated fuels and materials, including electron probe micro-analysis, scanning electron microscope, and secondary ion mass spectroscopy ${ }^{[34]}$. Installing this type of equipment in hot cells takes a significant amount of engineering (shielding, etc.) so that the equipment modification and installation costs are about equal to the actual equipment $\cos t^{[35]}$.

In addition to it's equipment and test capabilities, the centralization of nuclear research and development work at one facility nationwide contributes to CEA's success and world-class status. This was possible, in part, because France aligned their national laboratories to prevent competition. Each lab has a designated mission, and all work in that area is done at one place.

\subsubsection{Social Considerations.}

Research Atmosphere/Culture - It is widely perceived that at CEA, if they have a vision, they follow through to make it happen. CEA has had a large international program for a long time wherein all cultures and traditions are braced so that people feel comfortable with their diversity. As such, the work environment and people are extremely pleasant. The quality of life in the area and its impact on attracting the "best and brightest" researchers was considered an important factor in Cadarache recently being selected as the construction site for the International Thermonuclear Experimental Reactor (ITER), a \$15 billion construction project to demonstrate the scientific and technological feasibility of producing reliable electricity using fusion power ${ }^{[36]}$.

Employee Amenities - The work schedule and lifestyle are very comfortable. CEA employees work a 35 -hour week, 7-hour days x 5 days a week, with a 2-hour lunch break ${ }^{[35]}$. The cafeteria is also excellent, providing a dining experience with great food.

Operating Policies/Procedures - Collaborations at Cadarache are common. Collaborations with regional companies, three universities, and two French research institutes are conducted via scientific partnerships, joint teaching programs, and the creation of mixed laboratories. There are also numerous exchanges and collaborations within the framework of European and international research programs on nuclear energy. In 2003, about 130 foreign scientists worked in the Cadarache Research Center ${ }^{[34]}$.

Community Involvement - The center at Cadarache has a positive impact on the local economy, generating about 170 million euros per year through activities such as the purchase of equipment, subcontracting, etc. The center has also fostered many start-up companies, resulting in a technical area similar to Silicon Valley and the resultant economic growth.

4.4.1.5 Summary. CEA's Cadarache facility is one of the largest technological research and development centers for energy in Europe. Employing over 4,100 people, the center is known for its national and international collaborations with research institutes and universities. The research is primarily focused on nuclear energy (fission and fusion), with another branch that studies improving support services for nuclear energy, such as management of materials, environment, waste, and safety. Another research branch studies the affects of radiation on plant life, and the last branch conducts research into new energy sources, such as solar and biomass. CEA has made a significant long-term investment in developing test and experimentation equipment and reactors at Cadarache. In some cases, expenditures are made to prove a principle at a smaller-scale to reduce the risk associated with the largerscale version. Notably, in some cases, CEA makes strategic decisions that enable novel capabilities by installing state-of-the-art equipment in older facilities (such as hot cells). This was done in the LECASTAR facility so that nuclear fuel examination and characterization can be done within a hot cell. France's decision to organize their national laboratories with specific charters that eliminate competition and provide a clear mission has also been instrumental in achieving world-class status. 


\section{SUMMARY OF FINDINGS}

The results of this benchmarking project are presented below as a series of findings. These findings suggest key characteristics of world-class research institutions despite the unique conditions and research policies of the benchmark institutions.

\subsection{Campus Design}

1. The "connectivity" of the campus is critical both internally to the campus as well as externally to the surrounding community.

2. A cohesive core campus that is easily walkable between buildings is preferred, with parking concentrated on the perimeter or in defined areas.

3. Attractive "common spaces" (i.e., lounges, cafeteria space, conference rooms, patios with outdoor seating, picnic areas, recreation areas, etc.) should be incorporated into both campus and building designs to foster social interactions and research collaborations. Consider central locations to encourage interaction.

4. Areas and opportunities for family and community interaction should be considered.

5. "Green spaces" (i.e., landscaped courtyards, natural vegetation, landscaped walkways around and between buildings, etc.) should be incorporated into the campus design to unify the campus community with the physical environment.

\section{a. Highlight natural environmental features}

b. Create enhanced environmental features (i.e., ponds and landscaping).

6. Whether or not formal certification is pursued, LEED guidelines should be followed for all new construction and campus modifications. Such consideration will strongly contribute to campus sustainability and lower administrative costs by focusing design on energy efficiency, lowemission and recycled-content materials, and native landscaping.

\subsection{Facility Design}

1. For laboratory designs, it is important to have the services of an architectural engineering firm that has design experience for research laboratories as opposed to other types of laboratories (i.e., hospital laboratories, etc.).

2. Security requirements should be considered early in the infrastructure modernization process. Individual laboratories, research wings, or entire buildings may require various security features.

3. Work space and equipment should be planned and configured to promote facility optimization (e.g., modular walls, reconfigurable utilities, etc.). This is particularly important for "adaptable" and user facilities.

4. "Adaptable" laboratory designs support reconfiguration for varying research needs and should provide movable and reusable components (i.e., workbenches, cabinets, HVAC, electrical systems, etc.) to accommodate individual laboratory needs. 
5. Reuse of materials, such as industrial waste-water for use in air conditioning chillers or other applications, provides cost savings, increases sustainability, and improves community perception of the facility.

6. Laboratories should be designed to be in close proximity to offices (i.e., attached or adjacent).

7. Utility corridors between laboratory suites should be used to locate primary utility systems. These corridors should provide for utility isolation of individual laboratories for safety and ease of reconfiguration.

8. Laboratories should include local controls of basic features (i.e., heating, cooling, hood airflow, etc.) and centralized monitoring (and override control) of individual laboratory features.

9. Research staff should be actively involved in the design configuration of dedicated laboratories.

10. A centralized, computerized management system (i.e., space/lab managers and equipment/resource managers) can improve space and equipment utilization. These management systems directly support security, safety, training, and reporting requirements.

11. Access to natural day lighting and external landscape should be maximized for both laboratories and office space. Individual offices that provide day lighting and outside views are the preferred layout. "Bull pen" layouts are not regularly used and are viewed as decreasing productivity.

12. Space allocation (both laboratory and office) is generally determined by research and operational needs and not by organizational hierarchy.

13. Collocation of researchers from different departments and research disciplines should be should be strongly considered to facilitate research collaboration, strengthen interdisciplinary interactions, promote the development of new ideas, and enhance research results.

14. Facility designs that plan for necessary expansion should be strongly considered; however, to reduce costs do not install excess equipment (i.e., excess chillers).

15. The physical work environment should be designed to create a positive research culture:
a. State-of-the-art equipment
b. Modern, reconfigurable facilities
c. Strong link to the natural environment.

\subsection{Organization and Policy}

1. Successful world-class research organizations are focused on unique and compelling research agendas.

a. Senior researchers at world-class research organizations are routinely "self" managed in that they lead the formulation of such research agendas.

b. World-class institutions attract and retain new talent because of the reputation of senior staff as well as the research agenda. 
c. Senior staff members mentor new and young researchers for 5-6 years.

2. Research agendas are moving away from the isolated engineering and science disciplines to more interdisciplinary efforts.

a. Researchers are collocated to foster cross-organizational interactions.

b. "Seed" funding is provided to foster interdisciplinary relations.

3. The management, administration, and associated processes at world-class research organizations are viewed as "support" structures to enable world-class research.

a. Senior management is routinely comprised of senior and accomplished researchers, and compensation is tied to performance (i.e., publications, impact of research, funding, etc.).

4. The organizational work environment is designed to create a positive research culture.

a. User-friendly operating procedures and policies that enable, rather than hinder, researchers are the norm.

b. Collaborative peer-to-peer and cross-discipline relationships are strongly encouraged.

5. A streamlined visitor security process can be achieved through a centralized management system.

6. Office and laboratory space should be allocated based on project priority and research importance. This approach rewards performance by providing more resources to high-impact research projects.

7. Ownership of office and lab space should be coordinated by management. If office and lab space is underutilized, it would re-assigned by management. Space and equipment would be charged to the research organization, with office, wet, and dry lab space charged at different rates.

\subsection{Planning and Implementation}

1. Vision, mission, and objectives of the infrastructure modernization program must be clearly defined early in the process and prior to engaging with architectural engineering firms.

a. Clearly define the intent of the modernization (building).

i. Foster collaboration

ii. Energy efficiency

iii. Laboratory adaptability/flexibility

iv. State-of-the-art space/equipment

b. Clearly define the functions that will be performed in individual laboratories.

2. It is crucial to have a detailed campus plan that matches the organization's mission in place before initiating conversations with architects or proceeding with the detailed design. During the 
planning process, the plan should be rechecked often to ensure the facility goals are being met by the new design.

3. Successful infrastructure modernization programs require "ownership" and leadership by senior management.

4. The distinction between Campus Planning (master plans, concepts) vs. Campus Design (designs, standards) must be clearly understood.

5. Initial campus-wide planning can be managed as a single program (i.e., Conceptual DesignPhase 1) to accelerate federal approval, and then be divided into individual projects depending on the financial/acquisition strategy.

6. Use of an independent construction project manager should be considered to represent the client's interests rather than relying solely on an architectural engineer/builder.

7. For campus-level planning, it is important to have a strong link between architectural engineering and landscape architecture. The independent landscape architectural firm should be involved early, rather than relying solely on an architectural engineer/builder. 


\section{REFERENCES}

\section{National Research Council / DOE / GAO Recommendations}

1. Committee on the Renewal of Department of Energy Infrastructure, Board on Infrastructure and the Constructed Environment, Division on Engineering and Physical Sciences, National Research Council of the National Academies, Intelligent Sustainment and Renewal of Department of Energy Facilities and Infrastructure, Washington, D.C.: The National Academies Press, 2004. ISBN 0-309-09444-5 (book), ISBN 0-309-54652-4 (pdf), http://www.nap.edu

2. Klein, Andrew C., et al, Report of the Nuclear Energy Research Advisory Committee Subcommittee on Nuclear Laboratory Requirements, September 30, 2004.

3. U.S. DOE Federal Energy Management Program, Greening Federal Facilities: An Energy, Environmental, and Economic Resource Guide for Federal Facility Managers and Designers, Second Edition. Edited by Alex Wilson, BuildingGreen, Inc. Produced for the U.S. DOE Federal Energy Management Program and Office of Energy Efficiency and Renewable Energy by BuildingGreen, Inc., Brattleboro, Vermont, May 2001.

4. General Accountability Office, Comptroller General's Forum on High-Performing Organizations: Metrics, Means, and Mechanisms for Achieving High Performance in the 21st Century Public Management Environment, GAO-040343SP, High Performing Organizations Forum, February 2004.

5. Dalton, Jennifer, and Ernest Fossum, INL Green Building Strategy, INL/EXT-05-00331, Idaho Falls, ID: Idaho National Laboratory, May 2005.

\section{Pacific Northwest National Laboratory}

6. Pacific Northwest National Laboratory, http://www.pnl.gov, 2005.

7. “300 Area Transition,” PNNL Briefing to the INL, May 10, 2005.

8. Personal Communications between Dr. Kevin Kostelnik and Dr. Mike Lawrence, Deputy Laboratory Director and others, May 10, 2005.

9. "EMSL Resource System," PNNL Briefing to the INL by Linda Connell, May 11, 2005.

\section{Oak Ridge National Laboratory}

10. UT-Battelle, ORNL Presentations to INL Management, Oak Ridge, TN, January 5, 2005.

11. ORNL Strategic Facilities Plan for making ORNL a 21st Century Laboratory, ORNL/TM2000/238, UT-Battelle, October 2000.

12. ORNL 10-Year Site Plan, ORNL/TM-2004/131/RI, UT-Battelle, November 2004.

13. "Oak Ridge National Laboratory Fact Sheet," www.ORNLornl.gov., website last accessed June 2005. 
14. “About SNS," ORNL website, http://www.sns.gov/aboutsns/aboutsns.htm website last accessed June 2005.

\section{Stanford University}

15. Stanford University Space Planning Guidelines, March 2003.

16. Stanford University Communications, Stanford Facts 2005, Stanford, CA 2005.

17. Personal communication between Lyle Stephenson of the INL and Margaret Dyer-Chamberlain, Herb Fong, David Lenox, Adalaide Dawes, Mike Mithen, and Charles Carter of Stanford University, April 25, 2005.

18. Stanford Environmental Stewardship Committee, The Guidelines for Sustainable Buildings, Stanford, CA, March 2002.

19. Stanford Department of Capital Planning Land and Buildings, Stanford University Space Planning Guidelines, Stanford, CA, March 2003.

20. Stanford Capital Planning and Management, The Project Delivery Process at Stanford, Vol. 1, Version 1.0, Stanford, CA, September 2005.

21. Higginbotham, Julie S., editor, "Clark Center Provides the Ultimate "Plug-and-Play" Laboratory," http://www.stanford.edu. Website last visited 6-2005.

\section{Massachusetts Institute of Technology}

22. Massachusetts Institute of Technology Webpage, http://www.mit.edu, 2005.

23. “MIT Facts 2005," Massachusetts Institute of Technology, Cambridge, MA, 2005.

24. Personal Communications between Dr. Kevin Kostelnik and Deborah Poodry, Director for Capital Project Development, Massachusetts Institute of Technology, Cambridge, MA, June 8, 2005.

25. Personal Communications s between Dr. Kevin Kostelnik and Talitha Fabricius, Campus Landscape Architect, Massachusetts Institute of Technology, Cambridge, MA, June 8, 2005.

26. MIT - A Framework for Campus Development, Principles, Recommendations and Strategic Initiatives: Volume 1, Olin Partnership, November 2001.

\section{IBM Corporation - Almaden Research Center}

27. Personal communication between Dr. Kevin Kostelnik and Ann Marie Phillips of the INL and Dr. Robin Williams, Ray Dias, Sarah Mosso, Christina Oliveira, Anais Nguyen, Steve Wheat, John Beacher, Robert Scott, and Mark Carlson of the IBM Almaden Research Center, May 24, 2005.

28. Almaden Research Center, IBM Research Website, http://www.almaden.ibm.com/almaden/welcome.html, 2005. 


\section{Woods Hole Oceanographic Institute}

29. Woods Hole Oceanographic Institute 2004 Annual Report, Woods Hole Oceanographic Institute, Woods Hole, MA. 2005.

30. Woods Hole Oceanographic Institute Webpage, Woods Hole Oceanographic Institute, Woods Hole, MA., http://www.whoi.edu, 2005.

31. Woods Hole Oceanographic Institute - An Introduction, Woods Hole Oceanographic Institute, Woods Hole, MA. 2004.

32. Personal Communication with Dr. James Luyten, Executive Vice President and Director of Research, Woods Hole Oceanographic Institute, Woods Hole, MA. June 8, 2005.

33. Vermeulens Cost Consultants Webpage, http://www.vermeulens.com, Richmond Hill, ON, Canada, L4B 3Y4, 2004.

\section{Commissariat à l'Energie Atomique (CEA) Cadarache Research Center}

34. CEA website, http://www.cad.cea.fr/

35. Personal communication between Ann Marie Phillips and INL Fellow Dr. Dave Petti, June 2005.

36. ITER website, http://www.iter.org/ 


\section{Appendix \\ Benchmarking Questionnaire}


This page intentionally left blank. 


\section{Benchmarking Questionnaire}

Date:

INL People:

Organization Visited:

Facility Visited:

Interviewees:

\section{Facility Planning}

Facility modernization (level of modernization, modernization underway)

Mission compatibility (alignment of infrastructure with current and future missions)

Space utilization (percent used, percent used for lab vs. office)

Flexibility (of the space to be modified for changing missions, cubicles or other non-permanent structures))

\section{Facility Design}

Energy efficiency/conservation (energy efficiency of facilities, conservation projects, commissioning, automated control systems)

Green buildings (buildings designed or retrofitted to be green; LEED registered or certified? To what level?)

Landscape design (match with environment, natural/wild areas included in landscaping, aesthetics, water conservation, types of irrigation, drip irrigation, composting building waste, xeriscaping)

HVAC (centralized automated control system with logging capability to track use and conservation, individual building controls \{lighting, temperature, air flow $\}$, perimeter building controls, metering for measurement and verification, level of control for different areas in the building, complaints by workers Communication systems (modern systems, future capabilities) 


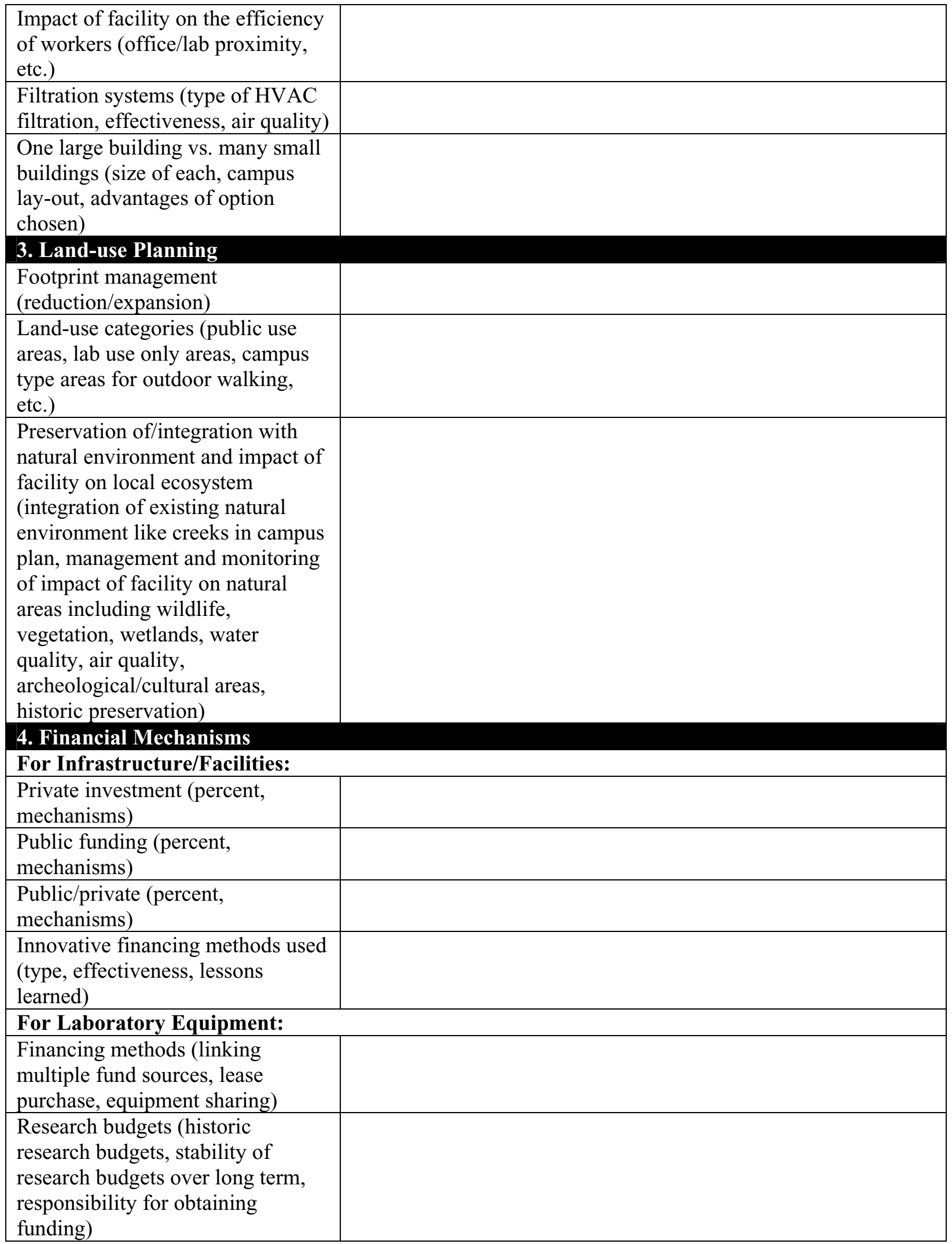




\section{Research Atmosphere}

Research culture (what is the culture/atmosphere, does it work well, open information sharing)

Researcher attitudes and motivation level (employee morale)

Research culture (and physical facilities to accomplish research) versus public face (is there a public reception area, then a separate area where research is actually conducted)

Access (ease of movement and interactions including international collaborations)

State of the art equipment (is equipment state of the art, level of investment to obtain)

Equipment storage (how much is available, long term)

\section{Policies and Procedures}

Operating policies and procedures (good and bad)

Barrier removal approaches (management approaches to remove red tape and enable research)

Procedures for assigning laboratory space

\section{Employee Concerns}

Common use space (copy centers, etc.)

Cafeterias (size, cost, importance)

Child care centers (do they have one on site)

Wellness centers (available to help employees with allergy shots, sudden illnesses, emergencies, health promotion campaigns)

Exercise areas (available on site, type, shower areas)

Conference rooms (number per employee, size)

Casual meeting areas (number, type, amount of time used)

\section{Community Involvement}

Public use (facilities or grounds for shared public use) 


\begin{tabular}{|l|l|}
\hline $\begin{array}{l}\text { User-facilities (lab facilities non- } \\
\text { employee entities can use for a } \\
\text { fee) }\end{array}$ & \\
\hline $\begin{array}{l}\text { Common space (space shared with } \\
\text { a University or private company or } \\
\text { adjacent research center) }\end{array}$ & \\
\hline $\begin{array}{l}\text { Transportation (rapid mass transit } \\
\text { available to the site, cost to } \\
\text { employees) }\end{array}$ & \\
\hline $\begin{array}{l}\text { Visitors (are visitors allowed, } \\
\text { encouraged) }\end{array}$ & \\
\hline 9. Waste Management & \\
\hline $\begin{array}{l}\text { Pollution prevention (methods } \\
\text { used, what is measured and } \\
\text { tracked, prevalence of recycling } \\
\text { stations around building, non- } \\
\text { standard recycling items } \\
\text { (electronics, etc.)) }\end{array}$ & \\
\hline $\begin{array}{l}\text { Material reuse/recycle (site wide } \\
\text { programs, effectiveness) }\end{array}$ & \\
\hline
\end{tabular}

10. Perceptions or Reference Framework of Interviewee

What is the single most important factor contributing to the success of this research facility? Relative importance of factors (facility vs. equipment vs. culture vs. people vs. policies/procedures.)

Interviewees ranking of benchmarking criteria by relative importance

\section{Space management}

General Space management philosophy - what is it? Is it shared?

Space use guidelines/standards established - formalized and institutionalized?

Assignment criteria - Is space assigned, who is accountable, fallback criteria

Employee customer management Is there a process? Who directs? How is this accomplished, how effective?

Daily move activity - managed in house, centralized, subcontracted? Facility maintenance philosophy centralized or dispersed, paid from programs or overhead? 


\begin{tabular}{|l|l|}
\hline $\begin{array}{l}\text { Use return policy - } \\
\text { established/functional? }\end{array}$ & \\
\hline $\begin{array}{l}\text { Lab/Ops/user space philosophy - } \\
\text { who has priority, how are } \\
\text { disputations resolved }\end{array}$ & \\
\hline $\begin{array}{l}\text { Pay for space criteria - is it } \\
\text { established, implementation } \\
\text { hurdles, user efficiency }\end{array}$ & \\
\hline $\begin{array}{l}\text { Security concerns - Labs, public } \\
\text { space, equipment }\end{array}$ & \\
\hline $\begin{array}{l}\text { Campus amenities - Types, access, } \\
\text { how administered }\end{array}$ & \\
\hline $\begin{array}{l}\text { Future vision - Where next, what } \\
\text { has worked, what will continue, } \\
\text { what would you change }\end{array}$ & \\
\hline $\begin{array}{l}\text { King for a day - If you were King } \\
\text { for a day with no limitations what } \\
\text { would you change? }\end{array}$ & \\
\hline Additional Information & \\
\hline Facility Tours & \\
\hline
\end{tabular}

